\title{
LUNGS AND LEGS: \\ ENTRAINMENT OF BREATHING TO LOCOMOTION IN HIGHLY-TRAINED DISTANCE RUNNERS
}

Jason R. Karp

Submitted to the faculty of the University Graduate School in partial fulfillment of the requirements

for the degree

Doctor of Philosophy

in the Department of Kinesiology, Indiana University

September, 2007 
Accepted by the Graduate Faculty, Indiana University, in partial fulfillment of the requirements for the degree of Doctor of Philosophy.

Doctoral Committee

Robert A. Robergs, Ph.D. (Co-Chair)

David M. Koceja, Ph.D.

(Co-Chair)

Jerry D. Wilkerson, Ph.D.

Alyce D. Fly, Ph.D.

September 24, 2007 
C인 2007

Jason R. Karp

ALL RIGHTS RESERVED 


\section{Acknowledgments}

It is an understatement to say that there are many people to thank as one completes an endeavor like this. Writing the acknowledgments section of the dissertation feels, I assume, much like giving an acceptance speech at the Oscars. Regardless of your sincerity, it is hard not to overlook someone. And, also much like the Oscars, it is an egregious sin to not thank your mother. So I would like to thank my mother, Muriel, who, despite her wishes for me to get a real job and a wife and present her with grandchildren, has always wanted what is best for me and has always supported the decisions I make. As I first wrote in my master's thesis ten years ago, she has always given me the opportunity to stand up in this world, even though sometimes I apt to fall. I also thank my twin brother, Jack, who suffered the brunt of my complaints during the last seven years, telling me repeatedly to suck it up. If it wasn't for his sarcastic wit that provided me with laughter when I needed it most, I would have gone nuts. Receiving this $\mathrm{Ph}$.D. would not be as fulfilling without the opportunity to share it with the two of them.

When it came to complaining, there was much of it to do, and Jack was not the only one whom I made listen. So I'd like to thank Cairril Mills, my friend and next door neighbor in Bloomington, Indiana, for her patience with my rants and her ability to help me see things rationally (not to mention her award winning brownies). She was one of only a few people in my life who truly understood my frustration.

The completion of a dissertation is not possible without the participation of subjects willing to be poked and prodded in the name of science (or in the name of a degree). Needless to say, I am grateful to the runners who selflessly served as subjects, 
including the elite Kenyan runners who live and train in Albuquerque, New Mexico. Standing two inches from those gifted runners while they ran on the treadmill was a privileged and humbling experience, and was certainly one of the perks of living in Albuquerque while working on this dissertation. I also thank Christina Muňoz, an intelligent and eager undergraduate at the University of New Mexico, who assisted me with data collection and faithfully took care of my cat when I was out of town. While I typically prefer to be left alone while I work, her inquisitiveness regarding lab procedures and my dissertation research kept me on my toes, and her company in the lab turned into a welcomed friendship.

As for my colleagues and educators, I would like to thank Dr. David Tanner of Indiana University, a soft-spoken guy who some would say is a bit of a loner and an ultra-endurance exercise extremist, for his technical understanding of data acquisition hardware and software. Maybe it was these qualities and him also being a twin that allowed me to relate to him. If it wasn't for his help, I would not have been able to accomplish much of the complex technical aspects of this and earlier research. I stand proudly on his shoulders.

I'd also like to thank my former academic advisor, Dr. Joel Stager, for his relentless criticism of my work that challenged me to think more critically, more logically, more like the scientist he knew I could be.

Of all of the people who played a role in my degree, the person who stood out the most was Dr. Robert Robergs of the University of New Mexico, without whom this degree may never have been completed. Four and a half years after I left the University of New Mexico for what I thought was a better opportunity at Indiana University, Dr. 
Robergs selflessly agreed to again serve as my advisor to see me to the completion of this degree. Despite his responsibilities to his current students, he gave me his time and allowed me to pursue my dissertation research in his laboratory. I also thank him for his help with the large technical aspect of this dissertation, which necessitated a lot of computer programming to collect and process breathing and gait signals from my subjects. It certainly wasn't something he had to do. Neither was answering my phone calls to his home. But he did these things anyway, without hesitation. He saw his role on my dissertation research as a collaborator, rather than as a dictator who makes demands from his Ivory Tower. Dr. Robergs is wise enough to know that good science is best done through collaboration and cooperation, and that the student's pursuit of a Ph.D. is most successful when viewed as an apprenticeship. At a time when I needed a hand to save me from drowning, Dr. Robergs lent his and lifted me to a height that I never would have been able to reach on my own. I will never be able to thank him (and his understanding wife, who allowed him to answer those home phone calls) enough.

Given the uniqueness of the final stages of my degree, its completion also took the cooperation of a number of people at Indiana University, including Dr. David Koceja (who served as my committee co-chair), Dr. Jerry Wilkerson, and Dr. Alyce Fly. The three of them worked together for my benefit, and I thank them for that. My committee showed that great things can happen when people work together, even when together is far apart.

I suppose that, looking back on my academic career that spanned four different universities, I have been lucky to have had such demanding academic advisors and committee members, who have expected from me nothing less than my very best. 
Although I am still far from perfect, I am undoubtedly a better scientist, a better product and, dare I say, a better person, because of their expectations. They have all, each in their own way, left an indelible mark on my life. Whatever direction I intend to pursue following this dissertation, I will always be guided by their influences. That alone is worth the price of admission. 


\section{Preface}

This dissertation marks the end of 27 years of formal education, 13 of which have come from four different universities. When I was young, little did I, or anyone else, know that I would one day earn a Ph.D. Certainly not my kindergarten teacher, who scolded me for pushing one of my classmates against the cubbies and causing him to get stitches in his head because he broke my Batman action figure. Certainly not my middle school French teacher, who kept yelling out my American name with a French accent in the middle of class as I clowned around. Certainly not the substitute teachers in high school, who tried to give me detention after throwing paper airplanes across the classroom, sometimes landing them on the teacher's desk. And certainly not my twin brother, who has rightfully thought, all these years, that he is the smarter one. Maybe my sixth grade math teacher had a hint of what was to come as she told my mother during a parent-teacher conference that I was "a wiz at math." Maybe she was just trying to find something positive to say.

Both my father, who passed away when I was eight years old, and my mother would have had every reason to believe that between their twin sons, Jack would be the more likely one to earn a Ph.D. After all, he was the one who spent weeks in first grade researching and preparing a slideshow on dinosaurs and exhausting our parents by studying every single display in New York's Museum of Natural History, helped the neighbor's kid make an active volcano for his class science project, and would later go on to spend his first year and a half in college on the dean's list majoring in aerospace engineering before getting even better grades with a double major in psychology and 
English. But even if I wasn't the likely candidate back then, I know that my father, who never attended college himself, would have probably been both bewildered by the fact that someone would want to spend so many years in school, and immensely proud of his son for the accomplishment. I know my mother is, as she tells me this every day.

It is an understatement to say that you learn a lot when working on a Ph.D., but what I have learned the most has nothing to do with exercise physiology or research or even science. What I have learned the most is patience, something I often have very little of. Maybe it's the New Yorker in me. I suppose it's ironic that I've made it this far. There were many obstacles to overcome and much waiting to endure while working on this degree, which caused me much frustration that often put a strain on my mental health. I often questioned whether I was ever going to finish it. At times, I felt like Estragon and Vladimir in Samuel Beckett's Waiting for Godot, hopelessly waiting for something that was never going to come, putting other areas of my life on hold in the process. It was even told to me by many that a Ph.D. certainly wasn't necessary for my career aspirations as an entrepreneur. But, despite the obstacles and the stress and the sometimes not-so-subtle signs that maybe I wasn't smart enough or worthy enough or savvy enough to earn this degree, I continued, sometimes blindly, to find ways that I could complete it. Even the great Albert Einstein needed multiple attempts to get a dissertation accepted and receive his doctorate, so busy he was at revolutionizing physics. I didn't have such distractions. "Why am I doing this to myself?" I asked countless times. Looking back, perhaps it was because I put the Ph.D. on a pedestal. A pedestal that I wanted to stand on. Although there may be a good chance of failing, people take risks because the chance of failing makes success taste even sweeter. 
Maybe that's why completing this dissertation, this culminating event, means so much to me- because I was never and still am not a likely candidate to pursue a Ph.D. I'm not exactly the most academic of doctoral students. In fact, throughout my work on this degree, I always told people that I am the least academic doctoral student they'll ever meet. Professors and academic advisors, of course, wished that wasn't the case. I think I told people that partly because it was true and partly because I didn't want people to think I was a nerd. Most doctoral students are nerds. I should know-after 13 years of education at multiple universities, including a year of classes in medical school, I've been around many of them. So I felt like I needed some way to connect with a student body that was, with each passing year, getting younger than me. If people saw that I was smart and cool, well, let's just say that everyone wants to feel part of a group. From the very beginning of graduate school, I saw myself as being different than my peers. I had different career aspirations and a different way of looking at things. After all, I'm not exactly a great scientist. I'm not the smartest person in my advisor's small cohort of graduate students. I'm not even the smartest person in my family.

But I achieved it nonetheless, with this manuscript representing the culmination of the effort and the journey that, looking back, was much too long. And as my twin brother tells me, now I am a Phony Doctor for the rest of my life. I wouldn't want it any other way. 


\section{Abstract \\ Jason R. Karp \\ LUNGS AND LEGS: \\ ENTRAINMENT OF BREATHING TO LOCOMOTION IN HIGHLY-TRAINED DISTANCE RUNNERS}

Research has found that breathing is coordinated, or entrained, to the rhythm of locomotion, possibly conferring an economical advantage. Highly-trained endurance athletes, whose ability to sustain high metabolic workloads sometimes results in exercise-induced hypoxemia (EIH) and expiratory flow limitation (FL), are a unique population in which to study this "lungs-legs" relationship. The purposes of this study were to examine the entrainment of breathing frequency to stride rate in elite distance runners during exercise at $70,90,100$, and $110 \%$ of the ventilatory threshold (VT), to compare the degree of entrainment between \% VT intensities, and to examine the relationship between entrainment and running economy. Given a sufficient number of entrained and non-entrained subjects, EIH and non-EIH subjects, and/or FL and non-FL subjects, secondary purposes were to compare economy at each intensity between entrained and non-entrained groups and to compare the proportion of subjects exhibiting entrainment and the percent entrainment between EIH and non-EIH groups and between FL and non-FL groups. Fifteen male distance runners performed a maximal oxygen consumption $\left(\dot{\mathrm{V}}_{2} \mathrm{max}\right)$ test and a locomotor-respiratory coupling test, during which running economy was also determined. EIH and FL were determined by pulse oximetry and flow-volume measurements during the $\dot{\mathrm{V}} \mathrm{O}_{2}$ max test, respectively. Only 5 subjects exhibited EIH and 2 exhibited FL, precluding group comparisons regarding entrainment. 
All subjects entrained breathing to stride rate, precluding group comparisons regarding running economy. The step-to-breath ratio decreased with increasing intensity up to $100 \%$ VT $(2.75 \pm 0.58,2.32 \pm 0.52$, and $2.14 \pm 0.56 ; \mathrm{p}<0.05)$ but did not decrease further at 110\% VT (2.16 \pm 0.48$)$. Subjects most often utilized 5:3 and 2:1 step-to-breath ratios. Percent entrainment during inspiration at $70 \%$ VT was less than at 100 and $110 \%$ VT $(13.1 \pm 7.8,23.1 \pm 14.5,28.4 \pm 16.5$, and $30.8 \pm 14.9 \%$ for $70,90,100$, and $110 \% \mathrm{VT}$, respectively; $\mathrm{p}<0.01)$, but did not change with intensity during expiration $(30.8 \pm 12.6$, $27.9 \pm 10.0,20.8 \pm 7.3$, and $25.7 \pm 11.2 \%$, respectively). At all intensities, percent entrainment was significantly greater than a chance occurrence. Correlations between the degree of entrainment and running economy were not significant at any intensity. Entrainment of breathing to locomotion is a physiological phenomenon in highly-trained distance runners, which is largely not influenced by intensity, but can differ between inspiration and expiration. Furthermore, running economy is not associated with entrainment. The methods used to quantify entrainment need additional research and critical reflection. 


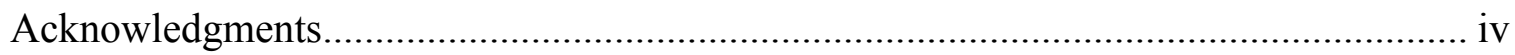

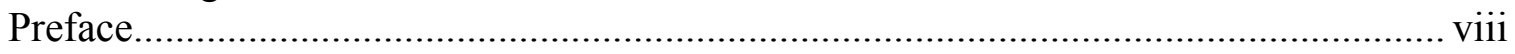

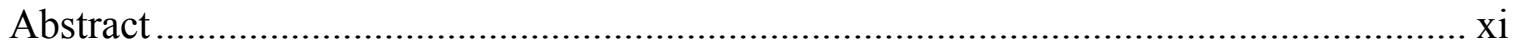

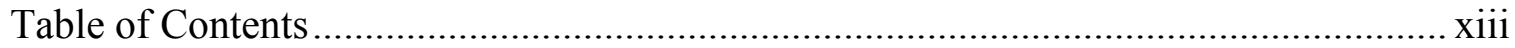

List of Tables .................................................................................................. Xvi

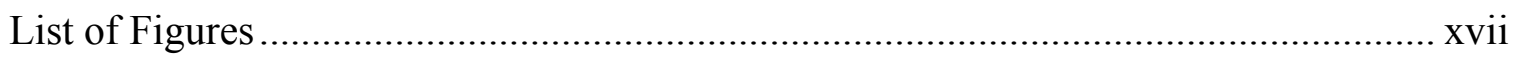

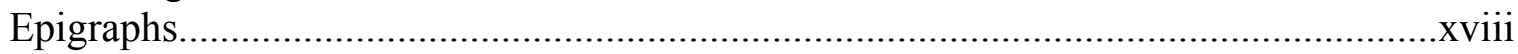

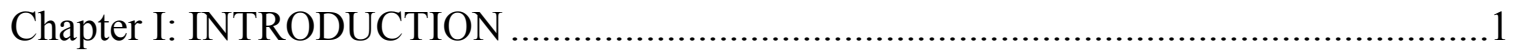

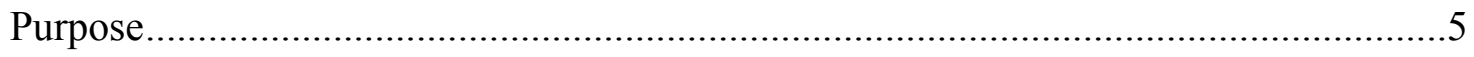

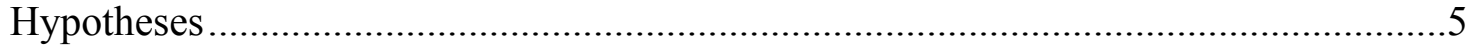

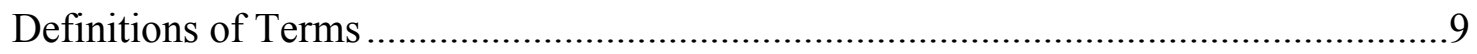

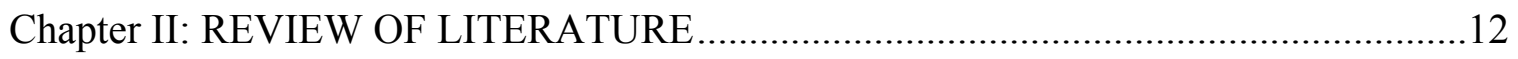

Ventilation During Exercise ............................................................................. 12

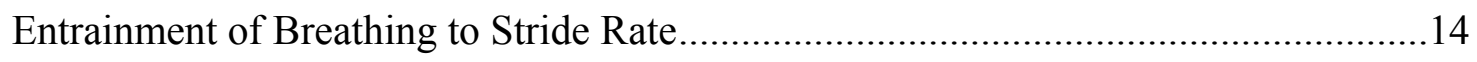

Determination of Entrainment .................................................................... 19

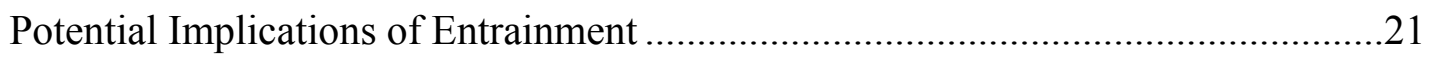

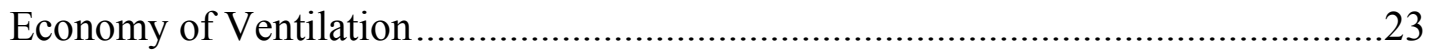

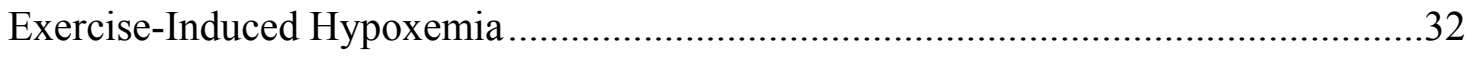

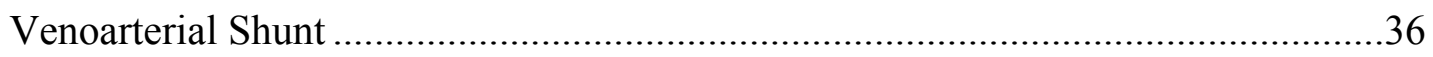

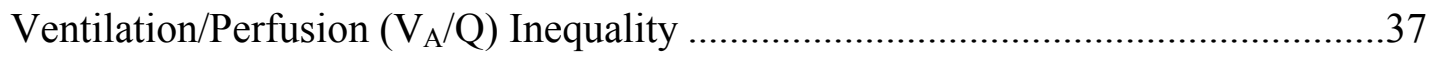

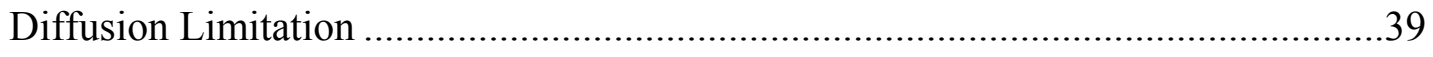

Hypoventilation (Inadequate Hyperventilation) …..........................................42

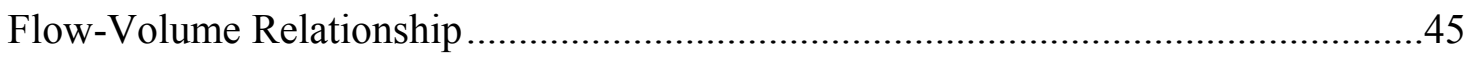

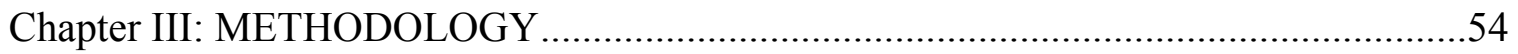

xiii 
Subjects

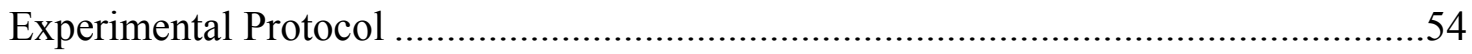

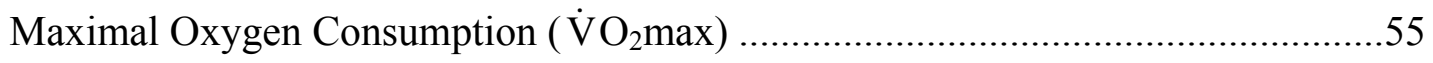

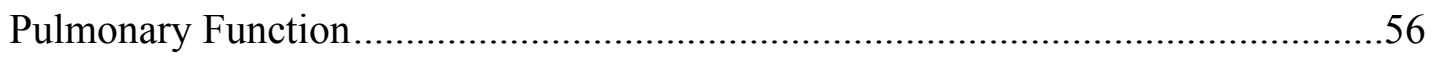

Locomotor-Respiratory Coupling and Running Economy .......................................56

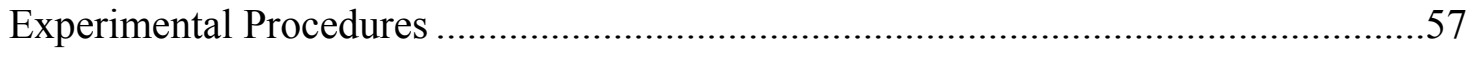

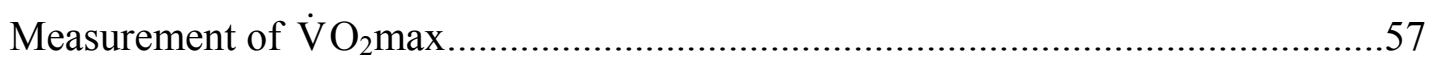

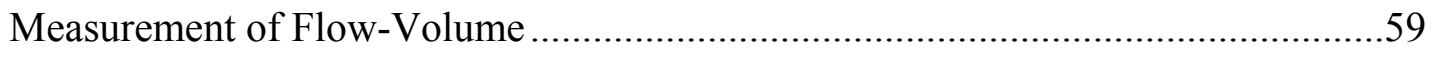

Measurement of Arterial Oxygen Saturation.............................................................59

Measurement of Locomotor-Respiratory Coupling ..................................................60

Measurement of Running Economy ………………….......................................61

Determination of Entrainment …………..........................................................62

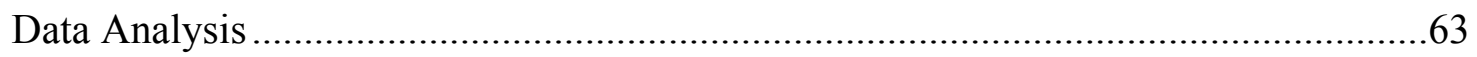

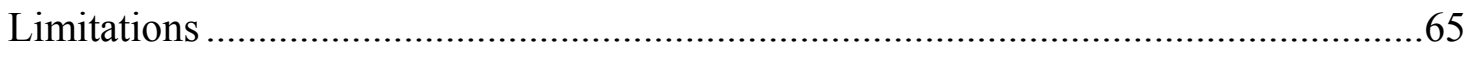

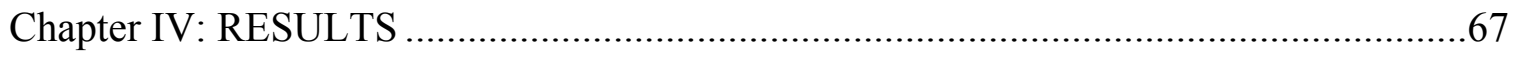

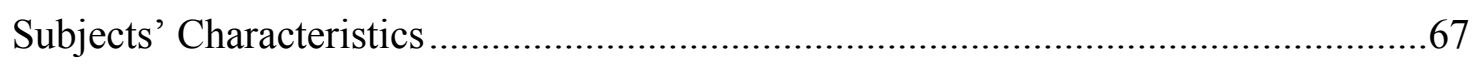

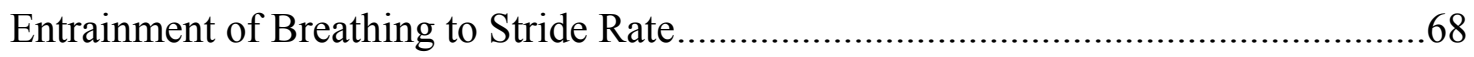

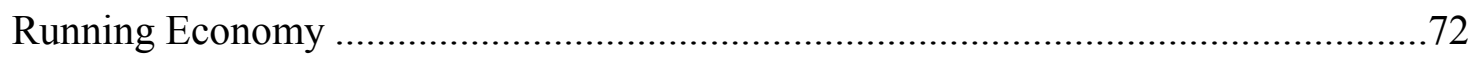

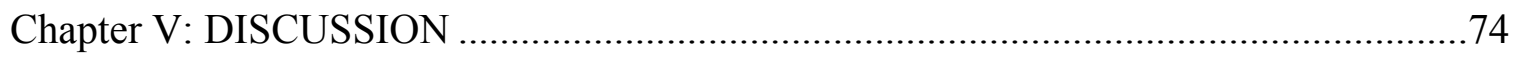

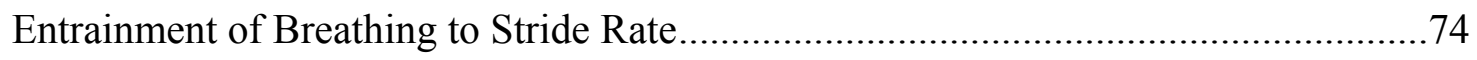

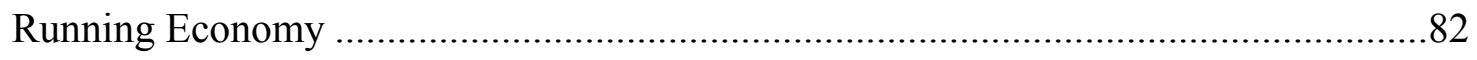

Directions for Future Research ............................................................................ 84

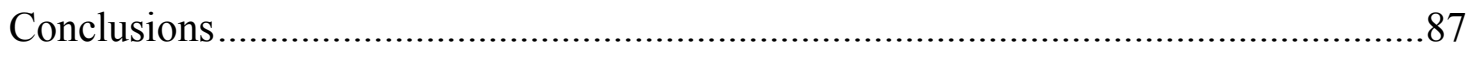

xiv 


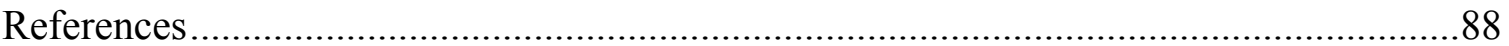

Appendix A. Institutional Review Board Approval and Consent Form...........................103

Appendix B. Physical Activity Readiness Questionnaire (PAR-Q) .................................113

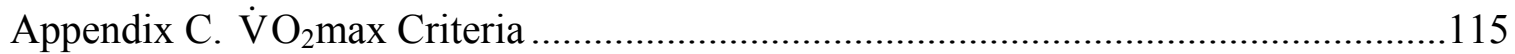




\section{List of Tables}

Table 1. Studies Examining Entrainment of Ventilation to Locomotion in Humans ....... 27

Table 2. Stride Rate, Stride Length, Breathing Frequency, and Locomotor-Respiratory

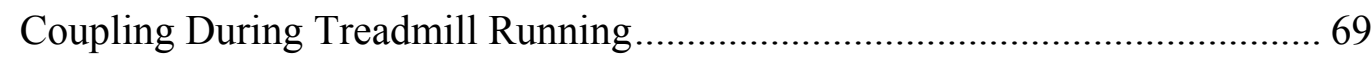

Table 3. Results of Three-Way Anova Comparing Actual and Random Entrainment..... 71

Table 4. Timing Between Inspirations and Steps $\left(\mathrm{T}_{\mathrm{i}}\right)$ and Expirations and Steps $\left(\mathrm{T}_{\mathrm{e}}\right) \ldots . .73$ 


\section{List of Figures}

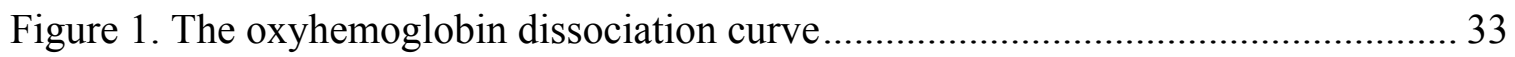

Figure 2. An example of pulmonary flow limitation .............................................. 47

Figure 3. Flow-volume loop showing possible entrainment of breathing to stride rate ... 51

Figure 4. Insoles containing foot switches for stride analysis ................................ 61

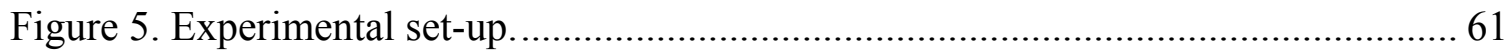

Figure 6. Timing of foot strikes and breaths during treadmill running ........................ 63

Figure 7. Degree of entrainment at four running intensities ................................... 72

Figure 8 . Timing of breathing and foot strikes at $70 \%$ of the ventilatory threshold........ 77

Figure 9. Timing of breathing and foot strikes at $90 \%$ of the ventilatory threshold........ 77

Figure 10. Timing of breathing and foot strikes at $100 \%$ of the ventilatory threshold.... 78

Figure 11. Timing of breathing and foot strikes at $110 \%$ of the ventilatory threshold..... 78 
And now, the end is near,

And so I face the final curtain.

My friend, I'll say it clear,

I'll state my case, of which I'm certain.

I've lived a life that's full,

I've traveled each and every highway.

And more, much more than this,

I did it my way.

Regrets, I've had a few,

But then again, too few to mention.

I did what I had to do,

And saw it through, without exemption.

I planned each charted course,

Each careful step, along the byway, And more, much more than this,

I did it my way.

Yes, there were times, I'm sure you knew,

When I bit off more than I could chew.

But through it all, when there was doubt, I ate it up and spit it out.

I faced it all and I stood tall,

And did it my way.

I've loved, I've laughed and cried,

I've had my fill, my share of losing.

And now, as tears subside, I find it all so amusing.

To think I did all that,

And may I say, not in a shy way,

Oh no, oh no not me,

I did it my way.

For what is a man, what has he got?

If not himself, then he has naught.

To say the things he truly feels, And not the words of one who kneels.

The record shows, I took the blows

And did it my way!

Yes, it was my way.

- Frank Sinatra \& Paul Anka, My Way

xviii 
The best dissertation is a signed one.

- Charles Little, Ed.D.

Indiana University, Class of 1978

xix 


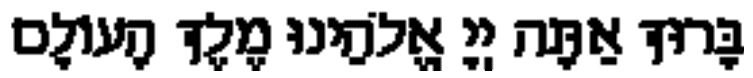

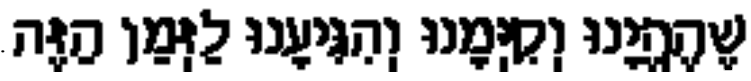

Blessed are You, Lord our God, King of the Universe, who has kept us alive, sustained us, and enabled us to reach this season.

- Jewish Blessing 


\section{Chapter I}

\section{INTRODUCTION}

Breathing is so obvious that it is often taken for granted. However, the control of breathing during exercise is a complicated matter. Ventilation, the movement of air into and out of the lungs, increases as a function of running velocity. Run faster, ventilate more. Minute ventilation ( $\dot{\mathrm{V} E})$, the volume of air exhaled in one minute, increases linearly at low exercise intensities but increases exponentially at higher intensities, as the need to eliminate the increased metabolic production of carbon dioxide $\left(\mathrm{CO}_{2}\right)$ increases (Brooks et al., 2000). This increase in $\dot{V} E$ is attributable to an initial increase in tidal volume (the amount of air in a single breath) at lower intensities, and an increase in breathing frequency at higher intensities (Dempsey, 1986; Grimby, 1969). Given the physiological demand for oxygen and the need to eliminate carbon dioxide at higher exercise intensities, humans have a large capacity to breathe. A large man who, at rest, breathes about 0.5 liter of air per breath and about six liters of air per minute, may breathe nearly 200 liters per minute during maximal exercise.

There is an ancient breathing technique associated with yoga called prãnãyãma, which means "the control of breath." Among yogis, air is the primary source of prãna, a physiological, psychological, and spiritual force that permeates the universe and is manifested in humans through the phenomenon of breathing. Masters and students of yoga believe that controlling the breath by practicing prãnãyãma clears the mind and provides a sense of well-being (Iyengar, 1985). 
This idea of controlling the breath may have greater implications than the yogis imagined. For example, it has been suggested that the rhythm of locomotion may impose its pattern, or entrain, the pattern of breathing, especially in animals that run on four legs (Bramble \& Carrier, 1983; Forster \& Pan, 1988). To entrain, literally, "to draw along with," can be thought of as one variable being forced to keep pace with another, and has been defined as the locking of frequency and phase (Kelso, 1995). The locomotory rhythm may, in effect, control the breath. Call it the physiologist's version of prãnãyãma.

There is considerable evidence that a pattern exists between breathing and stride rate in animals (Baudinette et al., 1987; Brackenbury \& Avery, 1980; Bramble \& Carrier, 1983; Iscoe, 1981; Kamau, 1990) and humans (Bechbache \& Duffin, 1977; Bramble \& Carrier, 1983; Berry et al., 1988; Bonsignore et al., 1998; Hill et al., 1988; McDermott et al., 2003; Paterson et al., 1987; Raßler \& Kohl, 1996; Takano, 1995), although this pattern does not seem to be preset, as many of the studies on humans have shown it to be infrequent or dependent on other factors, such as fitness level.

Of the two components of the running stride that influence speed — stride length and stride rate - stride length increases preferentially over stride rate with increasing distance running speed, while stride rate remains relatively constant (Cavanagh \& Kram, 1989). The stability in stride rate has also been found as speed decreases due to fatigue (Elliot \& Ackland, 1981). Because of this dynamic between stride length and stride rate, Cavanagh and Kram (1989) have suggested that economy, the amount of oxygen consumed at a given speed, governs the choice of both components, such that there may be a most economical stride length at a given speed and a most economical stride rate at all speeds used in distance running. 
While the subconscious manipulation of stride length and stride rate at different speeds may be governed by what is most economical for the runner, coordinating the other notable rhythm during running — breathing — to the rhythm of the stride may also have economical implications. A number of researchers have suggested that entraining breathing to stride rate may reduce the metabolic cost of ventilation (Bramble \& Carrier, 1983; Heinrich, 2001; Hill et al., 1988; Paterson et al., 1986). Therefore, it is possible that the economy of running, one of the most overlooked parameters of aerobic function, is improved by creating a synergy between two vastly different mechanisms-breathing and locomotion - by coordinating the activity of one's lungs to that of one's legs.

The physiology of endurance athletes is unique. There are a number of characteristics that separate them from their less fit counterparts, including a large cardiac output, a large and intricate capillary network perfusing the skeletal muscles, lots of red blood cells and hemoglobin to carry oxygen, and an abundance of oxygen-consuming mitochondria, all leading to a high rate of oxygen consumption ( $\left.\dot{\mathrm{V}}_{2} \max \right)$ (Robergs \& Roberts, 1997). Sometimes, the level of work that these athletes can do places too high of a demand on the cardiopulmonary system to supply the necessary oxygen to sustain the work. Ironically, this leads to these endurance athletes experiencing some of the same consequences during exercise as individuals with cardiopulmonary disease. For instance, many endurance athletes exhibit a decrease in the arterial partial pressure of oxygen $\left(\mathrm{P}_{\mathrm{a}} \mathrm{O}_{2}\right)$ during exercise at or near $\dot{\mathrm{V}} \mathrm{O}_{2}$ max, resulting in a loss of oxygen bound to hemoglobin (i.e., desaturation), a condition given the inauspicious name, "exercise-induced hypoxemia" (EIH) (Powers et al., 1993). Additionally, many of these athletes reach the lungs' mechanical limit of generating airflow during intense exercise 
and are said to be "flow-limited" because they cannot breathe enough to match their high metabolic demand, leading to the possibility of an inadequate pulmonary gas exchange (Johnson et al., 1992; Powers \& Williams, 1987). While pulmonary performance is not considered to limit endurance exercise performance in healthy but unfit individuals, it possibly can limit performance in highly-trained endurance athletes, as it does in individuals with pulmonary disease, but for vastly different reasons.

All of the studies examining entrainment between breathing and stride rate have been limited to unfit or moderately-fit subjects during submaximal workloads. It remains to be examined whether a pattern between these two variables still exists in highly-trained distance runners during steady-state and non-steady-state exercise, given the unique cardiopulmonary limitations that are curiously imposed upon them (e.g., EIH and flow limitation) as a result of their remarkable, if not envious, ability to achieve and sustain high workloads. Studying this "lungs-legs" relationship in highly-trained distance runners may help to answer both a pure biological question, such as what breathing strategy is employed by highly-trained human endurance athletes while running, and an applied science question, such as whether entraining breathing to stride rate confers an economical advantage to highly-trained endurance athletes while running at different speeds. 


\section{Purpose}

The purposes of this study were 1) to examine the relationship, and possible entrainment, of breathing frequency and stride rate in highly-trained distance runners during exercise at $70,90,100$, and $110 \%$ of the ventilatory threshold, 2) to compare the degree of entrainment between these different \% VT intensities, and 3) to examine the relationship between the degree of entrainment and running economy.

In addition, given a sufficient number of subjects who do and do not exhibit exercise-induced hypoxemia (EIH) and/or expiratory flow limitation (FL), a secondary purpose was to compare the proportion of subjects exhibiting entrainment of breathing frequency to stride rate and the percent entrainment between EIH and non-EIH groups and between FL and non-FL groups. Finally, given a sufficient number of subjects who do and do not exhibit entrainment of breathing frequency to stride rate, another secondary purpose was to compare economy at each intensity between entrained and non-entrained groups to test whether or not runners who entrain breathing to stride rate are more economical.

\section{Hypotheses}

The hypotheses of this study include:

1. Entrainment of breathing frequency $\left(F_{b}\right)$ to stride rate $(S R)$, defined as an integer step-to-breath ratio and a majority of breaths occurring within \pm 0.05 second from the closest step, will occur in the majority $(>50 \%)$ of subjects.

Rationale 
There is considerable evidence that the rhythms of breathing and stride rate in humans while running are coupled, or entrained, to one another. Although the presence of this entrainment is variable, in light of the findings that entrainment is more typical of subjects who are experienced with the mode of exercise (Berry et al., 1988; Bramble \& Carrier, 1983; Paterson et al., 1987) and who have a higher level of fitness (Berry et al., 1988; Mahler et al., 1991), it is reasonable to expect that entrainment will be most evident and clearly definable in highly-trained distance runners.

2. There will be no significant difference in the proportion of subjects who exhibit entrainment between all four intensities $(70,90,100$, and $110 \%$ VT).

Rationale

Since the subjects for this study were a homogeneous group of highly trained runners, all of whom regularly train at a variety of intensities, it is expected that the proportion of subjects who exhibit entrainment will not be significantly different between all four intensities.

3. The degree of entrainment (expressed as percent entrainment) will significantly decrease as intensity increases.

Rationale

While research on untrained and moderately-fit subjects has found that the degree of entrainment increases with increased speed (McDermott et al., 2003), research on trained athletes has found that the degree of entrainment decreases with increased speed (Bonsignore et al., 1998). Furthermore, since entrainment has been found to be most observable in subjects experienced with the mode of exercise, it is reasonable to expect 
that it will also be most observable among trained athletes at the intensity at which they are most experienced. The majority of a distance runner's weekly training distance is performed at a low intensity.

4. There will be a significant correlation between running economy (expressed as $\mathrm{ml} \mathrm{kg}^{-1} \mathrm{~km}^{-1}$ ) and the degree of entrainment (expressed as percent entrainment) at each running intensity.

Rationale

Since prior research has shown that there seems to be an economical advantage gained by entraining breathing frequency to stride rate (Bernasconi \& Kohl, 1993; Bonsignore et al., 1998; Bramble \& Carrier, 1983), it is reasonable to expect that there will be a significant correlation between percent entrainment and economy.

The secondary hypotheses of this study include (given sufficient number of subjects in each group):

1. The proportion of subjects exhibiting entrainment and the percent entrainment at the highest intensity (110\% VT) will be significantly greater in the non-EIH group compared to the EIH group.

Rationale

Research has shown that entrainment during submaximal running decreases linearly with increasing levels of hypoxia (Paterson et al., 1987). Therefore, it may be expected that athletes who exhibit EIH during intense exercise also do not exhibit entrainment, or at least exhibit it to a lesser degree. 
2. The percent entrainment at the highest intensity $(110 \%$ VT) will be significantly greater in the non-FL group compared to the FL group.

\section{Rationale}

Flow limitation may prevent breathing frequency from keeping up with SR, therefore preventing entrainment at high intensities.

3. Running economy at each intensity will be significantly greater in the entrained group compared to the non-entrained group.

Rationale

Research on humans while running has shown that entraining breathing frequency to stride rate improves running economy (Bernasconi \& Kohl, 1993; Bonsignore et al., 1998; Bramble \& Carrier, 1983), possibly by improving the economy of ventilation by reducing the metabolic cost of breathing (Bramble \& Carrier, 1983; Heinrich, 2001; Hill et al., 1988; Paterson et al., 1986). 


\section{Definitions of Terms}

Arterial Oxygen Saturation $\left(\mathrm{S}_{\mathrm{a}} \mathrm{O}_{2}\right)$. Hemoglobin's saturation of oxygen in arterial

blood. Also referred to as oxyhemoglobin saturation.

Arterial Partial Pressure of Oxygen $\left(\mathrm{P}_{\mathrm{a}} \mathrm{O}_{2}\right)$. The pressure exerted by oxygen in arterial blood.

Arterial Partial Pressure of Carbon Dioxide $\left(\mathrm{P}_{\mathrm{a}} \mathrm{CO}_{2}\right)$. The pressure exerted by carbon dioxide in arterial blood.

Breathing Frequency. The number of breaths taken per minute.

Desaturation. The decrease in oxygen saturation of hemoglobin below $92 \%$ at sea-level.

Entrainment. The involuntary coordination of two rhythms, such as breathing frequency and movement frequency; the locking of frequency and phase.

Exercise-Induced Hypoxemia (EIH). The decrease in oxygen saturation of hemoglobin below $92 \%$ at sea-level that occurs in many highly endurance-trained individuals during intense exercise.

Flow Limitation (FL). The encroachment or overlap of the exercise tidal flow-volume loop on the maximal flow-volume loop toward the end of expiration that occurs in many highly endurance-trained individuals during intense exercise.

Flow-Volume Loop. A graph of the relationship between the rate of airflow and the volume of air inhaled and exhaled. 
Forced Expiratory Volume $\left(\mathrm{FEV}_{1}\right)$. The volume of air or the percentage of vital capacity exhaled in the first second immediately after a maximal inspiration; used as a test of airflow to determine the presence of obstructive lung disease.

Hemoglobin. The protein in red blood cells that binds oxygen and transports it through the blood.

Locomotor-Respiratory Coupling. The coupling, or pairing, of the rhythm of movement and the rhythm of breathing.

Locomotion. The movement of an animal from one place to another by use of the limbs (e.g., walking and running).

Maximal Oxygen Consumption ( $\left.\dot{\mathrm{V}}_{2} \max \right)$. The maximal amount of oxygen consumed by the body per minute during whole-body exercise.

Non-Steady-State Exercise. A condition in which the energy expenditure provided during exercise is not balanced with the energy required to perform that exercise. During this condition, which includes exercise intensities above the lactate/ventilatory threshold, the oxygen consumption $\left(\dot{\mathrm{VO}}_{2}\right)$ continues to increase.

Oximetry. The indirect measurement of the oxygen saturation of hemoglobin in arterial blood.

Running Economy. The steady-state oxygen consumption when running at a given absolute or relative speed; typically expressed as milliliters of oxygen per kilogram of body mass per minute $\left(\mathrm{ml} \mathrm{kg}^{-1} \mathrm{~min}^{-1}\right)$ or milliliters of oxygen per kilogram of body mass per kilometer $\left(\mathrm{ml}^{1} \mathrm{~kg}^{-1} \mathrm{~km}^{-1}\right)$.

Steady-State Exercise. A condition in which the energy expenditure provided during exercise is balanced with the energy required to perform that exercise. During this 
condition, which includes exercise intensities below the lactate/ventilatory threshold, the oxygen consumption $\left(\dot{\mathrm{VO}}_{2}\right)$ is relatively constant and is directly proportional to the constant submaximal workload.

Stride Length. The distance from a foot strike to a foot strike of the opposite foot.

Stride Rate. The number of steps taken per minute with each leg.

Tidal Volume. The amount of air exhaled (or inhaled) in a single breath.

Ventilation ( $\dot{V} E)$. The bulk flow of air into and out of the lungs; typically expressed as the volume of air exhaled (in liters) in one minute.

Ventilatory Threshold. The exponential increase in ventilation corresponding to the development of metabolic acidosis; typically determined by non-linear increases in ventilation $(\dot{\mathrm{V}} \mathrm{E})$ and the volume of expired carbon dioxide $\left(\dot{\mathrm{VCO}}_{2}\right)$ relative to oxygen consumption $\left(\mathrm{V}_{2}\right)$, or by an increase in the ventilatory equivalent for oxygen $\left(\dot{\mathrm{V} E} / \dot{\mathrm{V}}_{2}\right)$ without a concomitant increase in the ventilatory equivalent for carbon dioxide ( $\left.\dot{\mathrm{V} E} / \dot{\mathrm{V}} \mathrm{CO}_{2}\right)$.

Vital Capacity (VC). The total volume of air exhaled immediately after a maximal inspiration; used as a test of lung volume to determine the presence of restrictive lung disease. 


\section{Chapter II}

\section{REVIEW OF LITERATURE}

\section{Ventilation During Exercise}

The prime function of the respiratory system is to supply oxygen $\left(\mathrm{O}_{2}\right)$ to and remove carbon dioxide $\left(\mathrm{CO}_{2}\right)$ from the exercising muscles. While both an increase in $\mathrm{CO}_{2}$ and a reduction in $\mathrm{O}_{2}$ in arterial blood, represented by their arterial partial pressures $\left(\mathrm{P}_{\mathrm{a}} \mathrm{CO}_{2}\right.$ and $\mathrm{P}_{\mathrm{a}} \mathrm{O}_{2}$, respectively), stimulate ventilation, the former is the more potent stimulus. For example, under conditions of normal $\mathrm{PO}_{2}$, ventilation increases by about two to three liters per minute for each $1 \mathrm{mmHg}$ increase in $\mathrm{PCO}_{2}$. However, under conditions of normal $\mathrm{PCO}_{2}$, ventilation does not increase with a decrease in $\mathrm{PO}_{2}$ until the normal, resting, sea-level $\mathrm{PO}_{2}$ is halved (to about $50 \mathrm{mmHg}$ ). The combined effect of an increased $\mathrm{PCO}_{2}$ and a decreased $\mathrm{PO}_{2}$ on ventilation is greater than the effect of each alone (West, 2000a).

Ironically, given the importance of ventilation in affecting the blood-gas profile, the control of ventilation during exercise is still not well-understood (Forster \& Pan, 1988; West, 2000a). It has historically been thought that ventilation during exercise is influenced, in part, by the sensed chemical changes occurring in the exercising muscles (Brooks et al., 2000; West, 2000a). At the start of exercise, ventilation increases abruptly from neurally-mediated muscle and joint mechanoreceptors that sense movement. As exercise continues at the same intensity, ventilation increases more slowly from humorally-mediated muscle and vascular chemoreceptors that sense changes in the body's chemical milieu (Turner, 1991). Exercise performance would be limited if the 
lungs and thoracic cavity failed to respond to these sensed changes and did not provide sufficient ventilation to adequately oxygenate the blood or remove $\mathrm{CO}_{2}$, or if there is an inefficient pulmonary gas exchange, leading to hypoxemia, a decreased oxygen level in the blood (Bye et al., 1983). Grimby (1969) suggested over thirty years ago that ventilation is not likely a limiting factor of exercise in all but the most extreme conditions, such as exercise at altitude and in highly-trained athletes who can achieve extremely high exercise ventilation rates.

It is believed that the pulmonary system, including the lungs, parenchyma, and respiratory muscles, unlike the cardiovascular and musculoskeletal systems, do not adapt to physical training (Dempsey, 1986; Dempsey et al., 1982). Thus, the argument that the lungs can limit exercise performance in those athletes who have developed the more trainable characteristics of aerobic capacity (e.g., cardiac output, hemoglobin concentration, muscle capillarization) to capacities that approach the genetic potential of the lungs to provide for adequate gas exchange (Jones \& Lindstedt, 1993) is an enticing one. In effect, the lungs can limit performance by "lagging behind" other, more readily adaptable characteristics (Dempsey, 1986). West (2003) suggests that the structure of an organism evolves to cope with all but the most extreme stresses to which it is subjected. Indeed, highly-trained athletes engaged in maximal exercise presents an extreme case in which the limits of pulmonary gas exchange can be tested, as ultrastructural changes in the blood-gas barrier have been shown to occur under such conditions (Hopkins et al., 1997; West, 2000b, 2003).

Among the factors which may indict the pulmonary system in limiting exercise performance in athletes are an inadequate ventilatory response to a high metabolic 
demand, a mechanical limitation to ventilation resulting from reaching the boundaries of the maximal expiratory flow-volume relationship (flow limitation), the high oxygen cost of ventilation at high workloads, and fatigue of the respiratory muscles (Bye et al., 1983). It has been proposed that the major consequence to the athlete of the high level of ventilatory work is the high oxygen cost associated with that ventilation, representing a potentially significant "steal" of blood flow from the main exercising muscles (Johnson et al., 1992). During moderate exercise $\left(70 \% \dot{\mathrm{V}}_{2} \max \right)$, the oxygen cost of ventilation has been estimated to equal 3 to $6 \%$ of total body oxygen consumption $\left(\dot{\mathrm{V}}_{2}\right)$, while during maximal exercise, it equals about $10 \%$ of $\dot{\mathrm{V}}_{2}$ max, costing as much as 13 to $15 \%$ in subjects who exhibit expiratory flow limitation (Aaron et al., 1992). This interesting finding led Aaron et al. (1992) to speculate that the closer one approaches the limits for inspiratory muscle pressure development and expiratory flow during maximal exercise, the greater the opportunity for deformation of the thoracic cavity, increased end-expiratory lung volume (EELV), extreme expiratory muscle pressure development, and very high velocities of muscle shortening, all of which may lead to excessive energy expenditure at a given ventilation.

Entrainment of Breathing to Stride Rate

In describing his run at the 1981 United States' National 100-Kilometer Championships, ultramarathoner and zoologist Bernd Heinrich, Ph.D. (2001) writes:

"The rhythm of my footsteps is steady, unvarying... it is unconsciously timed with my breathing... the breathing rhythm is usually also unconscious. It is timed to the same unconscious metronome that times the footsteps... Three steps with one long inspiration, a fourth step and a 
quick expiration. Over and over and over again. My mantra." (Why We Run, p.248)

Many animals seem to coordinate, or entrain, their breathing patterns to their locomotive rhythms (Boggs, 2002; Heinrich, 2001). For example, it has been reported that birds entrain their breathing frequency to their wing beats while flying (Butler \& Woakes, 1980; Funk et al., 1997) and their stride rates while walking (Brackenbury \& Avery, 1980). In mammals, it seems that breathing may also be entrained to the rate of limb movement, although some studies have found a large variation among subjects. While strict entrainment occurs in antelopes (Kamau, 1990), hopping wallabies (Baudinette et al., 1987), and in horses while running (Bramble \& Carrier, 1983; Young et al., 1992) and cantering (Lafortuna et al., 1996), it occurs infrequently in cats while walking (Iscoe, 1981) and in rabbits at slow running speeds (Simons, 1999). Entrainment has also been shown to occur, sometimes infrequently or transiently, in humans while walking and running (Bechbache \& Duffin, 1977; Bernasconi \& Kohl, 1993; Berry et al., 1988; Bonsignore et al., 1998; Bramble \& Carrier, 1983; Hill et al., 1988; McDermott et al., 2003; Paterson et al., 1987; Raßler \& Kohl, 1996; Takano, 1995), cycling (Bechbache \& Duffin, 1977; Bernasconi \& Kohl, 1993; Bonsignore et al., 1998; Jasinskas et al., 1980; Paterson et al., 1986), rowing (Mahler et al., 1991), and even while walking with crutches (Hurst et al., 2001) (Table 1). Animals that run on four legs seem to be constrained to a 1:1 ratio between steps and breaths, especially as speed increases (Boggs, 2002; Lafortuna et al., 1996; Simons, 1999). For example, the often-studied thoroughbred horse, which has remarkable aerobic capabilities, including a $\dot{\mathrm{V}} \mathrm{O}_{2} \mathrm{max}$ of about $150 \mathrm{ml} / \mathrm{kg}^{\prime} \mathrm{min}^{-1}$ and a cardiac output in excess of $600 \mathrm{Lmin}^{-1}$, links breathing 
frequency 1-to-1 with stride rate, with inspiration and expiration always occurring at the same point in the stride (Bramble \& Carrier, 1983). On the other end of the locomotion spectrum is the sluggish terrestrial turtle, which seems to be the only animal studied that does not entrain breathing to stride rate (Landberg et al., 2003).

Unlike their quadruped counterparts, humans utilize several step-to-breath ratios while walking and running, including 4:1, 3:1, 2:1, 5:2, and $3: 2$, with a $2: 1$ ratio being the most common pattern observed (Bernasconi \& Kohl, 1993; Berry et al., 1996; Bramble \& Carrier, 1983; McDermott et al., 2003; Paterson et al., 1987; Persegol et al., 1991; Takano, 1995). As Heinrich (2001) explains,

"At the most efficient running stride, arms, breaths, and heartbeats are multiples of one another. Those multiples change with pace and effort, but the synchronicity does not. It is as though his [the distance runner's] legs beat the tune to create the body's rhythm." (Why We Run, p.70)

McDermott et al. (2003) found that the coupling ratio changes as a function of running speed, from a 2:1 ratio at slower speeds $\left(7.2-8.0 \mathrm{kmhr}^{-1}\right)$ to a $3: 2$ ratio and finally to a 1:1 ratio at faster speeds $\left(11.2-12.1 \mathrm{~km}^{-1}\right)$, which were $20 \%$ faster than the subjects' preferred treadmill running speed. However, the tightly coupled 1:1 ratio was only observed at the fastest speed in two of the ten subjects (both non-runners), and was associated with short, shallow breaths (W.J. McDermott, personal communication). Takano (1995) also observed a 1:1 ratio in a couple of subjects who took an excessive number of breaths while running uphill.

Comparing entrainment during different modes of exercise, Bernasconi and Kohl (1993) found a greater degree of entrainment during running compared to cycling in fit but untrained subjects, with entrainment increasing slightly but not significantly with 
increasing running speed, while Bonsignore et al. (1998) obtained the opposite result in a group of triathletes, with the degree of entrainment decreasing at fast cycling and running speeds.

Interestingly, it has also been found that entrainment during submaximal running decreases linearly with increasing levels of hypoxia (Paterson et al., 1987), suggesting that any advantage conferred to humans by coordinating breathing frequency and stride rate is superseded at altitude by the increased need to ventilate to compensate for the decreased oxygen supply. For a similar reason, it may be expected that athletes who exhibit hypoxemia during intense exercise (exercise-induced hypoxemia, EIH) also do not exhibit entrainment, or at least exhibit it to a lesser degree.

Unlike cycling, running seems to impose mechanical constraints on breathing that require the respiratory cycle to be synchronized with gait (Bramble \& Carrier, 1983; Forster \& Pan, 1988), although it has been suggested that a mechanical link may not be obligatory (Jones \& Lindstedt, 1993). While it is proposed that locomotory movements may control ventilation in horses and other galloping mammals (Young et al., 1992), there does not seem to be a mechanical advantage of entraining breathing to stride rate in humans, as locomotory rhythm does not assist ventilation during walking or running (Banzett et al., 1992). Given the plethora of studies that have found entrainment when an imposed visual or auditory rhythm, such as a metronome, is introduced (Bechbache et al., 1977; Bernasconi \& Kohl, 1993; Bonsignore et al., 1998; Jasinskas et al., 1980; Paterson et al., 1986; van Alphen \& Duffin, 1994), the tendency of humans to entrain breathing to stride rate, if not imposed by a mechanical constraint of locomotion, may merely be another example of breathing becoming entrained to a rhythm (e.g., stride rate). 
In human studies, the reports on the percentage of subjects exhibiting entrainment have varied greatly (Bechbache \& Duffin, 1977; Bramble \& Carrier, 1983; Paterson et al., 1986), and has depended, in part, on the fitness level of the subjects (Berry et al., 1988; Mahler et al., 1991) and their experience at the exercise mode being tested (Berry et al., 1988; Bramble \& Carrier, 1983; Paterson et al., 1987). For example, Mahler et al. (1991) found a greater incidence of entrainment of breathing frequency to stroke rate in elite female rowers compared to untrained rowers. In studies on runners, Bramble and Carrier (1983) found that breathing and gait were tightly coupled in a group of six trained runners (average training volume of 15 to 70 miles per week) but not in a group of six non-runners (described as having little or no running experience). Furthermore, they found that the most experienced runners of the trained group coupled their breathing frequency to their gait earlier into a run (within the first 4 to 5 strides) compared to the less experienced runners of the group. The researchers also noted that, in runners who exhibit entrainment with even step-to-breath ratios (e.g., 4:1 or 2:1), the beginning and end of the respiratory cycle are associated with the same foot strike (Bramble \& Carrier, 1983). In contrast, McDermott et al. (2003) found no difference in the coupling of breathing to stride rate between runners and non-runners. However, their finding is not surprising given the small number of subjects ( $\mathrm{n}=5$ in each group), and the classification of "runners" as those averaging only 25 miles per week (with a range of 10 to 60 miles per week) for six months prior to the study. In addition, the difference in preferred running speed between the runners and non-runners was only $0.8 \mathrm{~km}^{-1} \mathrm{hr}^{-1}$, minor when attempting to make comparisons between trained and untrained subjects. Berry et al. (1988) discovered that stride rate has a greater influence on ventilation and breathing 
frequency in trained runners (average $\dot{\mathrm{V}} \mathrm{O}_{2} \max =65 \mathrm{ml}^{\mathrm{kg}} \mathrm{min}^{-1}$; average training volume of 40 miles per week) than in sedentary subjects (average $\dot{\mathrm{VO}_{2}} \max =44.1 \mathrm{ml}^{\mathrm{kg}} \mathrm{min}^{-1}$ ) or in trained cyclists (average $\dot{\mathrm{V}} \mathrm{O}_{2} \mathrm{max}=60.6 \mathrm{ml} \mathrm{kg}^{\prime} \mathrm{min}^{-1}$; average training volume of 225 miles per week) while running, suggesting that entrainment is a learned phenomenon. As zoologist Bernd Heinrich (2001) writes of the effect of his training: "The body's metronome has been fine-tuned by more tens of thousands of miles than I can begin to comprehend..." (Why We Run, p.248). Although a few studies have shown differences in the relationship between breathing frequency and stride rate between fit and sedentary subjects, all of these studies examined ventilation during submaximal exercise. Furthermore, group classification was tenuous, most often based on running history (e.g., runners vs. non-runners), rather than on physiological measurements, such as $\dot{\mathrm{V}} \mathrm{O}_{2} \mathrm{max}$ or lactate threshold, or on cardiopulmonary characteristics, such as EIH or pulmonary flow limitation. Whether the entrainment of breathing frequency to stride rate occurs in highly-trained runners during intense exercise has yet to be examined.

\section{Determination of Entrainment}

At least some of the variability in the findings on entrainment may be due to a lack of a strict, quantitative determination of entrainment. While a couple of studies calculated an integer step-to-breath ratio (e.g., 2:1 or 3:2) from the quotient of the stride rate and breathing frequency (Bonsignore et al., 1998; Simons, 1999), other studies calculated a step-to-breath ratio from a power spectral analysis of the measured breathing and gait signal frequencies (Berry et al., 1996; Jasinskas et al., 1980; Paterson et al., 1986; Paterson et al., 1987). Still others examined the phase relationship between steps 
and breaths, by either comparing the time interval between step onset and the onset of inspiration (or expiration) between steps (Hill et al., 1988; Hurst et al., 2001; Raßler \& Kohl, 1996; Takano, 1995; van Alphen \& Duffin, 1994), or by counting the number of inspirations or expirations beginning in the same phase of the stride and expressing it as a percentage of the total number of breaths recorded during the exercise period (Bernasconi \& Kohl, 1993).

In addition to the method of quantifying entrainment is the question of the frequency of its occurrence, either in the number of subjects or in the amount of time (or the percentage of steps) that subjects must exhibit coordination between breaths and steps for entrainment to be considered to occur. Many researchers acknowledge that not all of their subjects exhibited entrainment and, of those who did, exhibited it intermittently rather than for the entire exercise duration. The percentage of time or breaths that subjects have exhibited entrainment has varied between studies, including averages of 25\% while cycling (Paterson et al., 1986), 29\% (Hill et al., 1988) and 42 to $46 \%$ (Raßler \& Kohl, 1996) while walking on a treadmill, 50\% while running on a treadmill at sea-level, decreasing linearly with increasing levels of hypoxia (Paterson et al., 1987), and over 90\% while running over ground (Paterson et al., 1987). McDermott et al. (2003) examined both frequency and phase coupling between breaths and steps and found that the frequency coupling occurred for $60 \%$ of breaths while the phase coupling between end-inspiration and the preceding heel strike was maintained an average of $20 \%$ across a number of treadmill walking and running speeds. Currently, there is no minimal percentage of steps or breaths or amount of time for determining the presence of 
entrainment, other than a statistical comparison to that which would be expected to occur by chance.

Potential Implications of Entrainment

Since metabolism has been traditionally thought to influence ventilation ( $\dot{\mathrm{V} E})$, some studies have examined whether $\dot{\mathrm{V} E}$ would change under similar metabolic conditions if stride rate increased. When metabolic rate is held constant between treadmill walking and running (by including an incline during walking), $\dot{\mathrm{V} E}$ has been shown to remain the same (Berry et al., 1985; McMurray \& Smith, 1985) or increase slightly (Berry et al., 1996; McMurray \& Ahlborn, 1982) as stride rate increases from a walk to a run. All of these studies found an increase in breathing frequency and a decrease in tidal volume during running compared to walking, suggesting that ventilatory strategy changes in favor of breathing frequency as stride rate increases in order to maintain or slightly increase $\dot{V} E$ at the same metabolic rate. This finding, taken together with the above findings on entrainment, suggest that some advantage must be gained by coordinating breathing frequency and stride rate. So, what are some potential advantages? Since it is well known that ventilation affects the blood-gas profile (Norton et al., 1995; Powers et al., 1993; West, 2000a), entrainment may help to prevent a decrease in $\mathrm{P}_{\mathrm{a}} \mathrm{O}_{2}$ during intense exercise. None of the studies on entrainment examined its effects on blood gases. Banzett et al. (1992) suggest that entrainment has a neurophysiological benefit; that is, it may simply feel better to coordinate breathing with locomotion. Experienced runners may already know this, as Heinrich (2001) did: 
"I like the feeling of the strong, steady rhythm with everything in sync... Only the feeling of it remains. And it feels good." (Why We Run, p.248)

From a performance standpoint, a more attractive possibility is that entrainment may confer an economical advantage by decreasing the oxygen cost of breathing as locomotive rhythm increases. If the act of breathing itself could have a lesser metabolic cost, less oxygen would be needed by the ventilatory muscles, leaving more available to support oxidative metabolism in the skeletal muscles involved in locomotion.

Indeed, a few authors have suggested that entraining breathing to stride rate may improve the economy of ventilation by reducing its metabolic cost (Bramble \& Carrier, 1983; Heinrich, 2001; Hill et al., 1988; Paterson et al., 1986), which could be accomplished by reducing the mechanical interference between locomotion and ventilation and/or by the movements of locomotion relieving some of the work of the ventilatory muscles (Funk et al., 1997). As Heinrich (2001) reflected, "The rhythm preserves synchronicity, synchronicity translates to smoothness, and smoothness means energy efficiency." In quadrupeds, the changes in thoracic volume that accompany the movement of the limbs may reduce the amount of energy required for the mechanics of breathing (Heinrich, 2001). This is not considered to be the case in bipedal locomotion, as Banzett et al. (1992) found no mechanical advantage conferred upon the respiratory muscles by the movement of the limbs. However, research on humans while running has shown that entrainment does improve running economy (Bernasconi \& Kohl, 1993; Bonsignore et al., 1998; Bramble \& Carrier, 1983), although this does not seem to be the case while walking (Banzett et al., 1992; Raßler \& Kohl, 1996; van Alphen \& Duffin, 1994) or rowing (Maclennan et al., 1994). Although an improved economy as a result of 
entraining breathing to locomotion is an alluring concept, nearly all of the studies examining this issue measured whole body oxygen consumption and have not linked improvements in economy with a decreased oxygen cost of ventilation. Bernasconi and Kohl (1993) argue that changes in economy are not likely due to changes in the oxygen cost of ventilation, since they observed no difference in $\dot{\mathrm{V}} \mathrm{E}$, tidal volume, or breathing frequency between periods of high and low entrainment. Rather, they suggest that the entraining-induced improvements in economy are a result of a reduced tone of the sympathetic nervous system. Undoubtedly due to the difficulty in its measurement, only a couple of studies have compared the work of breathing between entrained and non-entrained conditions, with one study on birds reporting an improved economy (Funk et al., 1997) and the other study on humans while walking and running reporting no difference in economy (Banzett et al., 1992) between entrained and non-entrained conditions. Funk et al. (1997), who mechanically ventilated geese, found a significant reduction in the cost of breathing with entrainment, most notably when the breathing frequency to wing beat ratio was 1:1. Interestingly, no studies have compared economy between subjects who exhibit entrainment and those who do not.

\section{Economy of Ventilation}

Runners who perform a high volume of endurance training tend to be more economical (Scrimgeour et al., 1986), which has led to the suggestion that running high mileage ( $>70$ miles per week) seems to improve running economy (Scrimgeour et al., 1986; Sjodin \& Svedenhag, 1985; Jones \& Carter, 2000). However, it is unknown whether the relationship between training volume and economy is cause and effect or that 
the most economical runners are simply capable of training with a higher volume. Thus, the mechanism for an improved economy remains elusive. For example, Saunders et al. (2004) found that, while running economy improved as a result of a 20-day training program that incorporated living at altitude and training at sea-level, there was no difference in $\dot{V} E$ pre- and post-training, leading them to conclude that the increased economy was not related to ventilation. In contrast, Franch et al. (1998) observed that, when running economy was improved following a six-week training program, submaximal $\dot{\mathrm{V} E}$ significantly decreased $(\mathrm{p}<0.0001)$, with the reduction in $\dot{\mathrm{V}} \mathrm{E}$ correlated to improvements in running economy $(\mathrm{r}=0.77 ; \mathrm{p}<0.0001)$. Although the researchers acknowledge that this correlation does not imply cause and effect, they do suggest that ventilatory adaptation to training may play a role in improving running economy. Given the fact that it is metabolically expensive to breathe at high pulmonary flow rates, costing up to 10 to $15 \%$ of the total body $\dot{\mathrm{VO}}_{2}$ (Aaron et al., 1992), this adaptation may be very important. Runners may learn, through training, how to most effectively ventilate their lungs and minimize the metabolic cost of breathing. However, as Jones and Lindstedt (1993) point out, a more economical ventilation may come at the cost of maintaining effective alveolar ventilation since, theoretically, in order for the ventilatory rate to keep up with stride rate, very high average and peak pulmonary flows would have to be achieved. Such high flows may result in airway closure and cause an inadequate hyperventilatory response during intense exercise. In light of the influence of high pulmonary flows and inadequate hyperventilation on pulmonary flow limitation and the development of exercise-induced hypoxemia $(\mathrm{EIH})$, respectively, in elite endurance 
athletes, could Jones and Lindstedt's (1993) suggestion represent a connection between the occurrence of entrainment and either flow limitation or EIH?

In summary, a number of issues concerning entrainment have heretofore not been adequately resolved, including its measurement, its intermittent nature, and its changes with speed. Indeed, given the finding that humans are more likely to entrain breathing to stride rate when an extraneous rhythm is introduced (Bechbache et al., 1977; Bernasconi \& Kohl, 1993; Bonsignore et al., 1998; Jasinskas et al., 1980; Paterson et al., 1986; van Alphen \& Duffin, 1994), it cannot even be concluded that entrainment exists as a physiological, rather than (sub)cognitive, phenomenon. Studies examining this "lungs-legs" relationship while running have been limited to untrained or moderately-fit subjects during low-intensity or moderate-intensity exercise. The available evidence suggests that, while breathing frequency is tightly coupled to stride rate with a 1:1 ratio in quadruped animals, the relationship is more tenuous in humans, who exhibit a greater range of ratios, especially at slower speeds (Bechbache \& Duffin, 1977; Bernasconi \& Kohl, 1993; Berry et al., 1988; Berry et al., 1996; Bonsignore et al., 1998; Bramble \& Carrier, 1983; Hill et al., 1988; McDermott et al., 2003; Paterson et al., 1987; Persegol et al., 1991; Raßler \& Kohl, 1996; Takano, 1995). As speed increases, untrained or moderately-fit humans seem to exhibit a greater degree of entrainment (Bernasconi \& Kohl 1993; McDermott et al., 2003), approaching the 1:1 ratio of other mammals (McDermott et al., 2003), while the degree of entrainment seems to decrease with an increase in speed in trained athletes (Bonsignore et al., 1998). In light of the findings that entrainment of breathing frequency to stride rate is more typical of subjects who are experienced with the mode of exercise (Berry et al., 1988; Bramble \& Carrier, 1983; 
Paterson et al., 1987) and who have a higher level of fitness (Berry et al., 1988; Mahler et al., 1991), it may be expected that entrainment would be most evident and clearly definable in highly-trained distance runners. Given the curious cardiopulmonary characteristics common among highly-trained endurance athletes, namely EIH and flow limitation, it may also be expected that the relationship of breathing frequency to stride rate is unique in this population. 
Table 1. Studies Examining Entrainment of Ventilation to Locomotion in Humans

\begin{tabular}{|c|c|c|c|c|}
\hline Study & Subjects & Mode of Exercise & $\begin{array}{c}\text { Determination/Validation } \\
\text { of Entrainment }\end{array}$ & Results \\
\hline $\begin{array}{l}\text { Bechbache \& } \\
\text { Duffin (1977) } \\
\text { J. Physiol. }\end{array}$ & $\begin{array}{l}3 \text { groups of } 15 \\
\text { (untrained): } \\
\text { 1) } 12 \text { males, } 3 \text { females } \\
\text { ( } 21-46 \text { yrs) } \\
\text { 2) } 10 \text { males, } 5 \text { females } \\
\text { ( } 20-52 \text { yrs) } \\
\text { 3) } 13 \text { males, } 2 \text { females } \\
\text { (20-25 yrs) }\end{array}$ & $\begin{array}{l}\text { - } \text { Cycling } \\
\text { (moderate intensity; } 50 \text { \& } 70 \\
\text { RPM) } \\
\text { - Treadmill walking } \\
\text { (moderate intensity) } \\
\text { - Treadmill running } \\
\text { (moderate intensity) }\end{array}$ & $\begin{array}{l}\text { Cross-correlation of pulse trains } \\
\text { derived from exercise and } \\
\text { breathing rhythms on breath-to- } \\
\text { breath basis. Classified cross- } \\
\text { correlograms into strong, weak, } \\
\text { and no entrainment categories } \\
\text { based on pattern of breathing } \\
\text { rhythm pulses. }\end{array}$ & $\begin{array}{l}\text { - } 53 \% \text { and } 80 \% \text { of subjects } \\
\text { exhibited entrainment while walking } \\
\text { and running, respectively. } \\
\text { - Greater percentage of subjects } \\
\text { exhibited entrainment while cycling } \\
\text { at } 70 \text { RPM compared to } 50 \text { RPM. }\end{array}$ \\
\hline $\begin{array}{l}\text { Bernasconi \& } \\
\text { Kohl (1993) J. } \\
\text { Physiol. }\end{array}$ & $\begin{array}{l}23 \text { males, } 11 \text { females } \\
\text { (untrained; avg. age = } \\
26 \text { yrs) }\end{array}$ & $\begin{array}{l}\text { - Cycling } \\
(60 \% \text { \& 80\% PWC 170) } \\
\text { - Treadmill running } \\
(60 \% \text { \& 80\% PWC 170) }\end{array}$ & $\begin{array}{l}\text { Count of number of inspirations or } \\
\text { expirations beginning in same } \\
\text { phase of step or pedaling cycle and } \\
\text { expressing it as percentage of total } \\
\text { number of breaths recorded during } \\
\text { exercise period. No method of } \\
\text { validation. }\end{array}$ & $\begin{array}{l}\text { - Greater degree of entrainment } \\
\text { during running compared to cycling. } \\
\text { - Entrainment increased with } \\
\text { increasing running speed. } \\
\text { - } \mathrm{VO}_{2} \text { was lower as degree of } \\
\text { entrainment increased. }\end{array}$ \\
\hline $\begin{array}{l}\text { Berry et al. } \\
\text { (1996) } \\
\text { Eur. J. Appl. } \\
\text { Physiol. Occup. } \\
\text { Physiol. }\end{array}$ & $\begin{array}{l}7 \text { trained male runners } \\
\text { (avg. age }=28 \text { yrs) }\end{array}$ & $\begin{array}{l}\text { Treadmill walking and running } \\
\text { (at same metabolic rate) }\end{array}$ & $\begin{array}{l}\text { Calculation of step-to-breath ratio } \\
\text { from power spectral analysis of } \\
\text { breathing and gait signal } \\
\text { frequencies. Chi-square test used } \\
\text { to compare expected and observed } \\
\text { frequencies of entrainment. }\end{array}$ & $\begin{array}{l}\text { - } 86 \% \text { and } 43 \% \text { of subjects } \\
\text { exhibited entrainment while walking } \\
\text { and running, respectively. } \\
\text { - VE was greater while running } \\
\text { compared to walking. }\end{array}$ \\
\hline
\end{tabular}


Table 1. (Cont.)

\section{Study}

Subjects

Mode of Exercise

- Cycling

(incremental test to

exhaustion at 60 RPM)

- Treadmill running

(incremental tests w/

increasing speed/constant

grade \& increasing

grade/constant speed)

\section{Bramble \&}

Carrier (1983)

Science.

$\infty$
6 trained runners

6 non-runners

(11 males, 1 female;

20-45 yrs)
Track running

(slow, moderate, \& fast speeds)
Visual inspection of oscilloscope tracings of breaths and steps. No method of validation.
Calculation of integer step-tobreath ratio from quotient of stride rate and breathing frequency. No method of validation.

\section{Comparison of time interval}

between heel strike and onset of inspiration (or expiration) between steps. Monte Carlo simulation was used to estimate sensitivity and specificity of method.

\section{Results}

- Higher percentage of entrainment

while cycling compared to running.

- Degree of entrainment decreased

with increasing speed.

- Entrainment correlated with

fitness level.

- Lower $\mathrm{VE} / \mathrm{VO}_{2}$ in entrained

compared to non-entrained breaths.

- Entrainment occurred in runners

but not in non-runners.

- Most experienced runners coupled breathing frequency to gait earlier into run compared to less

experienced runners.

- Beginning \& end of respiratory cycle were associated with same footfall.

- $2: 1$ step-to-breath ratio was most common.

- Majority of subjects exhibit entrainment, albeit intermittently.

$\begin{array}{lll}\text { Hill et al. (1988) } & 38 \text { untrained } & \text { Treadmill walking } \\ \text { J. Appl. Physiol. } & \text { (18 males, 20 females; } & (2.5-3.0 \mathrm{mph}) \\ & 19-45 \mathrm{yrs}) & \end{array}$


Table 1. (Cont.)

\begin{tabular}{|c|c|c|c|}
\hline Study & Subjects & Mode of Exercise & $\begin{array}{c}\text { Determination/Validation } \\
\text { of Entrainment }\end{array}$ \\
\hline
\end{tabular}

$\begin{array}{lll}\begin{array}{l}\text { Hurst et al. } \\ \text { (2001) Am. } J .\end{array} & \begin{array}{l}18 \text { untrained } \\ \text { (12 males, } 6 \text { females; }\end{array} & \begin{array}{l}\text { Treadmill walking with crutches } \\ (\mathrm{w} / \text { leg swing; mean speed }=3.0\end{array} \\ \begin{array}{l}\text { Phys. } \text { Med. } \\ \text { avg. age }=24 \mathrm{yrs})\end{array} & \mathrm{mph})\end{array}$

Rehab.

Jasinskas et al.

(1980) Resp.

Physiol.

\author{
16 untrained \\ (10 males, 6 females; \\ 19-37 yrs)
}

\section{ㄱ}

Mahler et al.

(1991)

J. Appl. Physiol.

\section{0 untrained}

(4 males, 6 females;

avg. age $=27 \mathrm{yrs}$ )

9 elite rowers

(7 males, 2 females;

avg. age $=26$ yrs)

McDermott et al. 5 trained male runners

(2003) Eur. J.

5 untrained males

Appl. Physiol.

\section{Cycling \\ (40\% \& $\left.\geq 70 \% \mathrm{VO}_{2} \max \right)$}

Rowing ergometer

(incremental test to exhaustion

$\&$ steady-state test at $60 \%$

$\mathrm{VO}_{2} \max$ )

Treadmill walking \& running:

- $40 \%$ below prefer. walk speed

- $20 \%$ below prefer. walk speed

- prefer. walk speed

- prefer. walk transition speed

- prefer. run transition speed

- prefer. run speed

- $20 \%$ above prefer. run speed

\section{Comparison of time interval}

between onset of crutch gait cycle

and onset of inspiration (or

expiration) between steps. Only identified 1:1 ratios. Had one

subject intentionally entrain and

non-entrain to validate method.

Calculation of step-to-breath ratio from analysis of breathing and gait signal frequencies of post stimulus histogram. No method of validation.

Statistical analysis of matching inspiration with components of rowing stroke represented by circle plot. Chi-square test used to assess placement of breaths in circle plot as random or patterned.

\section{Evaluation of strength and}

variability of frequency and phase coupling patterns by calculating relative phase and plotting its time series against itself with different time lags (return maps). No method of validation.
- $56 \%$ of subjects exhibited entrainment.

- In $89 \%$ of entrainment episodes expiration occurred during crutch stance phase and inspiration occurred during crutch swing.

- No difference in entrainment between low and high workloads.

- Entrainment occurred in presence and absence of metronome.

- Entrainment occurred in majority of elite rowers at a ratio of $1: 1$ or 2:1.

- Greater incidence of entrainment in elite female rowers compared to untrained rowers.

- No difference in coupling of breathing to stride rate between runners and non-runners

- 2:1 step-to-breath ratio was most common.

- Coupling became tighter with increasing speed. 
Table 1. (Cont.)

\begin{tabular}{|c|c|c|c|c|}
\hline Study & Subjects & Mode of Exercise & $\begin{array}{c}\text { Determination/Validation } \\
\text { of Entrainment }\end{array}$ & Results \\
\hline $\begin{array}{l}\text { Paterson et al. } \\
\text { (1987) J. Appl. } \\
\text { Physiol. }\end{array}$ & $\begin{array}{l}2 \text { groups: } \\
\text { 1) } 5 \text { male Nepalese } \\
2 \text { male Caucasians } \\
\text { (avg. age }=23 \text { yrs) } \\
\text { 2) } 3 \text { males, } 4 \text { females } \\
\text { (avg. age }=20 \text { yrs) }\end{array}$ & $\begin{array}{l}\text { - Overground running } \\
\text { (preferred speed; at varying } \\
\text { altitudes) } \\
\text { - Treadmill running } \\
\text { (incremental } \mathrm{VO}_{2} \text { max test \& } \\
\text { steady-state test at } 40 \% \\
\mathrm{VO}_{2} \text { max; at gas mixtures } \\
\text { simulating varying altitudes) }\end{array}$ & $\begin{array}{l}\text { Calculation of step-to-breath ratio } \\
\text { from power spectral analysis of } \\
\text { breathing and gait signal } \\
\text { frequencies. Calculated all } \\
\text { possible coupling combinations of } \\
\text { step and breathing frequencies to } \\
\text { determine chance entrainment and } \\
\text { statistically compared chance and } \\
\text { actual couplings. }\end{array}$ & $\begin{array}{l}\text { - Degree of entrainment decreased } \\
\text { with increasing levels of altitude. } \\
\text { - } 2: 1 \text { step-to-breath ratio was most } \\
\text { common. } \\
\text { - Experienced runners had higher } \\
\text { degree of entrainment. }\end{array}$ \\
\hline $\begin{array}{l}\text { Paterson et al. } \\
\text { (1986) Eur. J. } \\
\text { Appl. Physiol. }\end{array}$ & $\begin{array}{l}19 \text { untrained males } \\
\text { (19-30 yrs) }\end{array}$ & $\begin{array}{l}\text { - Cycling } \\
\left(40 \% \& 80 \% \mathrm{VO}_{2} \max \right) \\
\text { - Arm cranking } \\
\left(30 \% \& 80 \% \mathrm{VO}_{2} \max \right)\end{array}$ & $\begin{array}{l}\text { Calculation of step-to-breath ratio } \\
\text { from power spectral analysis of } \\
\text { breathing and gait signal } \\
\text { frequencies. Calculated all } \\
\text { possible coupling combinations of } \\
\text { step and breathing frequencies to } \\
\text { determine chance entrainment and } \\
\text { statistically compared chance and } \\
\text { actual couplings. }\end{array}$ & $\begin{array}{l}\text { - Greater occurrence of entrainment } \\
\text { during cycling. } \\
\text { - No difference in entrainment } \\
\text { between low and high workloads. }\end{array}$ \\
\hline $\begin{array}{l}\text { Persegol et al. } \\
\text { (1991) J. } \\
\text { Physiol. (Paris). }\end{array}$ & 17 untrained & $\begin{array}{l}\text { Treadmill running } \\
\text { (at } 14 \text { different speeds) }\end{array}$ & $\begin{array}{l}\text { Calculation of step-to-breath ratio; } \\
\text { examination of "evolution" (the } \\
\text { gradual change over different } \\
\text { speeds) of locomotor-respiratory } \\
\text { coupling. No method of } \\
\text { validation. }\end{array}$ & $\begin{array}{l}\text { - Entrainment did not appear at all } \\
\text { locomotor frequencies, but only for } \\
\text { those close to harmonics of } \\
\text { respiratory ones. } \\
\text { - } 2: 1 \text { step-to-breath ratio was most } \\
\text { common. }\end{array}$ \\
\hline
\end{tabular}


Table 1. (Cont.)

\begin{tabular}{|c|c|c|c|c|}
\hline Study & Subjects & Mode of Exercise & $\begin{array}{c}\text { Determination/Validation } \\
\text { of Entrainment }\end{array}$ & Results \\
\hline $\begin{array}{l}\text { Raßler \& Kohl } \\
\text { (1996) Resp. } \\
\text { Physiol. }\end{array}$ & $\begin{array}{l}18 \text { untrained } \\
\text { (10 males, } 8 \text { females; } \\
22-53 \mathrm{yrs})\end{array}$ & $\begin{array}{l}\text { Treadmill walking: } \\
\text { - } 2.2 \mathrm{mph} ; 0 \% \text { grade } \\
\text { - } 3.4 \mathrm{mph} ; 0 \% \text { grade } \\
\text { - } 4.0 \mathrm{mph} ; 0 \% \text { grade } \\
\text { - } \text { preferred speed; } 0 \% \text { grade } \\
\text { - } 2.2 \mathrm{mph} ; 5 \% \text { grade } \\
\text { - } 2.2 \mathrm{mph} ; 10 \% \text { grade }\end{array}$ & $\begin{array}{l}\text { Comparison of time interval } \\
\text { between heel strike and onset of } \\
\text { inspiration (or expiration) between } \\
\text { steps using relative phase } \\
\text { histograms. No method of } \\
\text { validation. }\end{array}$ & $\begin{array}{l}\text { - Degree of entrainment increased } \\
\text { with increasing speed. } \\
\text { - No difference in } \mathrm{VO}_{2} \text { with } \\
\text { entrainment. }\end{array}$ \\
\hline $\begin{array}{l}\text { Takano (1995) } \\
\text { Jap. J. Physiol. }\end{array}$ & $\begin{array}{l}9 \text { trained male runners } \\
(19-22 \mathrm{yrs})\end{array}$ & $\begin{array}{l}\text { Overground running: } \\
\text { - uphill preferred speed } \\
\text { (7-9\% grade) } \\
\text { - downhill preferred speed } \\
\text { (7-9\% grade) }\end{array}$ & $\begin{array}{l}\text { Calculation of step-to-breath ratio } \\
\text { and comparison of time interval } \\
\text { between heel strike and onset of } \\
\text { inspiration and expiration between } \\
\text { steps. No method of validation. }\end{array}$ & $\begin{array}{l}\text { - During uphill \& downhill } \\
\text { running, entrainment occurred with } \\
\text { ratios of } 1: 1,2: 1, \& 2.5: 1 \text {. } \\
\text { - During uphill running, onset of } \\
\text { inspiration occurred during support } \\
\text { phase. } \\
\text { - During downhill running, onset of } \\
\text { inspiration occurred during airborne } \\
\text { phase. }\end{array}$ \\
\hline
\end{tabular}




\section{Exercise-Induced Hypoxemia}

It would be counterintuitive to think that highly-trained endurance athletes, who have thoroughly-developed aerobic metabolic systems, could experience a diminished ability to carry and transport oxygen (i.e., desaturate) during intense exercise. This characteristic would most commonly be thought to be specific only to a diseased population, such as those with cardiopulmonary dysfunction or anemia. After all, if a trained endurance athlete can cover a given distance faster than a recreational athlete or a healthy but sedentary individual, wouldn't that mean that he or she is better at supplying oxygen to the active muscles? Certainly much research has been devoted to this very issue, and it is unequivocal that highly-trained endurance athletes are better at supplying their active muscles with more blood and more oxygen. So, the common finding that many endurance athletes actually exhibit desaturation during intense exercise (Dempsey \& Johnson, 1992; Dempsey et al., 1984; Durand et al., 2000; Gavin \& Stager, 1999; McKenzie et al., 1999; Miyachi \& Tabata, 1992; Powers et al., 1988; Powers et al., 1992; Powers et al., 1993; Powers \& Williams, 1987; Préfaut et al., 1994; Rice et al., 1999; Rice et al., 2000; Rowell et al., 1964; Warren et al., 1991; Williams et al., 1986), termed exercise-induced hypoxemia (EIH), is curious to say the least.

During resting conditions at sea-level, the arterial partial pressure of oxygen $\left(\mathrm{P}_{\mathrm{a}} \mathrm{O}_{2}\right)$ is approximately $100 \mathrm{mmHg}$, resulting in a 97 to $98 \%$ saturation of hemoglobin with oxygen (West, 2000a). Although there is a slight reduction in $\mathrm{P}_{\mathrm{a}} \mathrm{O}_{2}$ during intense exercise, this near-maximal saturation is maintained in healthy individuals at sea-level (Powers \& Williams, 1987). The relationship between arterial oxygen saturation $\left(\mathrm{S}_{\mathrm{a}} \mathrm{O}_{2}\right)$ and $\mathrm{P}_{\mathrm{a}} \mathrm{O}_{2}$ is elucidated by the sigmoidal shape of the oxyhemoglobin dissociation curve 
(Figure 1). At a $\mathrm{P}_{\mathrm{a}} \mathrm{O}_{2}$ near $100 \mathrm{mmHg}$, the curve is relatively flat, so a slight reduction in $\mathrm{P}_{\mathrm{a}} \mathrm{O}_{2}$ does not have a significant effect on $\mathrm{S}_{\mathrm{a}} \mathrm{O}_{2}$. However, if $\mathrm{P}_{\mathrm{a}} \mathrm{O}_{2}$ decreases below approximately $70 \mathrm{mmHg}, \mathrm{S}_{\mathrm{a}} \mathrm{O}_{2}$ begins to decrease rapidly, and desaturation results.

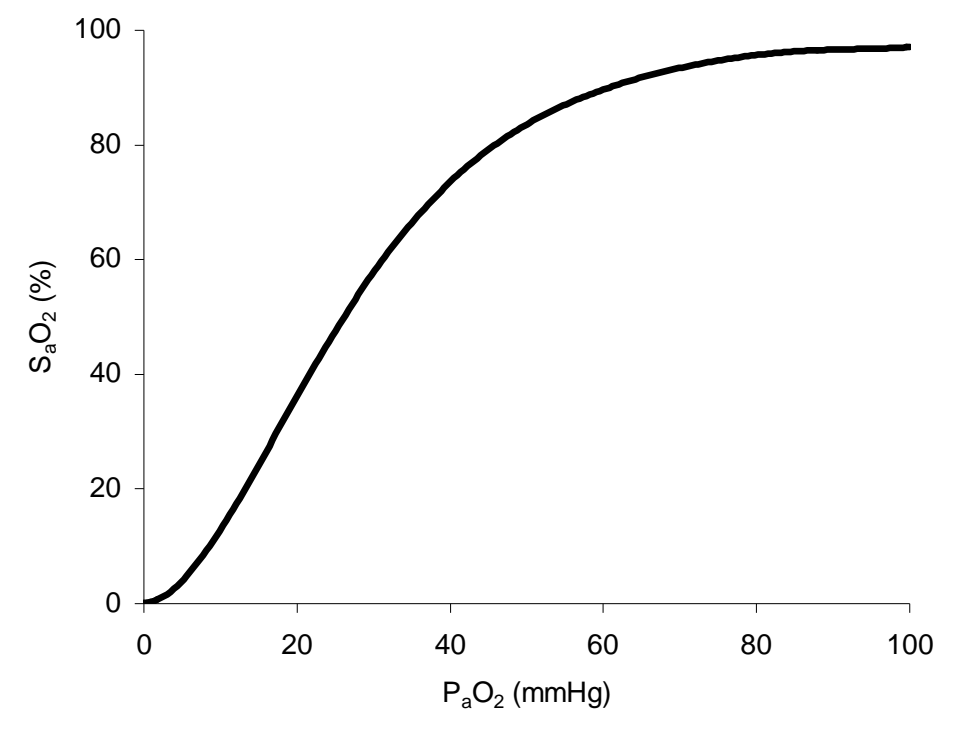

Figure 1. The oxyhemoglobin dissociation curve. Due to its sigmoidal shape, $\mathrm{S}_{\mathrm{a}} \mathrm{O}_{2}$ is maintained in the face of a decreasing $\mathrm{P}_{\mathrm{a}} \mathrm{O}_{2}$, down to about $70 \mathrm{mmHg}$.

For reasons not completely understood, approximately 40 to $50 \%$ of endurance athletes exhibit a significant reduction in $\mathrm{S}_{\mathrm{a}} \mathrm{O}_{2}$ during exercise at intensities approaching $\dot{\mathrm{V}} \mathrm{O}_{2} \max$ (Powers et al., 1993). Rowell et al. (1964) first reported a decrease in $\mathrm{S}_{\mathrm{a}} \mathrm{O}_{2}$ from $98 \%$ at rest to $85 \%$ during intense exercise. More recent studies have also reported large decreases in $\mathrm{S}_{\mathrm{a}} \mathrm{O}_{2}$ in trained endurance athletes during intense exercise, from 87 to 90\% (Buono \& Maly, 1996; Gavin \& Stager, 1999; Williams et al., 1986). While it is 
possible that desaturation during intense exercise results not only from a decrease in $\mathrm{P}_{a} \mathrm{O}_{2}$ but also from a rightward shift in the oxyhemoglobin dissociation curve due to increases in the arterial partial pressure of carbon dioxide $\left(\mathrm{P}_{\mathrm{a}} \mathrm{CO}_{2}\right)$ (termed the Bohr effect) and body temperature and a decrease in $\mathrm{pH}$ (West, 2000a), studies that have measured changes in blood gas responses in athletes during exercise have indeed found that large decreases in $\mathrm{P}_{\mathrm{a}} \mathrm{O}_{2}$ can occur. $\mathrm{P}_{\mathrm{a}} \mathrm{O}_{2}$ was first measured in endurance athletes during exercise by Holmgren and Linderholm (1958), who observed an extreme decrease in $\mathrm{P}_{\mathrm{a}} \mathrm{O}_{2}$ to $57 \mathrm{mmHg}$ (44 mmHg below resting values) in some athletes, while others maintained their $\mathrm{P}_{a} \mathrm{O}_{2}$ within 5 to $8 \mathrm{mmHg}$ of resting values. Other studies that measured $\mathrm{P}_{\mathrm{a}} \mathrm{O}_{2}$ in endurance athletes during exercise have also observed large decreases. For example, Warren et al. (1991) reported a decrease in $\mathrm{P}_{\mathrm{a}} \mathrm{O}_{2}$ from $101 \mathrm{mmHg}$ at rest to 85 mmHg during intense exercise, Gledhill et al. (1980) observed an average decrease in $\mathrm{P}_{\mathrm{a}} \mathrm{O}_{2}$ of $22 \mathrm{mmHg}$, and Dempsey et al. (1984) observed a fall in $\mathrm{P}_{\mathrm{a}} \mathrm{O}_{2}$ to less than 75 $\mathrm{mmHg}$ in half of their subjects, with two subjects less than $60 \mathrm{mmHg}$, a decrease of 21 to $35 \mathrm{mmHg}$ below resting values. These findings have lead to the determination of EIH as a $\mathrm{P}_{\mathrm{a}} \mathrm{O}_{2}<75 \mathrm{mmHg}$ or an $\mathrm{S}_{\mathrm{a}} \mathrm{O}_{2}<92 \%$ (Dempsey et al., 1984; Powers et al., 1989), since it is believed that values below these levels result in an impairment of oxygen transport and a reduction in $\dot{\mathrm{V}}_{2} \max$ (Powers et al., 1989). Based on the observation that $\dot{\mathrm{VO}}_{2} \mathrm{max}$ is reduced by 1 to $2 \%$ for every $1 \%$ reduction in $\mathrm{S}_{\mathrm{a}} \mathrm{O}_{2}$ below $95 \%$, Dempsey and Wagner (1999) further define EIH as mild $\left(\mathrm{S}_{\mathrm{a}} \mathrm{O}_{2}=93-95 \%\right)$, moderate $\left(\mathrm{S}_{\mathrm{a}} \mathrm{O}_{2}=88-93 \%\right)$, and severe $\left(\mathrm{S}_{\mathrm{a}} \mathrm{O}_{2}<88 \%\right)$.

Interestingly, not only do many endurance athletes exhibit EIH during exercise, the degree of EIH seems to be positively related to aerobic power ( $\left.\dot{\mathrm{VO}}_{2} \mathrm{max}\right)$. In other 
words, in general, the greater the athlete's $\dot{\mathrm{V}} \mathrm{O}_{2}$ max, the lower the $\mathrm{S}_{\mathrm{a}} \mathrm{O}_{2}$ during exercise (Powers et al., 1993; Powers \& Williams, 1987; Williams et al., 1986). Williams et al. (1986) found a significant correlation between $\mathrm{V}_{2}$ max and $\mathrm{S}_{2} \mathrm{O}_{2}$ during exercise at $95 \%$ $\dot{\mathrm{V}} \mathrm{O}_{2}$ max for $1 \frac{1}{2}$ minutes $(\mathrm{r}=-0.77, \mathrm{p}<0.05)$. Of the two groups of athletes studied in connection with $\mathrm{EIH}$ - distance runners and cyclists - the former seem to experience more severe EIH than the latter (Dempsey \& Wagner, 1999), experiencing a greater decrease in $\mathrm{S}_{\mathrm{a}} \mathrm{O}_{2}$ (Gavin \& Stager, 1999) and $\mathrm{P}_{\mathrm{a}} \mathrm{O}_{2}$ (Rice et al., 2000). Furthermore, Rowell et al. (1964) found that the $\mathrm{S}_{\mathrm{a}} \mathrm{O}_{2}$ of sedentary subjects during maximal exercise was lower following an endurance training program, suggesting that training, rather than the innate characteristics of highly-trained endurance athletes, is responsible for the development of EIH. It is possible that training-induced modifications in the distribution of blood flow and pulmonary perfusion predispose athletes to EIH (Todaro et al., 1995). Préfaut et al. (1994) found that EIH appeared more frequently in older compared to younger athletes (i.e., 65 vs. 23 years old), with older athletes experiencing a greater decrease in $\mathrm{P}_{\mathrm{a}} \mathrm{O}_{2}$ at the same absolute intensity. In addition, the more frequent appearance of EIH in the older athletes seemed to occur despite less rigorous training than that undertaken by the young athletes, leading the authors to suggest that EIH may be potentiated by aging (Préfaut et al., 1994).

Interestingly, the phenomenon of EIH is not limited to humans. Race horses, whose $\dot{\mathrm{V}}_{2}$ max is double that of endurance-trained humans $\left(140-155 \mathrm{ml} \mathrm{kg}^{\prime} \mathrm{min}^{-1}\right)$ also exhibit EIH during intense exercise (Bayly et al., 1999; Dempsey \& Wagner, 1999; Wagner et al., 1989), beginning to desaturate at an intensity as low as 60 to $70 \%$ $\dot{\mathrm{V}} \mathrm{O}_{2} \max$ (Dempsey \& Johnson, 1992). What is it about athletes with a high aerobic 
power that causes a decrease in $\mathrm{P}_{\mathrm{a}} \mathrm{O}_{2}$ and $\mathrm{S}_{\mathrm{a}} \mathrm{O}_{2}$ during exercise? Four potential causes have been implicated: 1) a venoarterial shunt, 2) a hypoventilatory (or an inadequate hyperventilatory) response, 3) an inequality between alveolar ventilation $\left(\mathrm{V}_{\mathrm{A}}\right)$ and pulmonary blood flow or perfusion (Q), and 4) a diffusion limitation across the blood-gas interface (Powers \& Williams, 1987; Powers et al., 1993; West, 2000a).

Venoarterial Shunt

A shunt is a mechanism for turning or diverting something away. Physiologically, it refers to the diversion of blood from one part of the body to another. For example, some of the blood returning to the heart in the venous system enters the arterial circulation without going through ventilated areas of the lungs (West, 2000a). By being diverted away from the lungs' rich supply of oxygen, this blood cannot become oxygenated as it diffuses into the arterial system, resulting in a slight decrease in $\mathrm{P}_{a} \mathrm{O}_{2}$ relative to $\mathrm{P}_{\mathrm{A}} \mathrm{O}_{2}$, the partial pressure of oxygen in the lungs' alveoli. Since it is well-documented that this difference between the partial pressures, called the 'Alveolar-arterial partial pressure difference' $\left(\mathrm{P}_{\mathrm{A}-\mathrm{a}} \mathrm{O}_{2}\right.$ difference), is greater in athletes with EIH compared to those without EIH (Dempsey et al., 1984; Durand et al., 2000; Powers et al., 1992; Powers \& Williams, 1987; Rice et al., 1999; Warren et al., 1991), the venoarterial shunt may be partly responsible, at least theoretically, for the occurrence of EIH. Although the venoarterial shunt has been found to account for about $50 \%$ of the $\mathrm{P}_{\mathrm{A}-\mathrm{a}} \mathrm{O}_{2}$ difference at rest (Gledhill et al., 1977; Whipp \& Wasserman, 1969), it comprises only approximately 0.18 to $2.0 \%$ of the cardiac output (Hammond et al., 1986; Torre-Bueno et al., 1985), and therefore does not seem to be a significant factor in the 
development of EIH during exercise (Dempsey et al., 1984; Powers et al., 1993; Rice et al., 1999).

Research involving subjects breathing a hyperoxic gas $\left(>21 \% \mathrm{O}_{2}\right)$ during intense exercise has shown that the falling $\mathrm{P}_{\mathrm{a}} \mathrm{O}_{2}$ in athletes experiencing EIH is rescued and even increased back to normal values (Dempsey et al., 1984; Powers et al., 1992). If the venoarterial shunt were a causative factor in EIH, the extra oxygen being breathed would not have an effect on $\mathrm{P}_{\mathrm{a}} \mathrm{O}_{2}$ since the shunted blood would not see the increased $\mathrm{P}_{\mathrm{A}} \mathrm{O}_{2}$ (Powers \& Williams, 1987). Rice et al. (1999), who had subjects breathe a hypoxic gas $\left(13 \% \mathrm{O}_{2}\right)$ during exercise, came to the same conclusion concerning the venoarterial shunt, based on their finding that the observed decrease in $\mathrm{P}_{\mathrm{a}} \mathrm{O}_{2}$ was much greater than what would be expected as a result of a normal-sized shunt.

Ventilation/Perfusion $\left(\mathrm{V}_{\mathrm{A}} / \mathrm{Q}\right)$ Inequality

For the complete transfer of oxygen and carbon dioxide to occur, alveolar ventilation $\left(\mathrm{V}_{\mathrm{A}}\right)$ must match the pulmonary blood flow $(\mathrm{Q})$, or perfusion, in different regions of the lungs (West, 2000a). However, there are differences in $\mathrm{V}_{\mathrm{A}}$ and $\mathrm{Q}$ between the apex and the base of the lungs. Both $\mathrm{V}_{\mathrm{A}}$ and $\mathrm{Q}$ are less at the apex than at the base, however the differences in $\mathrm{Q}$ are greater, causing the apex of the lungs to be over-ventilated relative to perfusion and the base of the lungs to be over-perfused relative to ventilation. In other words, the $\mathrm{V}_{\mathrm{A}} / \mathrm{Q}$ ratio is higher at the apex of the lungs than at the base (West, 2000a), creating a $V_{A} / Q$ inequality, or mismatch. The consequence of this inequality is a diminished ability of the lungs to oxygenate arterial blood, since the 
majority of blood leaving the lungs comes from the base, where the $\mathrm{PO}_{2}$ is much lower than at the apex.

During exercise, $\mathrm{V}_{\mathrm{A}} / \mathrm{Q}$ inequality increases (Gale et al., 1985; Gledhill et al., 1977, 1978; Hammond et al., 1986), causing $\mathrm{P}_{a} \mathrm{O}_{2}$ to fall below $\mathrm{P}_{\mathrm{A}} \mathrm{O}_{2}$ and a subsequent widening of the $\mathrm{P}_{\mathrm{A}-\mathrm{a}} \mathrm{O}_{2}$ difference (West, 2000a). For this reason, $\mathrm{V}_{\mathrm{A}} / \mathrm{Q}$ inequality is thought to be a major factor in the development of EIH (Dempsey \& Wagner, 1999; Powers \& Williams, 1987; Powers et al., 1993). Hopkins et al. (1994) reported that as much as $60 \%$ of the widening $\mathrm{P}_{\mathrm{A}-\mathrm{a}} \mathrm{O}_{2}$ difference in highly trained endurance athletes during incremental exercise is explained by $\mathrm{V}_{\mathrm{A}} / \mathrm{Q}$ inequality, while in a later study (Hopkins et al., 1998) they found that all of the increase in the $\mathrm{P}_{\mathrm{A}-\mathrm{a}} \mathrm{O}_{2}$ difference during prolonged, submaximal exercise $\left(65 \% \dot{\mathrm{V}} \mathrm{O}_{2} \mathrm{max}\right)$ is explained by $\mathrm{V}_{\mathrm{A}} / \mathrm{Q}$ inequality. Todaro et al. (1995) further explain that the $\mathrm{P}_{\mathrm{A}-\mathrm{a}} \mathrm{O}_{2}$ difference and associated EIH are not a result of an absolute $\mathrm{P}_{\mathrm{A}} \mathrm{O}_{2}$ deficit, but rather a deficit relative to the amount of the $\mathrm{V}_{\mathrm{A}} / \mathrm{Q}$ inequality.

Other studies have also implicated $\mathrm{V}_{\mathrm{A}} / \mathrm{Q}$ inequality as a determinant of EIH (Gavin \& Stager, 1999; Powers et al., 1992; Rice et al., 2000), however these studies came to this conclusion largely by process of elimination, after not finding support for inadequate hyperventilation as a cause of EIH. Two of these studies suggest that the greater degree of EIH with running compared to cycling is due, in part, to differences in $\mathrm{V}_{\mathrm{A}} / \mathrm{Q}$ inequality between the two exercise modes (Gavin \& Stager 1999; Rice et al., 2000).

As with the venoarterial shunt, there is some evidence that the $V_{A} / Q$ inequality is not responsible for the development of EIH. For example, having found a high $\mathrm{V}_{\mathrm{A}} / \mathrm{Q}$ 
ratio during intense exercise, Dempsey et al. (1984) conclude that it is unlikely that $\mathrm{V}_{\mathrm{A}} / \mathrm{Q}$ inequality explains EIH. Hammond et al. (1986) found that $V_{A} / Q$ inequality increased with exercise intensity up to a $\dot{\mathrm{V}} \mathrm{O}_{2}$ of about $3.0 \mathrm{Lmin}^{-1}$, but remained constant at higher intensities despite a continued increase in the $\mathrm{P}_{\mathrm{A}-\mathrm{a}} \mathrm{O}_{2}$ difference The greatest mixed findings may belong to Rice et al. (1999), who found no difference in $V_{A} / Q$ inequality between control subjects and subjects with EIH, although the degree of inequality still accounted for $30 \%$ of the difference in $\mathrm{P}_{\mathrm{A}-\mathrm{a}} \mathrm{O}_{2}$ in the EIH group and 35\% of the difference in the control group. While the exact cause of the increased $V_{A} / Q$ inequality with exercise is unknown, it has been suggested that interstitial pulmonary edema is a prominent possibility (Hopkins et al., 1998).

\section{Diffusion Limitation}

Diffusion, the passive but elegant biological process by which ions and molecules rapidly travel from an area of high concentration to an area of low concentration, determines to a large extent how effectively ions and molecules pass through membranes. Since hydrophobic ions such as oxygen $\left(\mathrm{O}_{2}\right)$ and carbon dioxide $\left(\mathrm{CO}_{2}\right)$ travel in this way, diffusion, in effect, governs how well the cardiopulmonary system works. A number of factors influence the ability of a molecule to diffuse from one side of a membrane to another, including the thickness of the membrane, the membrane's surface area, the size and speed of the molecule, the distance the molecule must travel, the magnitude of the molecule's concentration gradient, and the presence of fluid near the membrane (West, 2000a). A diffusion limitation can occur when any or a combination of these factors slows or prevents diffusion. For example, if a diffusion limitation exists between the 
lungs and the pulmonary capillaries, $\mathrm{O}_{2}$ will not effectively diffuse into the capillaries, and $\mathrm{P}_{\mathrm{a}} \mathrm{O}_{2}$ may decrease. It is possible that, under conditions when a rapid $\mathrm{O}_{2}$ diffusion is necessary (such as in highly-trained athletes during maximal exercise), the diffusion rate through the pulmonary capillaries is not fast enough for the blood to be fully oxygenated within the lungs (West, 2000b). The resulting decrease in $\mathrm{P}_{\mathrm{a}} \mathrm{O}_{2}$, if low enough, may lead to a decrease in $\mathrm{S}_{\mathrm{a}} \mathrm{O}_{2}$ and the consequent development of EIH.

It has been suggested that, along with $\mathrm{V}_{\mathrm{A}} / \mathrm{Q}$ inequality, both the increased $\mathrm{P}_{\mathrm{A}-\mathrm{a}} \mathrm{O}_{2}$ difference during exercise and EIH are primarily due to a diffusion limitation (Dempsey \& Wagner, 1999; Powers \& Williams, 1987). Rice et al. (1999) found that subjects with EIH developed significantly more $\mathrm{O}_{2}$ diffusion limitation than control subjects during intense exercise, based on the difference in the $\mathrm{P}_{\mathrm{A}-\mathrm{a}} \mathrm{O}_{2}$ difference, and that the lungs' diffusion capacity for oxygen $\left(\mathrm{DLO}_{2}\right)$ at rest explained $30.2 \%$ of the variance in $\mathrm{P}_{\mathrm{a}} \mathrm{O}_{2}$ during exercise. A similar measure of pulmonary diffusion capacity, using carbon monoxide (DLCO), which is dependent on the diffusing capacity of the alveolar membrane and the rate of reaction of $\mathrm{CO}$ with hemoglobin, has also been shown to decrease in athletes following intense exercise (McKenzie et al., 1999; Turner et al., 1992). However, McKenzie et al. (1999) reported that, since decreases in $\mathrm{S}_{a} \mathrm{O}_{2}$ during an initial bout of exercise were not exacerbated after a second bout of exercise following a 60-minute recovery period despite a continued decrease in pulmonary diffusion, post-exercise changes in pulmonary diffusion capacity cannot be related to the occurrence of hypoxemia during exercise.

The most common postulation for the cause of diffusion limitation is a short red blood cell transit time in the pulmonary circulation (Dempsey, 1986; Dempsey et al., 
1984; Powers \& Williams, 1987; Powers et al., 1993). While the time it takes for red blood cells to move through the entire lungs has been found to remain quite stable during moderate to intense exercise (Zavorsky et al., 2003), their movement through the pulmonary capillaries, an event that normally takes about 0.75 second at rest (West, 2000a), decreases with exercise (Hopkins et al., 1996; Warren et al., 1991). The minimal transit time necessary for $\mathrm{O}_{2}$ diffusion across the pulmonary capillaries is 0.35 to 0.40 second (Dempsey et al., 1982; Gledhill et al., 1977), however it has been suggested that very intense exercise can decrease transit time to about 0.25 second (West, 2000a). Dempsey and Wagner (1999) argue that, while diffusion limitation can be dictated by an intrinsically low lung diffusing capacity, a high oxygen extraction by the active muscles, and/or a high cardiac output, endurance athletes are among the most susceptible to diffusion limitation because of their characteristically high cardiac outputs, causing the short red blood cell transit time. At high exercise intensities that reveal their high cardiac outputs, such as at or near $\dot{\mathrm{V}} \mathrm{O}_{2} \mathrm{max}$, diffusion limitation appears to develop in trained athletes (Dempsey \& Wagner, 1999; Hammond et al., 1986).

Although it seems reasonable that a high cardiac output, with its associated rapid flow of red blood cells through the pulmonary circulation, could cause a short red blood cell transit time, whether cardiac output is the primary cause of a diffusion limitation remains to be resolved. Rice et al. (1999) found similar cardiac outputs between subjects with EIH and control subjects without EIH, and argued that if red blood cell transit time is the cause of diffusion limitation, then subjects with EIH must have either a smaller pulmonary capillary blood volume and/or less recruitment of pulmonary capillaries at the same exercise intensity compared to non-EIH subjects. 
The presence of diffusion limitation itself is debatable, as some studies have refuted its occurrence (Torre-Bueno et al., 1985; Warren et al., 1991). Torre-Bueno et al. (1985), investigating subjects exercising at sea-level and simulated altitude, detected a diffusion limitation only during exercise at altitude, a condition that presents an added stress on pulmonary gas exchange because of the decreased atmospheric $\mathrm{PO}_{2}$. By the researchers' own acknowledgment, the subjects in their study exercised at a $\dot{\mathrm{VO}}_{2}$ of $<3.0$ $\mathrm{L}_{\mathrm{min}}{ }^{-1}$, which may be too low for a diffusion limitation to be observed. Warren et al. (1991) found that the lungs' membrane diffusing capacity did not explain any of the variation in the $\mathrm{P}_{\mathrm{A}-\mathrm{a}} \mathrm{O}_{2}$ difference, nor was it statistically different between exercise intensities, although it tended to decline at near maximal intensities.

\section{Hypoventilation (Inadequate Hyperventilation)}

Hypoventilation, literally meaning, "less than normal ventilation," has also been considered as a possible mechanism causing EIH in many highly-trained endurance athletes. To maintain a normal value of $\mathrm{P}_{\mathrm{a}} \mathrm{O}_{2}$, alveolar ventilation $\left(\mathrm{V}_{\mathrm{A}}\right)$ must meet the metabolic demands of the tissues (Powers et al., 1993; West, 2000a). Since many highly-trained endurance athletes do not maintain normal partial pressures during intense exercise (e.g., $\mathrm{P}_{\mathrm{a}} \mathrm{O}_{2}$ and $\mathrm{P}_{\mathrm{A}} \mathrm{O}_{2}$ below normal), and a decreased $\mathrm{P}_{\mathrm{A}} \mathrm{O}_{2}$ is caused by a reduced alveolar ventilation (West, 2000a), it has been suggested that these athletes may hypoventilate or, more accurately, inadequately hyperventilate at exercise intensities near $\dot{\mathrm{V}} \mathrm{O}_{2} \max$ (Dempsey et al., 1984). Derchak et al. (2000) conclude that, while some athletes with EIH exhibit inadequate hyperventilation due to a lack of an aggressive ventilatory response, others have a sufficient or even excessive ventilatory drive, but are 
unable to express it because they have reached their lungs' mechanical limit for ventilation. This latter suggestion has support from others, as Bye et al. (1983) and McClaran et al. (1999) argue that the mechanical limit of $\dot{V} E$, resulting from a pulmonary flow limitation, likely explains, in part, the stunted hyperventilatory response in highly trained athletes to intense exercise, resulting in a failure to compensate for an increased $\mathrm{P}_{\mathrm{A}-\mathrm{a}} \mathrm{O}_{2}$ difference and arterial hypoxemia. However, Norton et al. (1995) found no consistent relationship between the occurrence of severe EIH and flow limitation, suggesting that EIH does not result from a mechanical limitation of $\dot{V} E$. Whatever the precise cause, it is generally agreed that endurance athletes exhibit a ventilatory response that is inadequate to meet the high metabolic demands that characterize these athletes (Dempsey, 1986; Dempsey \& Johnson, 1992). Whether this inadequate hyperventilation leads to EIH is another matter and is equivocal at this time, as some studies support (Durand et al., 2000; Harms \& Stager, 1995; Miyachi \& Tabata, 1992; Rice et al., 1999) while others refute (Buono \& Maly, 1996; Dempsey et al., 1984; Powers et al., 1992; Williams et al., 1986) its cause of EIH. Rice et al. (1999) and Harms and Stager (1995) both reported that ventilation during intense exercise explains about $50 \%$ of the variability in $\mathrm{S}_{\mathrm{a}} \mathrm{O}_{2}$. Dempsey et al. (1984) and Powers et al. (1992) observed a decrease in $\mathrm{P}_{\mathrm{a}} \mathrm{CO}_{2}$, rather than an expected increase with inadequate hyperventilation, in athletes exhibiting EIH during intense exercise. In contrast, Durand et al. (2000) observed an increase in $\mathrm{P}_{\mathrm{a}} \mathrm{CO}_{2}$ along with a decrease in $\mathrm{P}_{\mathrm{a}} \mathrm{O}_{2}$ in endurance athletes with EIH during maximal exercise, a finding consistent with inadequate hyperventilation, leading them to conclude that athletes with EIH lack a compensatory hyperpnea (an increased ventilation to match an increased metabolic rate) to the decreased $\mathrm{P}_{\mathrm{a}} \mathrm{O}_{2}$. Using another marker of 
hyperventilation, Williams et al. (1986) found no difference in the ventilatory equivalent for oxygen consumption $\left(\dot{\mathrm{V} E} / \mathrm{V}_{2}\right)$ between trained subjects who exhibited EIH and untrained subjects who did not. Not all studies have found this result, as Miyachi and Tabata (1992) found a modest but significant correlation between $\mathrm{S}_{\mathrm{a}} \mathrm{O}_{2}$ and $\dot{\mathrm{V}} \mathrm{E} / \dot{\mathrm{V}}_{2}$ $(\mathrm{r}=0.74)$, leading them to conclude that ventilation is an important factor for arterial $\mathrm{O}_{2}$ desaturation during maximal exercise. However, it may be possible that a lower $\dot{\mathrm{V}} / \dot{\mathrm{V}}_{2}$ during maximal exercise is a result of a greater $\dot{\mathrm{V}} \mathrm{O}_{2}$ max in endurance athletes, rather than a lower hyperventilation. Buono and Maly (1996) significantly increased subjects' ventilation by $21 \%$ by breathing normoxic helium $\left(21 \% \mathrm{O}_{2}, 79 \% \mathrm{He}\right)$ during exercise compared to ambient air, however this augmented hyperventilation did not affect EIH, as $\mathrm{S}_{\mathrm{a}} \mathrm{O}_{2}$ at maximal exercise was $90 \%$ while breathing ambient air and $89 \%$ while breathing the oxygen-helium mixture. In contrast, Dempsey et al. (1984) and Norton et al. (1995) observed an amelioration in the degree of EIH with an increase in ventilation, in the former study when subjects breathed a hyperoxic gas $\left(24 \% \mathrm{O}_{2}\right)$, and in the latter study when exercise intensity was increased from $\dot{\mathrm{V}}_{2} \max$ to $115 \% \dot{\mathrm{VO}}_{2} \max$. Although still not definitive, the majority of these findings suggest that inadequate hyperventilation per se is not responsible for, or at least is not the sole factor in, EIH in endurance athletes.

It has been argued that inadequate hyperventilation, if not being a direct cause of EIH, may contribute to differences in the magnitude of EIH between athletes, since athletes with the least amount of hyperventilation seem to exhibit the lowest $\mathrm{S}_{\mathrm{a}} \mathrm{O}_{2}$ during exercise (Dempsey et al., 1984; Powers \& Williams, 1987; Rice et al., 2000). Moreover, Rice et al. (2000) conclude that the greater EIH observed during running compared to cycling is caused, in part, by a reduced hyperventilation during running. However, this 
conclusion is not shared by everyone, as Gavin and Stager (1999) opined, based on their finding of a lack of a relationship between the differences in $\mathrm{S}_{\mathrm{a}} \mathrm{O}_{2}$ and ventilation between running and cycling, that while ventilation is important in the maintenance of $\mathrm{S}_{\mathrm{a}} \mathrm{O}_{2}$, the difference observed in $\mathrm{S}_{\mathrm{a}} \mathrm{O}_{2}$ between running and cycling cannot be explained by differences in ventilation.

In summary, the available evidence suggests that the occurrence of EIH in endurance athletes is due to multiple factors, with $\mathrm{V}_{\mathrm{A}} / \mathrm{Q}$ inequality and pulmonary diffusion limitation the most prominent ones.

Flow-Volume Relationship

Returning to the question of whether or not ventilation has the potential to limit exercise performance, research in this area has focused on the nature and control of ventilation during exercise. Contrary to the belief of the out of shape runner who huffs and puffs as he or she runs down the street, there is no indication among healthy subjects of average or below average fitness that pulmonary characteristics limit ventilation during moderate exercise (Bye et al., 1983). Ventilatory limitation during exercise has traditionally been determined by the ratio between the maximal minute ventilation ( $\dot{V} E)$ achieved during exercise and the maximal voluntary ventilation (MVV) achieved during voluntary hyperventilation at rest (Dueck, 2000). Using this method, Folinsbee et al. (1983) found that sedentary subjects used an average of $71 \%$ of their MVV during maximal exercise, compared to $89 \%$ among elite cyclists. Mota et al. (1999) reported a similar result in $\dot{\mathrm{V} E}(88 \%$ of MVV) in cyclists during maximal exercise. It would seem, therefore, that there is still room to increase ventilation even in highly-fit subjects, albeit 
less so than in their sedentary counterparts. However, this method of determining ventilatory reserve or limitation is like comparing apples and oranges, since maximal exercise $\dot{\mathrm{V} E}$ is controlled by metabolism, while MVV is under voluntary control, regardless of the metabolic conditions. Moreover, MVV is calculated from a test lasting only 12 to 15 seconds, while maximal exercise $\dot{V} E$ is the actual amount breathed in a minute during exercise.

Another, more elegant, method to examine ventilatory characteristics is to measure the rate of airflow at the mouth, calculate the volume of air inhaled or exhaled by integrating the flow rate over time, and graph the relationship between the flow rate and volume. The graph is called a flow-volume curve, or loop. Graphs can be generated for different intensities of exercise, with the tidal flow-volume loops produced during exercise plotted within a larger reference expiratory flow-volume loop obtained from a maximal breathing maneuver during rest. This method has been widely used to assess the degree of expiratory flow limitation and ventilatory constraint (Aaron et al., 1992; Babb et al., 1991; Chapman et al., 1998; Derchak et al., 2000; Grimby, 1969; Johnson et al., 1991a,b, 1992, 1995; Marciniuk et al., 1994; McClaran et al., 1999; Martinez et al., 1996; Mota et al., 1999; Regnis et al., 1996; Stubbing, 1980a). Indeed, Bye et al. (1983) suggest that pulmonary flow-volume characteristics are perhaps the most important determinant of exercise limitation because of their implications for matching ventilation to metabolic demand. The degree of flow limitation during exercise is commonly expressed as the percent of the tidal volume that meets or exceeds the expiratory boundary of the maximal flow-volume loop (Johnson et al., 1995, 1991a,b; 1999a,b) (Figure 2). However, unlike the use of a minimal value of $\mathrm{S}_{\mathrm{a}} \mathrm{O}_{2}$ to determine the 
presence of $\mathrm{EIH}$, there is no accepted minimal value for the percent of tidal volume overlapping the maximal flow-volume loop to determine the presence of flow limitation. Therefore, its determination remains largely subjective.

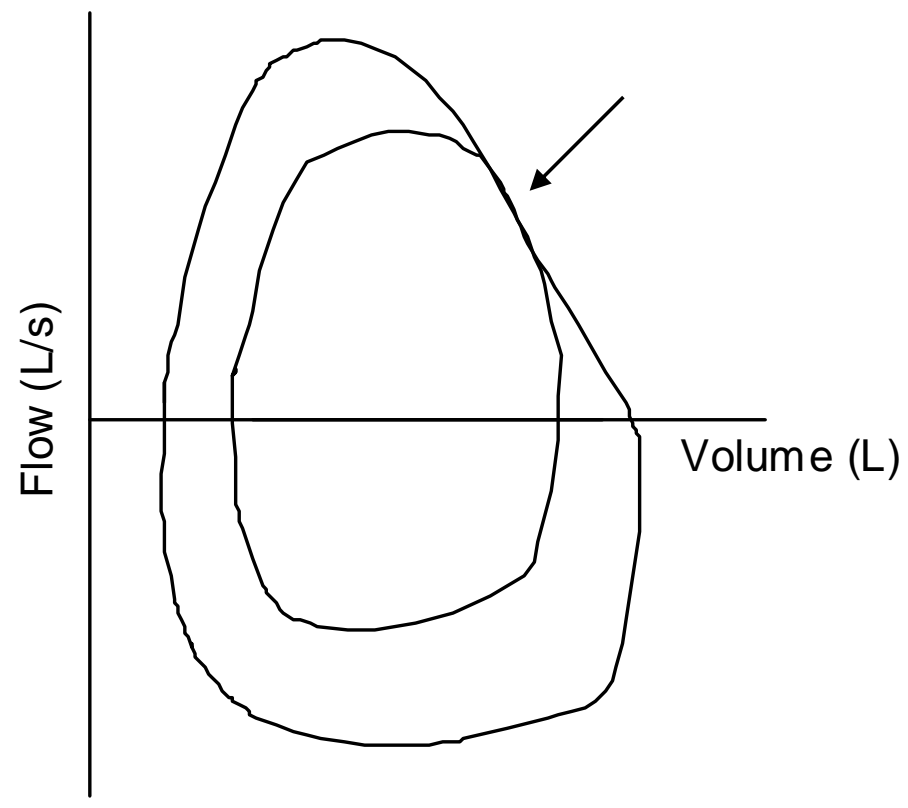

Figure 2. An example of pulmonary flow limitation. The outer loop represents the maximal expiratory flow-volume loop, while the inner loop represents the tidal flow-volume loop during maximal exercise. The portion of the loop above the $\mathrm{x}$-axis represents expiration, while the portion of the loop below the $\mathrm{x}$-axis represents inspiration. Note the overlap of the exercise flow-volume loop on the maximal flow-volume loop during expiration, indicated by the arrow.

Historically, determining the relationship between pulmonary airflow and volume during rest and exercise has been primarily limited to comparisons between healthy and aged populations and patients with pulmonary diseases, including asthma, chronic obstructive pulmonary disease (COPD), and lung transplant recipients. In young, healthy 
subjects of low or average fitness, little ventilatory constraint exists during exercise (Aaron et al., 1992; Johnson et al., 1999a), as there is no overlap between the tidal flow-volume loops and the maximal flow-volume loop (Grimby, 1969; Grimby et al., 1971; Stubbing et al., 1980a). Olafsson and Hyatt (1969) observed that the tidal flow-volume loop may approach or attain the maximal flow-volume loop in healthy subjects toward the end of expiration during intense exercise. However, this finding has been questioned, as Stubbing et al. (1980a) argue that small differences in total lung capacity during exercise compared to rest can cause erroneous placement of the tidal volume loop within the maximal flow-volume loop. In contrast, individuals with pulmonary disease commonly exhibit pulmonary flow limitation, often experiencing it even at rest (Dueck, 2000). Babb et al. (1991) found that 11 of 12 subjects with abnormal pulmonary function exhibited flow limitation during maximal exercise, with 7 of the 12 exhibiting some degree of flow limitation at rest.

Much has been revealed by examining flow-volume relationships in other subjects, as older, highly-fit individuals, who have a mild decline in lung function but are able to maintain a high ventilatory demand, experience flow limitation beginning at a low exercise intensity and $\dot{V} E$ (Johnson et al., 1999a). Interestingly, many young endurance athletes, who have normal pulmonary function but excessively high metabolic and thus ventilatory demands, also exhibit expiratory flow limitation during maximal exercise (Chapman et al., 1998; Dempsey et al., 1984; Derchak et al., 2000; Grimby, 1969; Henke et al., 1988; Johnson et al., 1992; McClaran et al., 1999), indicating that they have reached, much like their older or diseased counterparts, their maximal mechanical capacity to ventilate (Derchak et al., 2000; Johnson et al., 1992). The tidal flow-volume 
loops of endurance athletes regularly reach the maximal flow-volume loop throughout most of expiration (Grimby et al., 1971; McClaran et al., 1999), however not all studies have reported similar results (Mota et al., 1999). With intense exercise, expiratory flow limitation in athletes increases to greater than $50 \%$ of the tidal volume, representing a severe mechanical ventilatory constraint (Johnson et al., 1999a). Even in the face of additional ventilatory stimuli, these flow-limited athletes are unable to increase $\dot{V} E$ during maximal exercise (Chapman et al., 1998; Johnson et al., 1992). For example, Chapman et al. (1998) found that athletes with no flow limitation had a significantly higher $\dot{\mathrm{V} E}$ at $\dot{\mathrm{V}} \mathrm{O}_{2} \max$ when exercising under hypoxic $\left(18.7 \% \mathrm{O}_{2}\right)$ compared to normoxic conditions, while $\dot{V} E$ in the flow-limited athletes was not different between normoxia and hypoxia.

It has been argued that flow limitation prevents a full expiration, causing an increase in end-expiratory lung volume (EELV) (Johnson et al., 1995; Pellegrino et al., 1993), which has been observed in patients with pulmonary disease (Grimby \& Stiksa, 1970; Leaver \& Pride, 1971; Potter et al., 1971; Stubbing et al., 1980b), older, highly-fit individuals (Johnson et al., 1991a), and elite endurance athletes (Grimby et al., 1971; Jensen et al., 1980; Mota et al., 1999). In contrast, EELV decreases in healthy, unfit subjects with exercise (Aliverti et al., 1997; Babb et al., 1991; Henke et al., 1988; Younes \& Kivinen, 1984), by 0.1 to 0.3 liter during mild exercise and 0.5 to 1.0 liter during intense exercise (Henke et al., 1988). Mota et al. (1999) argue that the increase in EELV in endurance athletes is caused by something other than flow limitation, in light of their finding that flow limitation was not commonly attained in their subjects. 
Flow limitation may constrain $\dot{V} E$ by causing dynamic compression of the airways or thorax (Chapman et al., 1998; Johnson et al., 1992, 1999b), or by increasing the work and oxygen cost of breathing (Johnson et al., 1999b). The degree of mechanical constraint on $\dot{\mathrm{V} E}$ is dependent on both the area of the maximal flow-volume loop and the $\dot{V} E$ demand (Johnson et al., 1999b). Since endurance athletes have a high demand for ventilation to match the high level of metabolic work, $\dot{V} E$ of a highly-fit athlete during exercise may encroach on the maximal flow-volume loop to a similar degree as that of an unfit individual with pulmonary disease.

When referring to flow limitation in highly-trained athletes, the term 'flow-maximized,' rather than 'flow-limited,' may be a better descriptor of what is taking place, since endurance athletes reach their uppermost limit of ventilation, and therefore maximize, rather than limit, their ability to ventilate. Indeed, it could be said that they are "using everything they have." When assessing pulmonary characteristics of collegiate distance runners, it has been observed that flow limitation is more prevalent in the upperclassmen compared to the lowerclassmen (J.M. Stager, personal communication). It is possible that the upperclassmen have learned, through two or three more years of high-level training, to maximize their ventilatory capability. Contrast this situation to the patient with pulmonary disease, who is in fact 'flow-limited,' as he or she is mechanically constrained from breathing at a greater volume and/or a faster flow rate. Having pointed out this key difference in meaning, the term 'flow limitation' will continue to be used for the remainder of this manuscript in order to conform to the terminology used in the scientific literature and to prevent confusion for the reader. 
Like all pictures, the flow-volume loop is also worth a thousand words, and therefore there may be information other than the rate of airflow at a given volume that can be gleaned from it. For example, Tanner (2001) observed a characteristic hump or dip in the inspiratory flow rate in eight of 22 subjects while running during the final minute of an incremental exercise test (Figure 3). When the tidal flow-volume loop was examined for the penultimate minute, the number of subjects exhibiting the dip in flow rate increased to 13. Interestingly, this change in shape of the flow-volume loop was not seen when these same subjects cycled. Based on the appearance of these flow-volume loops and the evidence that humans often entrain their breathing to their stride rate, Tanner (2001) suggested that the flow-volume loop may be used as a tool to examine the relationship of breathing and locomotion.

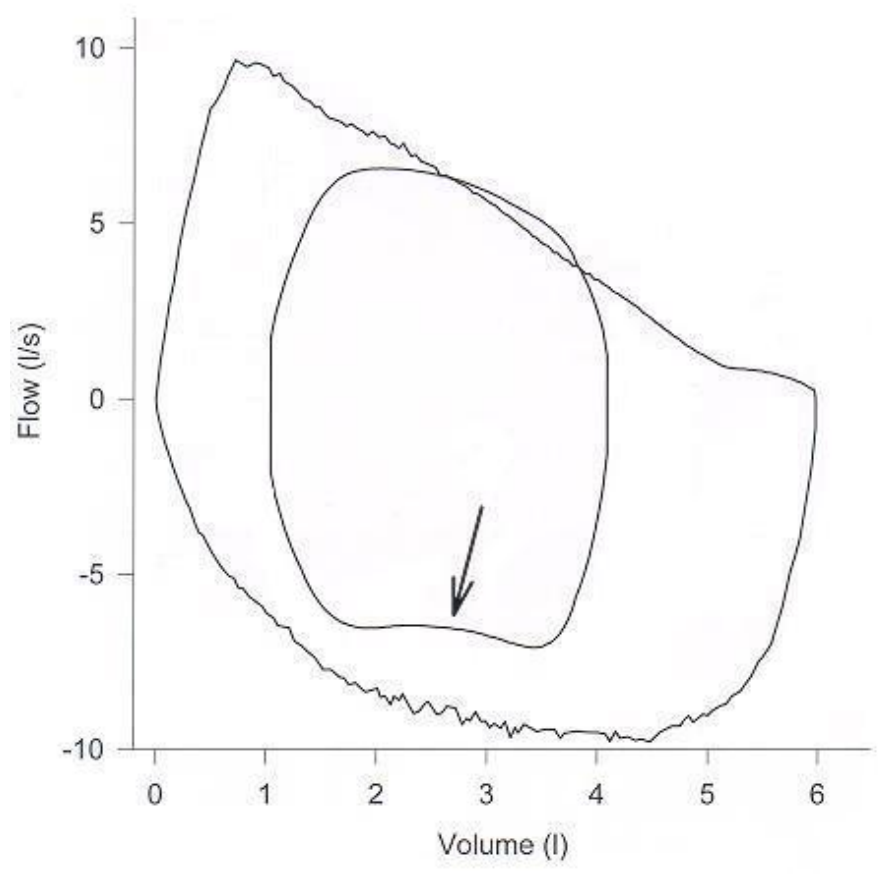

Figure 3. Flow-volume loop showing possible entrainment of breathing to stride rate. Note the humped appearance of the exercise flow-volume loop during inspiration (indicated by the arrow). Reprinted from Tanner (2001) with permission. 
Regarding the relationship between flow limitation and entrainment, a flow limitation may prevent breathing frequency from keeping up with stride rate, and therefore prevent entrainment at high intensities. Moreover, if entrainment confers an economical advantage, it is possible that athletes with flow limitation are less economical because they cannot entrain ventilation to stride rate and/or they cannot adopt the optimal breathing frequency/tidal volume combination to minimize ventilatory work at higher intensities. Conversely, it is possible that economical considerations govern the ventilatory strategy adopted during intense exercise (i.e., economy may be "driving the bus"). For example, some athletes may exhibit flow limitation because breathing must be entrained to stride rate, and stride rate, as suggested by Cavanagh and Kram (1989), is itself governed by what is most economical. Although stride rate does not change as much as stride length during distance running at different speeds, the step-to-breath ratio does change (McDermott et al., 2003), becoming more tightly coupled at faster speeds. Thus, once a 1:1 ratio is approached, the only way to continue this ratio as speed (and, hence, ventilation) increases would be to either increase tidal volume rather than breathing frequency, or increase stride rate (with a concomitant, matched increase in breathing frequency). Neither of these two situations occurs, since breathing frequency increases preferentially over tidal volume at higher intensities (Dempsey, 1986; Grimby, 1969), and since stride rate does not change dramatically (Cavanagh \& Kram, 1989). The end result of trying to entrain the two rhythms at high intensities may be that breathing becomes constrained, causing a pulmonary flow limitation. However, it is not clear which of these two phenomena is a cause and which is an effect. For example, it 
has been suggested that, as tidal volume becomes constrained at high workloads during rowing, the demand for an increased breathing frequency may result in stroke rate becoming entrained to breathing frequency (Steinacker et al., 1993). Clearly, there is much to be studied in this area. 


\section{Chapter III}

\section{METHODOLOGY}

Subjects

Eighteen male, highly-trained distance runners $\left(\dot{\mathrm{V} O}{ }_{2} \max >60 \mathrm{mlkg}^{\mathrm{min}}{ }^{-1}\right.$; 5,000-meter performance at altitude of $14 \mathrm{~min} 30 \mathrm{sec}$ to $19 \mathrm{~min} 45 \mathrm{sec}$ ) from the Albuquerque, New Mexico community were recruited for this study. Three subjects were not able to complete the study, resulting in 15 subjects for data analyses. Subjects were recruited by word of mouth through the local running community. For inclusion in the study, subjects must not have had any history of pulmonary dysfunction or disease, including exercise-induced bronchoconstriction, which was determined by a health history questionnaire (Appendix B) and a pulmonary function test. Since having knowledge of the study's purpose may have influenced their conscious control of breathing, subjects were blinded to the purpose of the study until after they completed the testing. Each subject was verbally explained the nature of the study, including the risks associated with performing a maximal physical effort, and was required to sign an informed consent form prior to his participation. All procedures of this study were approved by the Institutional Review Boards of Indiana University and the University of New Mexico (Appendix A).

Experimental Protocol

All testing took place in the Exercise Physiology Laboratory at the University of New Mexico at an altitude of 1,524 meters. Testing was carried out on two separate days 
for each subject and occurred between September, 2006 and March, 2007. The first day consisted of a test of maximal oxygen consumption ( $\dot{\mathrm{V}}_{2} \mathrm{max}$ ), and the second day consisted of a locomotor-respiratory coupling test during which running economy was also measured.

\section{Maximal Oxygen Consumption ( $\left.\dot{\mathrm{VO}}_{2} \max \right)$}

Each subject performed an incremental exercise test to exhaustion on a motor-driven treadmill (Precor, Woodinville, WA) to determine maximal oxygen consumption ( $\left.\dot{\mathrm{V}}_{2} \max \right)$. Prior to the start of the test, each subject warmed up for ten minutes using progressively increasing speeds, culminating with a speed close to his 5,000-meter race pace for the last two minutes. During the subsequent five minutes of recovery, the indirect calorimetry equipment was calibrated and the subject was fitted with a mouthpiece and nose clips to prepare for $\dot{\mathrm{V}}_{2}$ measurement. A pulse oximeter was also placed on the subject's index finger to determine blood oxygen saturation during exercise.

The test began with the treadmill speed at $2.0 \mathrm{mi}^{-1}$ below the subject's final warm-up speed (approximately 5,000-meter race pace) and $0 \%$ grade. Every two minutes, the speed increased $1.0 \mathrm{mi}^{-1} \mathrm{hr}^{-1}$ until 5,000-meter race pace was reached. After two minutes at 5,000-meter race pace and $0 \%$ grade, the grade of the treadmill increased by $2 \%$ every minute until the subject reached volitional exhaustion. 


\section{Pulmonary Function}

Each subject underwent pulmonary function testing as a screening tool for pulmonary dysfunction and inclusion in the study. Vital capacity (VC), a test of lung volume, and one-second forced expiratory volume $\left(\mathrm{FEV}_{1}\right)$, a test of airflow, were measured to determine the presence of restrictive or obstructive lung disease, respectively. Immediately before and after the $\dot{\mathrm{V}} \mathrm{O}_{2} \max$ test, subjects performed three maximal expiratory (to residual volume) and inspiratory (to total lung capacity) maneuvers to determine $\mathrm{VC}$ and $\mathrm{FEV}_{1}$, and to acquire the reference maximal flow-volume loop for later determination of the presence of flow limitation. The breathing maneuver included an initial emptying of air in the lungs, immediately followed by a forced maximal inhalation and a forced maximal exhalation performed at maximal speed. The subjects were verbally coached through each maneuver.

To screen subjects for exercise-induced bronchoconstriction, subjects performed the breathing maneuver again every 10 minutes for 30 minutes following the $\dot{\mathrm{V}}{ }_{2}$ max test. Normal pulmonary function (and subsequent inclusion in the study) was defined as attainment of at least $80 \%$ of age-group and sex-based norms (Knudson et al., 1976; Morris, 1976).

Locomotor-Respiratory Coupling and Running Economy

On the second day of testing, each subject ran on a motor-driven treadmill (Precor, Woodinville, WA) at 0\% grade for six minutes at each of three intensities: 70, 90 , and $100 \%$ of the speed at the ventilatory threshold (VT), and three minutes at $110 \%$ VT. Each of the four runs was separated by five minutes of recovery (based on Abe et 
al., 1998; Daniels \& Daniels, 1992; Morgan \& Daniels, 1994; Weston et al., 2000). Before the test, insoles containing foot switches were placed in the subject's running shoes to determine foot strike on the treadmill belt.

Since oxygen uptake kinetics are different at exercise intensities above and below the lactate/ventilatory threshold (below the lactate threshold, $\dot{\mathrm{V}} \mathrm{O}_{2}$ reaches a steady-state value within three minutes (Barstow, 1994; Gaesser \& Poole, 1996; Morgan et al., 1989), while above the lactate threshold, a slow component of $\mathrm{V}_{2}$ is introduced, during which $\mathrm{V}_{2}$ rises more slowly before reaching a steady-state value, if one is reached at all (Barstow, 1994; Gaesser \& Poole, 1996; Whipp, 1994; Xu \& Rhodes, 1999; Żołądź \& Korzeniewski, 2001)), economy was assessed using only the first three intensities.

\section{Experimental Procedures}

\section{Measurement of $\dot{\mathrm{VO}}_{2} \mathrm{max}$}

Respiratory gases were sampled using a unidirectional flow turbine (KL Engineering, Madison, WI) as subjects wore nose clips and breathed through a one-way valve mouthpiece (Hans Rudolph, Kansas City, MO). The expired side of the mouthpiece was connected to a second flow turbine (KL Engineering, Madison, WI). A three-liter mixing balloon connected to the expired side of the flow turbine was used to mix air with minimal dead space $(<50 \mathrm{~mL})$, from which the expired air was sampled continuously and directed to rapid response carbon dioxide and oxygen analyzers (AEI Technologies, Pittsburgh, PA) with a delay of less than three seconds. Breath-by-breath values for minute ventilation ( $\dot{\mathrm{V}} \mathrm{E})$, oxygen consumption $\left(\dot{\mathrm{V}} \mathrm{O}_{2}\right)$, expired carbon dioxide $\left(\dot{\mathrm{V} C \mathrm{C}_{2}}\right)$, and the respiratory exchange ratio (RER) were obtained from electronic signals 
sampled at $500 \mathrm{~Hz}$ from the expired turbine and gas analyzers using an analog signal junction box and data acquisition system (CA-1000, National Instruments, Austin, TX) using custom-developed software (LabVIEW, National Instruments, Austin, TX). Subjects' heart rates during the tests were also recorded using electrocardiography (Q-4000, Quinton, Bothell, WA) and blood oxygen saturation was recorded using pulse oximetry (MP100, BIOPAC Systems, Inc., Goleta, CA).

Following the test, data were processed using custom-developed software (LabVIEW, National Instruments, Austin, TX) with a digital low-pass filter of $0.06 \mathrm{~Hz}$. $\dot{\mathrm{V}} \mathrm{O}_{2}$ max was defined as the highest $\dot{\mathrm{VO}}_{2}$ post-filtering value, provided at least two of three criteria were met during the exercise test: (1) a respiratory exchange ratio of greater than 1.10 (Howley et al., 1995), (2) achievement of $\geq 90 \%$ of age-predicted maximal heart rate, and (3) an increase in $\dot{\mathrm{VO}}_{2}$ of less than $0.15 \mathrm{Lmin}^{-1}$ over the previous workload (Taylor et al., 1955). A brief discussion of these criteria used to validate the attainment of $\dot{\mathrm{V}}_{2} \max$ can be found in Appendix C.

Ventilatory threshold was determined by a custom-written computer program (LabVIEW, National Instruments, Austin, TX) using bi-segmental linear regression of the $\dot{\mathrm{V} C O}{ }_{2}$-time, $\dot{\mathrm{V} E}$-time, and $\dot{\mathrm{V} E} / \dot{\mathrm{VO}}_{2}$-time relationships. The time at each VT determination was used to identify a $\mathrm{V}_{2}$ value from linear regression of the middle segment of the $\dot{\mathrm{V}} \mathrm{O}_{2}$-time curve, and this $\dot{\mathrm{V}}_{2}$ value was used as the method-specific VT. VT was defined as the average of the three $\dot{\mathrm{VO}}_{2}$ values identified by the regression analyses. 


\section{Measurement of Flow-Volume}

Flow-volume data were collected continuously from inspired and expired airflow turbines during the $\dot{\mathrm{V}} \mathrm{O}_{2} \max$ test. A maximal flow-volume loop and exercise flow-volume loops were created from the raw flow and volume data using custom-developed software (LabVIEW, National Instruments, Austin, TX). The best trial of the three maximal breathing maneuvers immediately preceding the $\dot{\mathrm{V}} \mathrm{O}_{2}$ max test was used as the maximal flow-volume loop. The exercise flow-volume loops were created from each breath during the final 30 seconds of the $\dot{\mathrm{V}} \mathrm{O}_{2}$ max test. The presence of flow limitation was determined by counting the exercise tidal loops that overlapped the maximal tidal loop.

Measurement of Arterial Oxygen Saturation

Arterial oxygen saturation $\left(\mathrm{S}_{\mathrm{a}} \mathrm{O}_{2}\right)$ during the $\dot{\mathrm{V}} \mathrm{O}_{2} \mathrm{max}$ test and locomotor-respiratory coupling test was estimated using a pulse oximeter (MP100, BIOPAC Systems, Inc., Goleta, CA), which was interfaced to a data acquisition system (CA-1000, National Instruments, Austin, TX). Breath-by-breath values of $\mathrm{S}_{\mathrm{a}} \mathrm{O}_{2}$ were recorded and displayed on the computer screen. The estimation of $\mathrm{S}_{\mathrm{a}} \mathrm{O}_{2}$ was used to determine the presence or absence of $\mathrm{EIH}$, defined at sea-level as an $\mathrm{S}_{\mathrm{a}} \mathrm{O}_{2}$ less than $92 \%$ (Powers et al., 1988), which was adjusted to $87 \%$ for this study considering the altitude of 1,524 meters (Robergs et al., 1998). Although the validity of pulse oximetry has been questioned for its ability to detect EIH in athletes (Brown et al., 1993) and during conditions of severe or rapid desaturation, hypotension, hypothermia, and low perfusion states (Jensen et al., 1998), it is still generally believed to be accurate (Chapman et al., 
1983; Hansen \& Casaburi, 1987; Jensen et al., 1998), and is commonly used to estimate $\mathrm{S}_{\mathrm{a}} \mathrm{O}_{2}$ during exercise. Jensen et al. (1998) found pulse oximeters to be accurate within $2 \%$ of in vitro oximetry when arterial saturation is 70 to $100 \%$.

Measurement of Locomotor-Respiratory Coupling

Each subject's running stride pattern was assessed with foot switches (Berry et al., 1996; Hausdorff et al., 1995; Liggins \& Bowker, 1991; Ross \& Ashman, 1987). Insoles containing four embedded foot switches at different parts of the foot (B \& L Engineering, Tustin, CA) (Figure 4) were placed in each subject's running shoes and interfaced to a data acquisition system (CA-1000, National Instruments, Austin, TX). The individual switches, which were located at the heel, the base of the first and fifth metatarsals, and the head of the big toe, determined heel strike, stance phase, and toe-off, respectively. When each foot touched down on the treadmill belt, each of the foot switches was turned on as force was applied to the switch, and was turned off as each part of the foot was lifted off the treadmill belt. The signals from the foot switches were acquired at $500 \mathrm{~Hz}$ and processed using custom-developed software (LabVIEW, National Instruments, Austin, TX) to determine the exact moment each part of the foot landed. Data collection began with the click of a start button on the computer screen to ensure that recording of both breathing and step signals began at the same time for later determination of entrainment between breaths and steps. During the locomotor-respiratory coupling trial, metabolic and ventilatory data were collected as described previously. 


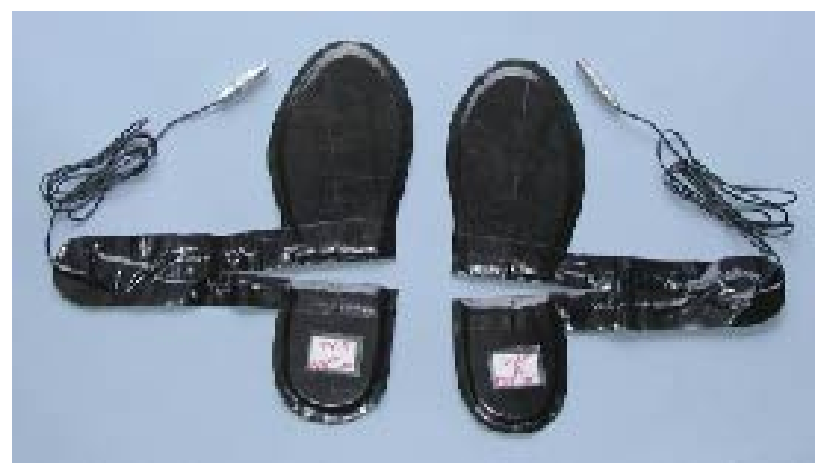

Figure 4. Insoles containing foot switches for stride analysis.

\section{Measurement of Running Economy}

Running economy was also determined during the locomotor-respiratory coupling test. The average $\dot{\mathrm{V}}_{2}$ over the final two minutes of exercise at each intensity was used to determine each subject's running economy (Morgan \& Daniels, 1994; Morgan et al., 1996). To facilitate comparisons of economy since subjects were tested at the same relative, but different absolute, intensities, oxygen cost was expressed as a function of distance traveled $\left(\mathrm{ml} \mathrm{kg}^{-1} \mathrm{~km}^{-1}\right)$ (Daniels \& Daniels, 1992; Morgan et al., 1995).

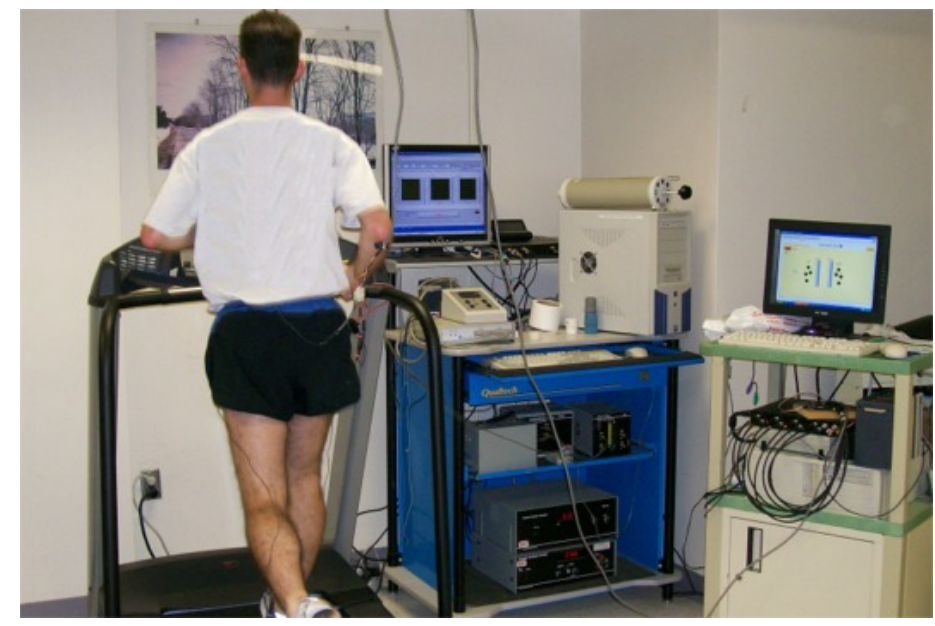

Figure 5. Experimental set-up. While subject ran on the treadmill, metabolic data ( $\dot{\mathrm{V}}_{2} \max$, economy) were collected by the left computer and entrainment data were collected by the right computer. 


\section{Determination of Entrainment}

From the locomotor-respiratory coupling test, the breath data and foot strike data derived from the foot switches were plotted against time for each intensity for a visual inspection of locomotor-respiratory coupling (Figure 6). Entrainment of breathing frequency $\left(\mathrm{F}_{\mathrm{b}}\right)$ to stride rate $(\mathrm{SR})$ was quantified using a combination of the two most commonly employed methods of prior studies. First, the stride rate was divided by the breathing frequency for the final three minutes of each intensity. From this quotient, an integer step-to-breath ratio (e.g., 2:1, 5:2, or 3:2) for each subject was calculated for each intensity (Berry et al., 1996; Jasinskas et al., 1980; Paterson et al., 1986, 1987). Limits of \pm 0.05 of the $\mathrm{SR} / \mathrm{F}_{\mathrm{b}}$ quotient were used as boundaries for calculating step-to-breath ratios (Berry et al., 1996; Paterson et al., 1986, 1987). For example, a SR/F $\mathrm{F}_{\mathrm{b}}$ quotient of 2.00 \pm 0.05 (i.e., 1.95 to 2.05 ) would result in a step-to-breath ratio of $2: 1$. Once these step-to-breath ratios were identified, percent entrainment was calculated by dividing the number of breaths occurring within \pm 0.05 second from the closest step by the total number of breaths taken during exercise. In addition, the means and standard deviations of the time between the closest foot strike to the beginning of an inspiration $\left(\mathrm{T}_{\mathrm{i}}\right)$ and to the beginning of an expiration $\left(\mathrm{T}_{\mathrm{e}}\right)$ were calculated (Hill et al., 1988; Raßler \& Kohl, 1996; Takano, 1995) to examine when these breathing events occurred in relation to foot strike. For the purpose of comparison to a chance occurrence, a set of random numbers was generated to represent random breaths, and the probability of getting a random breath to occur within \pm 0.05 second from the closest step was calculated. 


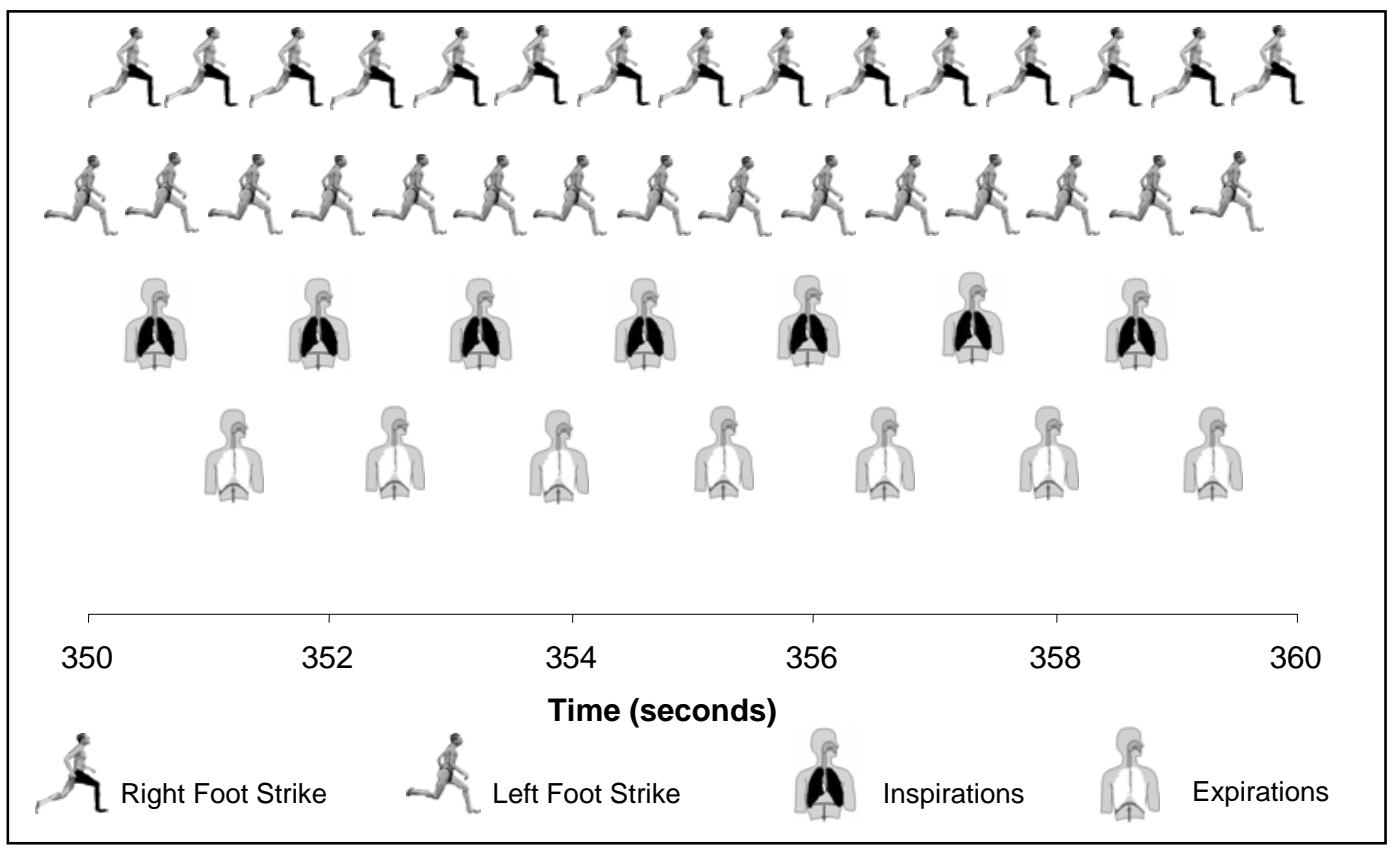

Figure 6. Timing of foot strikes and breaths during treadmill running at the speed of the ventilatory threshold for a representative subject.

Data Analysis

A chi-square test was used to compare the frequency of subjects who exhibited entrainment of breathing frequency to stride rate to those who did not.

A three-way mixed analysis of variance (ANOVA) was used to compare the actual and chance percent entrainment during inspiration and expiration for each intensity. As a significant main effect was found for the actual vs. random percent entrainment, an additional two-way repeated measures ANOVA was used to compare percent entrainment during inspiration and expiration between intensities to specify main effects and interaction effects for breathing phase (inspiration and expiration) and intensity (70, 90, 100 and 110\% VT). Additional one-way repeated measures ANOVAs 
were used to compare $S R, F_{b}, S R / F_{b}$ quotient, $T_{i}, T_{e}$, and running economy between intensities and $\mathrm{VC}$ and $\mathrm{FEV}_{1}$ between time periods. In the case of a significant main effect for repeated measures factors, a Tukey's post hoc test was used to detect the source of the differences. Pearson correlations were used to determine the relationships between running economy and percent entrainment and between economy and the $S R / F_{b}$ quotient at each intensity. All data were analyzed using commercially available software (Statistica $^{\mathrm{TM}}$, version 5.1, StatSoft ${ }^{\circledR}$, Tulsa, OK). For all tests, statistical significance was set at $\mathrm{p}<0.05$, with a Bonferroni adjustment made for multiple comparisons. 


\section{Limitations}

The following represent limitations of this study:

1. The first limitation is the inability to generalize the results to populations different from that of the present study. Since many highly-trained endurance athletes exhibit unique cardiopulmonary characteristics when exercising at high intensities, the relationship between breathing frequency and stride rate may also be unique in this population.

2. Another limitation is the possible inability to generalize the results obtained by running on a treadmill to track or overground running. While no previous studies have reported significant differences in stride mechanics between treadmill and overground running, it has been reported that overground running incurs a greater metabolic energy cost compared to treadmill running, particularly at faster speeds (Daniels, 1985; Morgan et al., 1989). The greater metabolic cost associated with overground running may alter the relationship between ventilation and stride rate from that determined by running on a treadmill.

3. The effects of breathing into a mouthpiece represents a third limitation of this study. To monitor ventilation, subjects breathed into a mouthpiece connected to a breathing valve. In addition, nose clips were used to prevent the subjects from breathing through their noses. This method of breathing, while common in a laboratory setting, differs from what these athletes do in practice, which may alter the ventilatory strategy normally used. In addition, the heightened awareness of breathing in a laboratory setting, when subjects 
know that breathing is being monitored, may cause subjects to subconsciously alter their breathing patterns.

4. Ventilation during exercise at altitude is greater than at sea-level to compensate for the decreased partial pressure of oxygen (Brooks et al., 2000; Cibella et al., 1996; Paterson et al., 1987; Robergs \& Roberts, 1997). Therefore, a fourth limitation is the inability to generalize the results to exercise at sea-level, as subjects' breathing frequencies may have been greater in this study.

5. The act of running on a treadmill introduces an auditory rhythm as each foot lands on the motor-driven treadmill belt. This extraneous rhythm represents a fifth limitation of this study, as a number of studies have found that entrainment of breathing to stride or pedal rate occurs when an imposed visual or auditory rhythm, such as a metronome, is introduced (Bechbache et al., 1977; Bernasconi \& Kohl, 1993; Bonsignore et al., 1998; Jasinskas et al., 1980; Paterson et al., 1986; van Alphen \& Duffin, 1994). Thus, the tendency of humans to entrain breathing to stride rate may merely be an example of two unrelated rhythms becoming coordinated. 


\section{Chapter IV}

\section{RESULTS}

\section{Subjects' Characteristics}

Subjects' mean ( \pm S.D.) age, height, body mass, and maximum oxygen consumption $\left(\dot{\mathrm{VO}}_{2} \max \right)$ were $27.5 \pm 6.5 \mathrm{yrs}, 178.7 \pm 7.1 \mathrm{~cm}, 71.4 \pm 8.4 \mathrm{~kg}$, and $68.8 \pm$ $6.8 \mathrm{ml} \mathrm{kg}^{\cdot} \mathrm{min}^{-1}$, respectively. Since all subjects had normal pulmonary function, as determined by $\mathrm{VC}$ and $\mathrm{FEV}_{1}$, at rest $(5.4 \pm 1.2 \mathrm{~L}$ and $84.2 \pm 5.8 \%$, respectively) and for 10, 20, and 30 minutes post-exercise $(5.4 \pm 1.3,5.3 \pm 1.1$, and $5.4 \pm 1.4 \mathrm{~L}$ and $81.8 \pm 5.6$, $83.8 \pm 5.8$, and $82.3 \pm 8.4 \%$, respectively), all were included in the data analysis. There were no significant differences in either of these pulmonary measures between time periods.

It was determined a priori from a power analysis that 26 subjects would have been needed ( $\mathrm{n}=13$ in each group) for $80 \%$ power in detecting group differences in running economy and entrainment. Following the testing of 15 subjects, the data were analyzed to determine whether there was a sufficient number of subjects who exhibited exercise-induced hypoxemia $(\mathrm{EIH})$ and expiratory flow limitation (FL) to warrant further testing to address the secondary purposes of the study. Only five of the 15 subjects exhibited EIH (i.e., an $\mathrm{S}_{\mathrm{a}} \mathrm{O}_{2}<87 \%$ ) during the $\dot{\mathrm{V}} \mathrm{O}_{2}$ max test and only two exhibited FL (i.e., the maximal exercise tidal flow-volume loop overlapping the maximal resting flow-volume loop). There was no relationship between end-exercise $\mathrm{S}_{\mathrm{a}} \mathrm{O}_{2}$ and percent entrainment, as the correlation between the two $(\mathrm{r}=-0.22)$ was low and not significant. Given this finding and the insufficient number of subjects exhibiting these 
cardiopulmonary characteristics, subjects were not classified into separate groups. Therefore, for the purpose of data analysis, all of the subjects were treated as one group and no additional subject recruitment and testing were pursued.

Entrainment of Breathing to Stride Rate

There was a significant number of subjects who exhibited entrainment of breathing to stride rate $(\mathrm{p}<0.001)$. Individual stride rates $(\mathrm{SR})$, stride lengths $(\mathrm{SL})$, breathing frequencies $\left(\mathrm{F}_{\mathrm{b}}\right)$, and step-to-breath ratios are presented in Table 2. Both SR and $F_{b}$ significantly increased with increasing intensity. The difference in SR was significant between the lowest intensity ( $70 \%$ of the ventilatory threshold, VT) and the two highest intensities (100 and 110\% VT; $\mathrm{p}=0.027$ and $\mathrm{p}<0.001$, respectively), between 90 and $110 \%$ VT $(p<0.001)$, and between 100 and $110 \%$ VT $(p=0.001)$. The increase in $\mathrm{F}_{\mathrm{b}}$ was significant up to $100 \% \mathrm{VT}(\mathrm{p}<0.001)$. However, there was no significant difference in $\mathrm{F}_{\mathrm{b}}$ between the two highest intensities.

The $\mathrm{SR} / \mathrm{F}_{\mathrm{b}}$ quotient, from which an integer step-to-breath ratio was calculated, revealed that entrainment of breathing to stride rate was a distinct characteristic of these subjects, with 5:3 and 2:1 step-to-breath ratios the most common ratios utilized (Table 2). As the intensity increased, the subjects took fewer steps per breath, as the $\mathrm{SR} / \mathrm{F}_{\mathrm{b}}$ quotient significantly decreased with increasing intensity up to $100 \%$ VT (Table 2). However, there was no significant difference in the $\mathrm{SR} / \mathrm{F}_{\mathrm{b}}$ quotient between 100 and $110 \% \mathrm{VT}$. 
Table 2. Stride Rate, Stride Length, Breathing Frequency, and Locomotor-Respiratory Coupling During Treadmill Running

\begin{tabular}{|c|c|c|c|c|c|c|c|c|c|c|c|c|c|c|c|c|c|c|c|c|}
\hline \multirow[b]{2}{*}{ Subject } & \multicolumn{5}{|c|}{$70 \%$ VT } & \multicolumn{5}{|c|}{$90 \% \mathrm{VT}$} & \multicolumn{5}{|c|}{$100 \% \mathrm{VT}$} & \multicolumn{5}{|c|}{ 110\% VT } \\
\hline & SR & SL & $\mathbf{F}_{\mathbf{b}}$ & $\mathrm{SR} / \mathbf{F}_{\mathrm{b}}$ & Ratio & SR & SL & $\mathbf{F}_{\mathbf{b}}$ & $\mathrm{SR} / \mathbf{F}_{\mathrm{b}}$ & Ratio & SR & SL & $\mathbf{F}_{\mathbf{b}}$ & $\mathrm{SR} / \mathbf{F}_{\mathrm{b}}$ & Ratio & SR & SL & $\mathbf{F}_{\mathbf{b}}$ & $\mathrm{SR} / \mathbf{F}_{\mathrm{b}}$ & Ratio \\
\hline 1 & 86 & 2.4 & 30 & 2.86 & & 87 & 3.0 & 39 & 2.23 & & 90 & 3.2 & 45 & 2.00 & $2: 1$ & 97 & 3.3 & 47 & 2.08 & \\
\hline 2 & 93 & 2.3 & 33 & 2.79 & & 92 & 3.0 & 40 & 2.31 & & 88 & 3.5 & 44 & 1.98 & $2: 1$ & 90 & 3.7 & 45 & 2.02 & $2: 1$ \\
\hline 3 & 82 & 2.2 & 25 & 3.34 & & 82 & 2.8 & 28 & 2.94 & $3: 1$ & 85 & 3.1 & 32 & 2.67 & & 88 & 3.2 & 34 & 2.61 & \\
\hline 4 & 71 & 2.7 & 20 & 3.54 & & 76 & 3.2 & 23 & 3.29 & & 82 & 3.3 & 25 & 3.23 & & 83 & 3.6 & 27 & 3.08 & \\
\hline 5 & 76 & 2.3 & 35 & 2.16 & & 77 & 2.9 & 41 & 1.85 & & 77 & 3.2 & 47 & 1.64 & $5: 3$ & 83 & 3.3 & 48 & 1.72 & $5: 3$ \\
\hline 6 & 75 & 2.5 & 24 & 3.15 & & 80 & 3.0 & 32 & 2.51 & $5: 2$ & 83 & 3.2 & 35 & 2.36 & & 84 & 3.4 & 39 & 2.19 & \\
\hline 7 & 78 & 2.2 & 33 & 2.34 & & 81 & 2.8 & 44 & 1.84 & & 80 & 3.1 & 52 & 1.54 & $3: 2$ & 89 & 3.0 & 53 & 1.68 & $5: 3$ \\
\hline 8 & 83 & 2.2 & 49 & 1.68 & $5: 3$ & 91 & 2.5 & 57 & 1.60 & & 92 & 2.8 & 62 & 1.47 & $3: 2$ & 94 & 3.0 & 66 & 1.43 & \\
\hline 9 & 77 & 2.1 & 24 & 3.23 & & 82 & 2.5 & 31 & 2.66 & & 83 & 2.8 & 29 & 2.83 & & 83 & 3.0 & 33 & 2.49 & $5: 2$ \\
\hline 10 & 71 & 2.6 & 21 & 3.39 & & 77 & 3.1 & 25 & 3.13 & & 80 & 3.3 & 27 & 2.91 & & 91 & 3.2 & 31 & 2.95 & $3: 1$ \\
\hline 11 & 78 & 2.2 & 26 & 3.02 & $3: 1$ & 81 & 2.8 & 33 & 2.46 & $5: 2$ & 84 & 2.9 & 37 & 2.29 & & 88 & 3.1 & 38 & 2.33 & \\
\hline 12 & 79 & 1.8 & 36 & 2.20 & & 79 & 2.4 & 42 & 1.89 & & 79 & 2.6 & 48 & 1.63 & $5: 3$ & 84 & 2.7 & 46 & 1.82 & \\
\hline 13 & 91 & 2.0 & 32 & 2.82 & & 88 & 2.6 & 40 & 2.20 & & 91 & 2.8 & 45 & 2.02 & $2: 1$ & 94 & 3.1 & 49 & 1.91 & \\
\hline 14 & 79 & 2.1 & 27 & 2.94 & & 79 & 2.7 & 36 & 2.21 & & 79 & 3.0 & 39 & 2.04 & $2: 1$ & 85 & 3.1 & 36 & 2.38 & \\
\hline 15 & 72 & 2.1 & 39 & 1.86 & & 73 & 2.6 & 44 & 1.66 & $5: 3$ & 75 & 2.9 & 48 & 1.54 & $3: 2$ & 79 & 3.0 & 45 & 1.78 & \\
\hline Mean & 79 & 2.2 & 30 & 2.75 & & 82 & $2.8^{*}$ & $37 *$ & $2.32 *$ & & $83^{*}$ & $3.0^{* \dagger}$ & $41^{*^{\dagger}}$ & $2.14^{* \dagger}$ & & $87^{* \dagger+}$ & $3.2^{* *+}$ & $42^{* \dagger}$ & $2.16^{* \dagger}$ & \\
\hline S.D. & 7 & 0.2 & 8 & 0.58 & & 5 & 0.2 & 9 & 0.52 & & 5 & 0.2 & 10 & 0.56 & & 5 & 0.3 & 10 & 0.48 & \\
\hline
\end{tabular}

${ }^{1} \mathrm{VT}=$ ventilatory threshold; $\mathrm{SR}=$ stride rate $\left(\operatorname{steps} \mathrm{min}^{-1}\right) ; \mathrm{SL}=$ stride length $\left(\mathrm{m}^{\prime} \mathrm{step}^{-1}\right) ; \mathrm{F}_{\mathrm{b}}=$ breathing frequency $\left(\right.$ breaths $\left.\mathrm{min}{ }^{-1}\right) ;$ Ratio $=$ ratio between steps and breaths when $\mathrm{SR} / \mathrm{F}_{\mathrm{b}}$ quotient resulted in a whole-integer ratio. $\mathrm{SR}$ and $\mathrm{F}_{\mathrm{b}}$ rounded to nearest whole number. $*$ Significantly different from $70 \% \mathrm{VT}$ ( $\mathrm{p}<0.05$ ). ${ }^{\dagger}$ Significantly different from $90 \%$ VT $(\mathrm{p}<0.05)$. ${ }^{\star}$ Significantly different from $100 \% \mathrm{VT}(\mathrm{p}<0.05)$. 
There was large variability in the degree of entrainment between subjects. From analysis of the time between the beginning of a breath and foot strike, the subjects entrained their breathing to their stride rates $23.9 \pm 15.1 \%$ of all inspired breaths and 26.3 $\pm 10.8 \%$ of all expired breaths during exercise. The results of the two-way repeated measures ANOVA comparing percent entrainment during inspiration and expiration between intensities revealed a significant interaction of breathing phase and intensity $\left(\mathrm{F}_{3,42}=8.83, \mathrm{p}<0.001\right)$, with significant differences for inspiration between $70 \% \mathrm{VT}$ and the two highest intensities. The degree of entrainment during expiration slightly decreased with increasing intensity up to $100 \%$ VT, but the decrease was not significant (Figure 7). At the two lowest intensities (70 and 90\% VT), percent entrainment was greater during expiration, while at the two highest intensities (100 and 110\% VT), it was greater during inspiration, however the difference between breathing phases was only significant at the lowest intensity $(\mathrm{p}=0.001)$. The results of the three-way mixed ANOVA comparing the actual and chance percent entrainment during inspiration and expiration for each intensity are listed in the Table 3. There was a significant difference between the actual and chance percent entrainment between steps and inspired breaths at each intensity $(13.1 \pm 7.8,23.1 \pm 14.5,28.4 \pm 16.5$, and $30.8 \pm 14.9 \%$ vs. $2.2 \pm 1.2,2.6 \pm$ $1.5,4.4 \pm 1.8$, and $4.8 \pm 2.3 \%$ for $70,90,100$, and $110 \% \mathrm{VT}$, respectively; $\mathrm{p}<0.001)$ and between steps and expired breaths at each intensity $(30.8 \pm 12.6,27.9 \pm 10.0,20.8 \pm 7.3$, and $25.7 \pm 11.2 \%$ vs. $3.2 \pm 1.5,4.4 \pm 1.6,4.5 \pm 1.8$, and $4.4 \pm 2.4 \%$ for $70,90,100$, and $110 \%$ VT, respectively; $\mathrm{p}<0.001)$. 
Table 3. Results of Three-Way Anova Comparing Actual and Random Entrainment

\begin{tabular}{lcccccc}
\hline \multicolumn{1}{c}{ Source of Variation } & $\begin{array}{c}\text { df } \\
\text { (effect) }\end{array}$ & $\begin{array}{c}\text { MS } \\
\text { (effect) }\end{array}$ & $\begin{array}{c}\text { df } \\
\text { (error) }\end{array}$ & $\begin{array}{c}\text { MS } \\
\text { (error) }\end{array}$ & F-ratio & p-value \\
\hline $\begin{array}{l}\text { Type of Entrainment } \\
\quad \text { Actual/Random) }\end{array}$ & 1 & 26044.13 & 27 & 131.76 & 197.66 & $<0.001$ \\
$\begin{array}{l}\text { Breathing Phase } \\
\quad \text { Inspiration/Expiration) }\end{array}$ & 1 & 136.35 & 27 & 222.07 & 0.61 & NS \\
$\begin{array}{l}\text { Intensity } \\
\quad(70 / 90 / 100 / 110 \% \text { VT) }\end{array}$ & 3 & 160.78 & 81 & 34.22 & 4.70 & 0.004 \\
$\begin{array}{l}\text { Type x Breathing Phase } \\
\text { Type x Intensity }\end{array}$ & 1 & 46.09 & 27 & 222.07 & 0.21 & NS \\
$\begin{array}{l}\text { Breathing Phase x Intensity } \\
\text { Type x Breathing Phase x Intensity }\end{array}$ & 3 & 57.15 & 81 & 34.22 & 1.67 & NS \\
\hline
\end{tabular}

Foot strike (as determined by touchdown of the first metatarsal) occurred an average of $0.10 \pm 0.03$ second from the beginning of an inspiration $\left(\mathrm{T}_{\mathrm{i}}\right)$ and $0.09 \pm 0.02$ second from the beginning of an expiration $\left(T_{e}\right)$. Seventy percent of the inspirations occurred before and 30\% occurred after foot strike, while $49 \%$ of the expirations occurred before and 51\% occurred after foot strike. $T_{i}$ significantly decreased with increased intensity from $70 \%$ VT to the two highest intensities when inspiration occurred before foot strike and significantly decreased from $70 \%$ VT to the other three intensities when inspiration occurred after foot strike (Table 4). The timing between breaths and steps during expiration exhibited greater stability, as there were no significant differences in $T_{e}$ between intensities. 


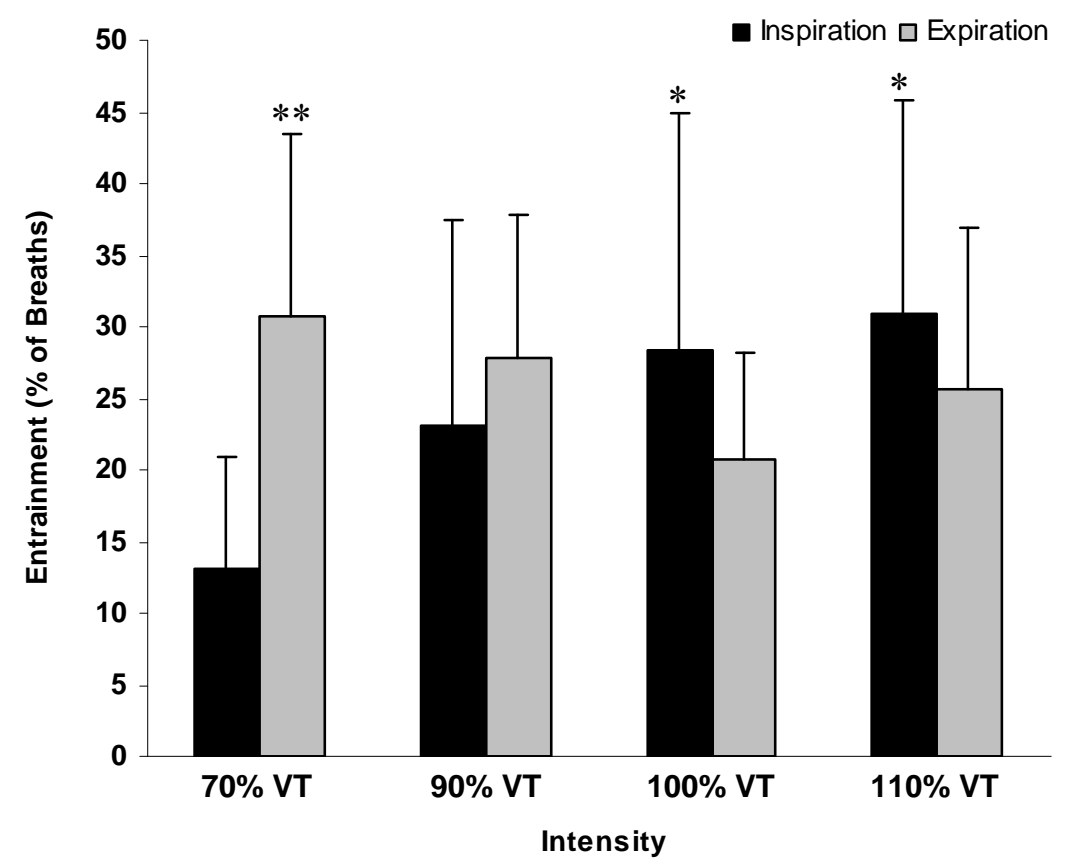

Figure 7. Degree of entrainment at four running intensities. *Significantly greater than $70 \%$ VT $(\mathrm{p}<0.01) .{ }^{* *}$ Significantly greater than inspiration.

\section{Running Economy}

Subjects' mean running economy values at 70, 90, and 100\% VT were $231.6 \pm$ $21.1,217.1 \pm 24.8$, and $213.8 \pm 23.7 \mathrm{ml} \mathrm{kg}^{-1} \mathrm{~km}^{-1}$. The subjects were more economical at 90 and $100 \%$ VT compared to $70 \%$ VT $(p<0.01)$, but there was no significant difference in running economy between 90 and $100 \%$ VT. There was no significant correlation between running economy and percent entrainment at 70, 90, and 100\% VT $(\mathrm{r}=-0.28$, 0.01 , and 0.07 , respectively; $\mathrm{p}>0.05$ ) or between running economy and the $\mathrm{SR} / \mathrm{F}_{\mathrm{b}}$ quotient $(r=-0.09,0.12$, and 0.24 , respectively; $\mathrm{p}>0.05)$. 
Table 4. Timing Between Inspirations and Steps $\left(T_{i}\right)$ and Expirations and Steps $\left(T_{e}\right)$

\begin{tabular}{|c|c|c|c|c|c|c|c|c|c|c|c|c|c|c|c|c|}
\hline & \multicolumn{4}{|c|}{$\mathbf{T}_{\mathbf{i}}(-)^{1}$} & \multicolumn{4}{|c|}{$\mathbf{T}_{\mathbf{i}}(+)$} & \multicolumn{4}{|c|}{$\mathbf{T}_{\mathrm{e}}(-)$} & \multicolumn{4}{|c|}{$\mathbf{T}_{\mathrm{e}}(+)$} \\
\hline & $\begin{array}{c}70 \% \\
\text { VT }\end{array}$ & $\begin{array}{c}90 \% \\
\text { VT }\end{array}$ & $\begin{array}{c}100 \% \\
\text { VT }\end{array}$ & $\begin{array}{c}110 \% \\
\text { VT }\end{array}$ & $\begin{array}{c}70 \% \\
\text { VT }\end{array}$ & $\begin{array}{c}90 \% \\
\text { VT }\end{array}$ & $\begin{array}{c}100 \% \\
\text { VT }\end{array}$ & $\begin{array}{c}110 \% \\
\text { VT }\end{array}$ & $\begin{array}{c}70 \% \\
\text { VT }\end{array}$ & $\begin{array}{c}90 \% \\
\text { VT }\end{array}$ & $\begin{array}{c}100 \% \\
\text { VT }\end{array}$ & $\begin{array}{c}110 \% \\
\text { VT }\end{array}$ & $\begin{array}{c}70 \% \\
\text { VT }\end{array}$ & $\begin{array}{c}90 \% \\
\text { VT }\end{array}$ & $\begin{array}{c}100 \% \\
\text { VT }\end{array}$ & $\begin{array}{c}110 \% \\
\text { VT }\end{array}$ \\
\hline Mean & -0.11 & -0.10 & $-0.09 *$ & $-0.08 *$ & 0.12 & $0.11^{*}$ & $0.09 *$ & $0.09 *$ & -0.09 & -0.09 & -0.10 & -0.09 & 0.09 & 0.09 & 0.10 & 0.09 \\
\hline S.D. & 0.02 & 0.02 & 0.02 & 0.01 & 0.02 & 0.03 & 0.02 & 0.03 & 0.02 & 0.02 & 0.01 & 0.02 & 0.02 & 0.02 & 0.02 & 0.02 \\
\hline
\end{tabular}

${ }^{1}(-)$ represents time before a step; $(+)$ represents time after a step. Numbers are in seconds. ${ }^{*}$ Significantly different from $70 \%$ VT $(\mathrm{p}<0.05)$. 


\section{Chapter V}

\section{DISCUSSION}

\section{Entrainment of Breathing to Stride Rate}

There is considerable evidence that animals entrain their breathing rhythm to their rhythm of locomotion. In quadruped animals, this entrainment seems to result from the movement of the legs controlling or assisting the movement of the thoracic cavity, leading to a tightly coupled 1:1 ratio between steps and breaths. In the bipedal human, however, there is an obvious anatomical separation between the legs and thoracic cavity, which may partly explain why research on humans has found a wider range of coupling ratios and a more transient occurrence of entrainment of the breathing rhythm to the stride rate. In addition, while quadrupeds more readily increase their stride rates with increasing running speed, humans are more confined to a particular stride rate, the choice of which may be governed by economy (Cavanagh \& Kram, 1989). In the present study, SR increased by $10.2 \%$ from the lowest to highest intensity, while stride length increased by $42.1 \%$. Unlike stride rate, humans' ventilation increases greatly with increasing speed, which would result in a greater variety of step-to-breath ratios. Much like changing the gears on a bicycle to optimize the cyclist's power output and effort per pedal revolution, the wider range of step-to-breath ratios utilized by humans may represent a type of gearing mechanism that allows humans to subconsciously alter their breathing patterns to optimize the energy cost of ventilation. Although the presence of entrainment in humans is variable, past research has shown that entrainment is more typical of subjects who are experienced with the mode of exercise (Berry et al., 1988; 
Bramble \& Carrier, 1983; Paterson et al., 1987) and who have a higher level of fitness (Berry et al., 1988; Mahler et al., 1991). It was therefore hypothesized that entrainment would be evident in the highly trained distance runners examined in the present study.

Entrainment of breathing to stride rate was indeed evident in these subjects. Fourteen of the 15 subjects exhibited a whole integer step-to-breath ratio for at least one intensity, with 5:3 and 2:1 step-to-breath ratios the most common ratios utilized (Table 2). With increasing intensity, the subjects more tightly coupled their breaths to their steps, taking close to three steps per breath at $70 \% \mathrm{VT}$ and two steps per breath at 100 and 110\% VT (Figures 8-11). A number of other studies have also found that humans most often use a 2:1 step-to-breath ratio while running (Bernasconi \& Kohl, 1993; Berry et al., 1996; Bramble \& Carrier, 1983; McDermott et al., 2003; Paterson et al., 1987; Persegol et al., 1991; Takano, 1995) and that the ratio becomes tighter as speed increases (McDermott et al., 2003). McDermott et al. (2003) even found a quadruped-like 1:1 step-to-breath ratio in two of their subjects when running at the fastest tested speeds (11.2-12.1 $\left.\mathrm{km}^{-1}{ }^{-1}\right)$, which were similar to the slowest speeds used in the present study. Takano (1995) also observed a 1:1 ratio in two subjects who breathed excessively during uphill running. While none of the subjects in the present study exhibited a 1:1 step-to-breath ratio, five subjects exhibited a ratio smaller than $2: 1$ at $100 \%$ VT and six subjects did so at $110 \% \mathrm{VT}$ (Table 2). Given that the average stride rates in this study ranged from 79 to 87 steps per minute, values characteristic of human distance runners (Daniels, 1998), it is not likely that humans would often achieve a 1:1 step-to-breath ratio, as that would require an equivalent breathing frequency not typically reached 
during exercise. The lack of a 1:1 ratio in humans has been corroborated by others (Bramble \& Carrier, 1983; J.T. Daniels, personal communication). Bramble and Carrier (1983) found a 4:1 step-to-breath ratio at their slowest tested speed, which decreased to a 2:1 ratio at the fastest speed. While five subjects in the present study exhibited a step-to-breath ratio slightly larger than 3:1 at the lowest intensity and two subjects did so at $90 \% \mathrm{VT}$ (Table 2), a 4:1 ratio was never utilized.

Interestingly, a whole-integer step-to-breath ratio occurred most often at 100\% VT, in nine of the 15 subjects (Table 2). The VT represents an important physiological variable, since it represents the transition between running that generates energy almost purely aerobically and running that includes energy from both aerobic and oxygen-independent (anaerobic) metabolism. It can therefore be considered the highest steady-state intensity and is the best physiological predictor of distance running performance (Basset \& Howley, 2000; Farrell et al., 1979). Due to the upper limit steady-state and rhythmic, metronome-like nature of this intensity, at which one begins to breathe heavily, it may be advantageous, or simply feel better, to coordinate breathing with stride rate. 


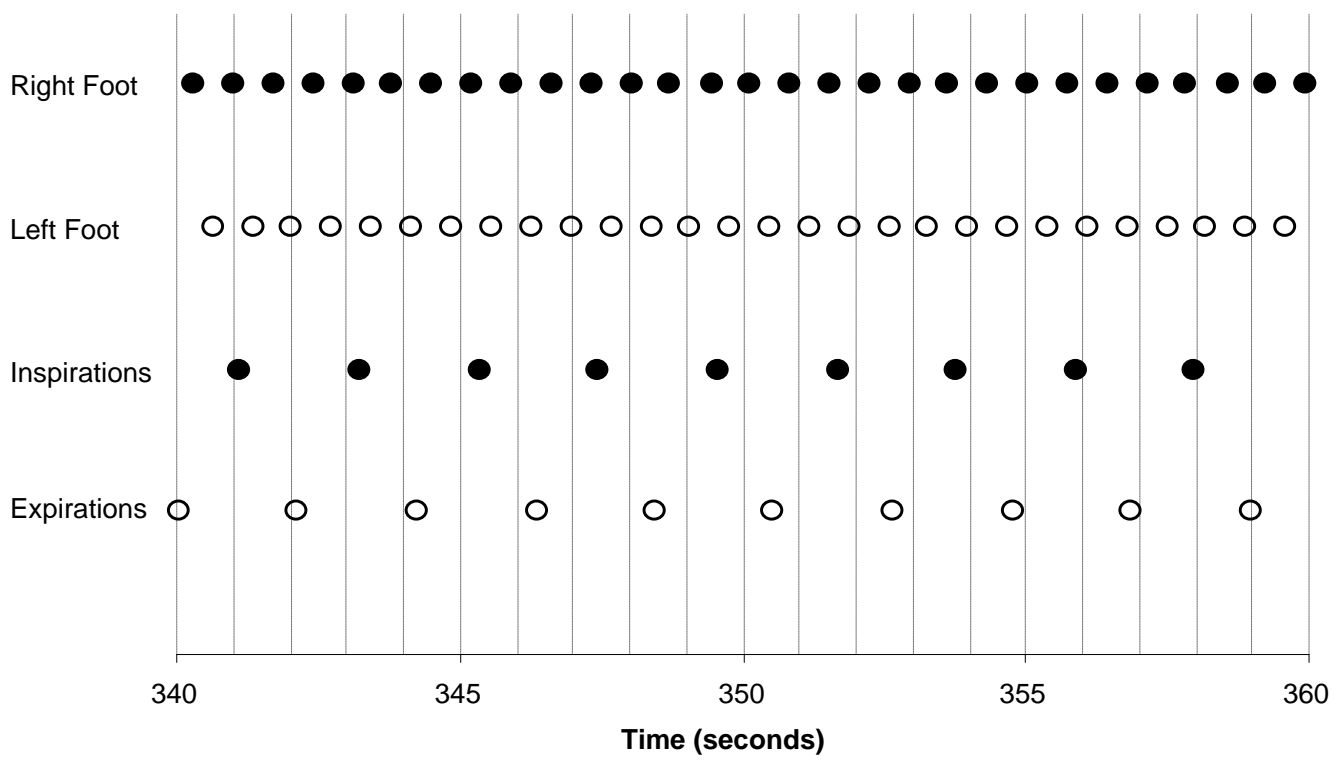

Figure 8. Timing of breathing and foot strikes during the final 20 seconds of treadmill running at $70 \%$ of the ventilatory threshold. At this intensity, this subject took 2.8 steps per breath.

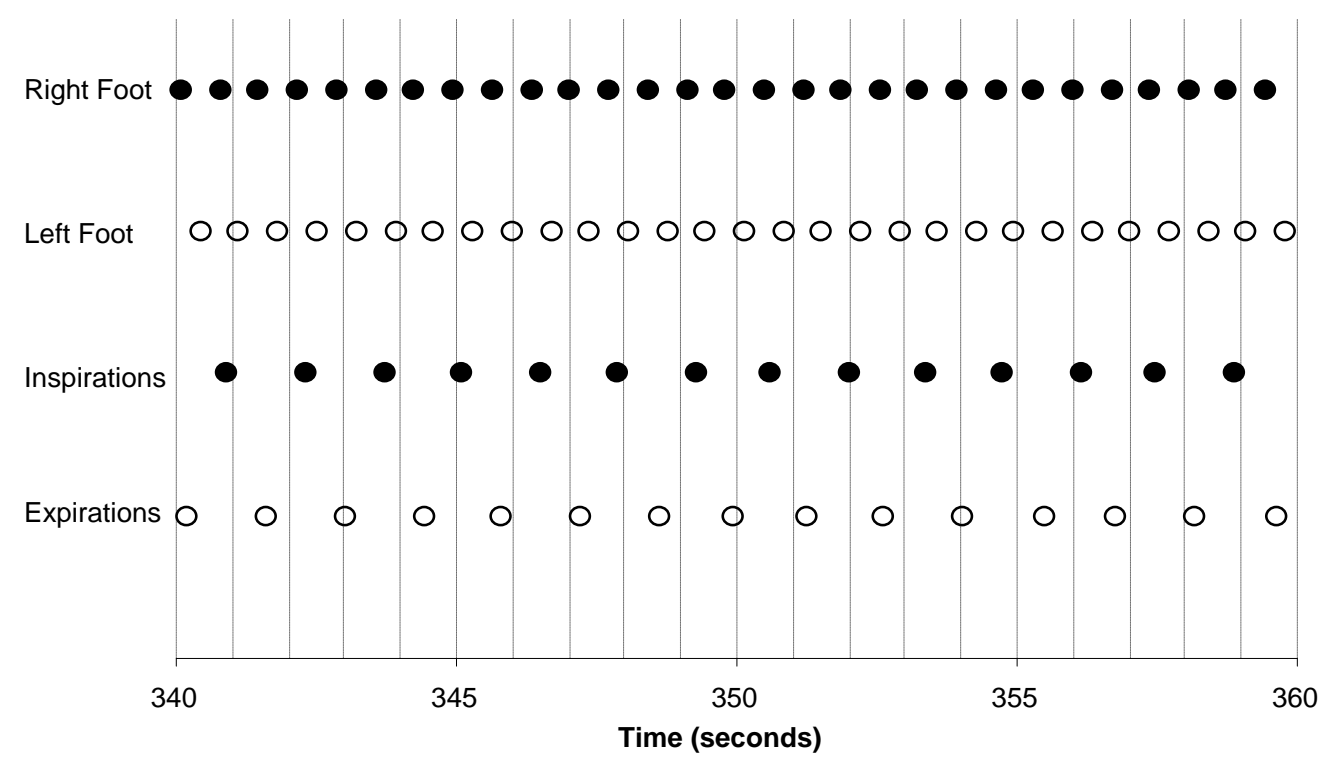

Figure 9. Timing of breathing and foot strikes during the final 20 seconds of treadmill running at $90 \%$ of the ventilatory threshold. At this intensity, this subject took 2.3 steps per breath. 


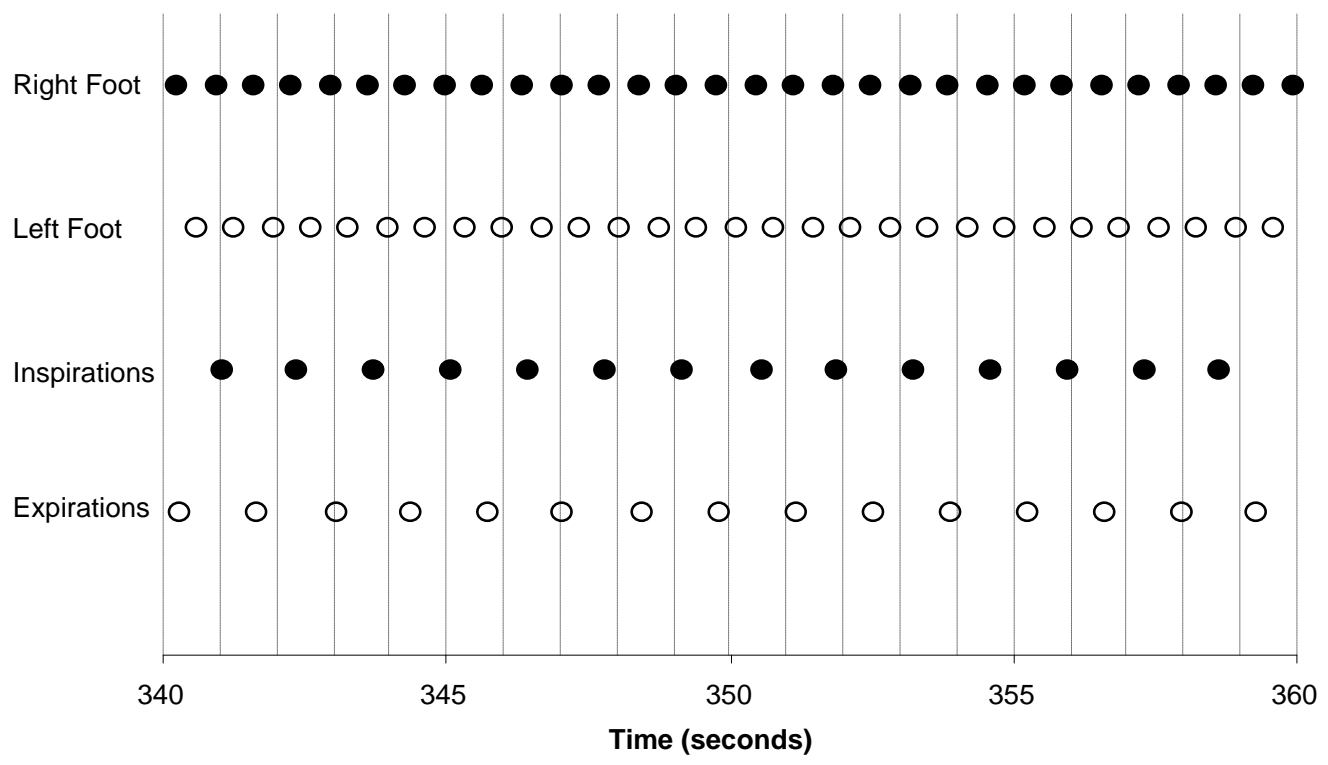

Figure 10. Timing of breathing and foot strikes during the final 20 seconds of treadmill running at $100 \%$ of the ventilatory threshold. At this intensity, this subject took 2 steps per breath.

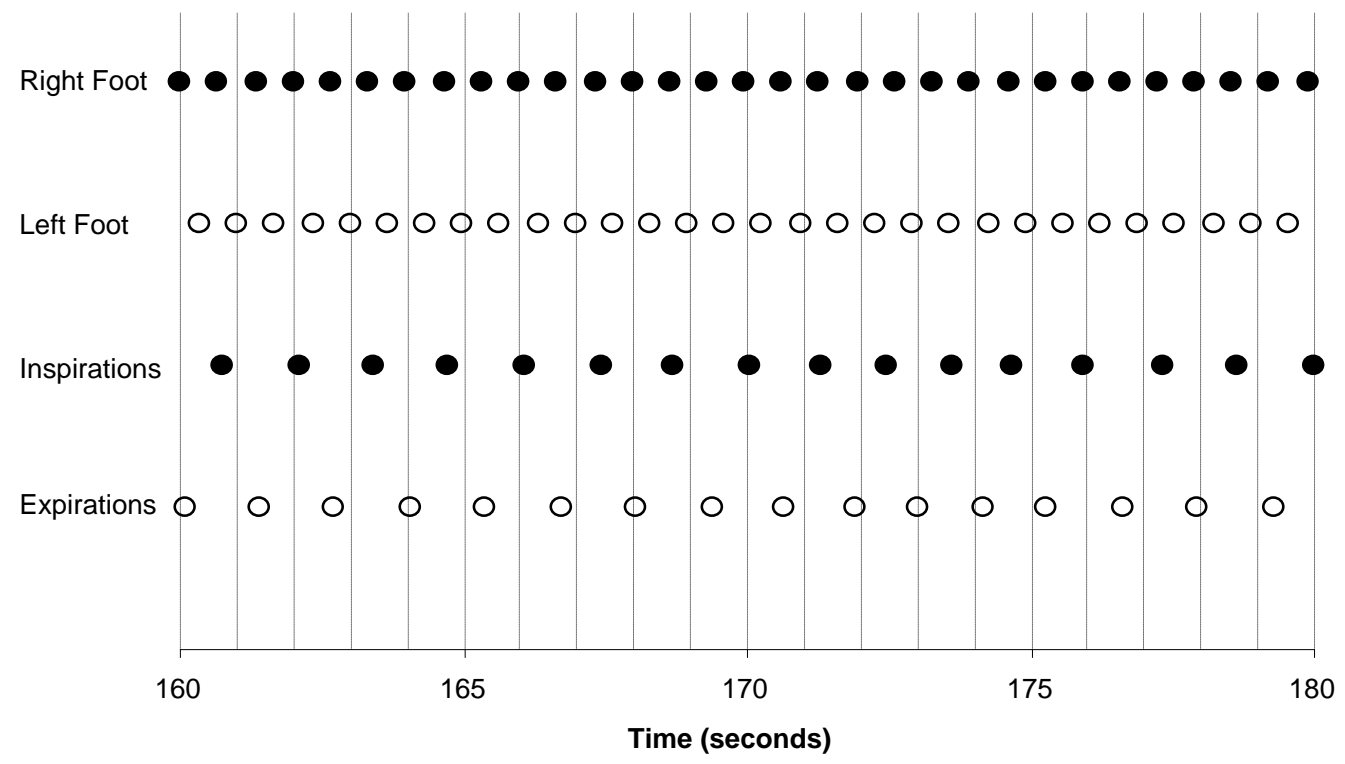

Figure 11. Timing of breathing and foot strikes during the final 20 seconds of treadmill running at $110 \%$ of the ventilatory threshold. At this intensity, this subject took 2 steps per breath. 
It was initially hypothesized that the subjects would exhibit entrainment for the majority of breaths. However, the subjects entrained their breaths to their steps only 23.9 $\pm 15.1 \%$ of all inspired breaths and $26.3 \pm 10.8 \%$ of all expired breaths. A closer examination of the method used to quantify entrainment reveals that the percent entrainment calculated is dependent on the criteria used. For example, since the average time difference between a breath and the closest step was \pm 0.10 second, if the degree of entrainment were determined by calculating the percentage of breaths occurring within \pm 0.10 second of a step, the value obtained would be approximately $50 \%$. Therefore, when calculating the percentage of breaths occurring within a specific time frame from a step, the chosen time frame must be disconnected from the average time difference. Because the time frame used in this study ( \pm 0.05 second) was half that of the average time difference, it is no surprise that the percent entrainment obtained was approximately $25 \%$. If \pm 0.06 or \pm 0.07 second were used instead, a greater percent entrainment would have been found. To obtain a value larger than $50 \%$, a time frame larger than the average time difference between a breath and a step would have to be used, which is not logical. Given this mathematical link between the chosen time frame and the percent entrainment obtained, a determination of whether entrainment is a real physiological phenomenon can best be made by statistically comparing the calculated percent entrainment to that which would occur by chance. Using the actual stride rates and breathing variability of the subjects, a set of random numbers was generated to represent random breaths with a breath interval range of zero to the maximal breath interval value(s) for the data set, and the probability of getting a random breath to occur within \pm 0.05 second from the closest 
step was calculated. As expected, there was a significant difference between the actual and chance percent entrainment for both inspiration and expiration at each intensity. Therefore, entrainment was a real physiological phenomenon in these subjects.

Given the differences in quantifying entrainment between studies, it is difficult to compare the results of the present study with those of other studies. Paterson et al. (1987) found that the coupling ratio occurred $50 \%$ of the time when running on a treadmill at sea-level, however this percentage decreased linearly when subjects breathed decreasing fractions of oxygen $\left(\mathrm{F}_{\mathrm{i}} \mathrm{O}_{2}\right)$. At an $\mathrm{F}_{\mathrm{i}} \mathrm{O}_{2}$ corresponding to an altitude similar to that of the present study, they found approximately 35\% entrainment. McDermott et al. (2003) found that an integer step-to-breath ratio occurred for $60 \%$ of breaths at sea-level. However, when examining the timing relationship between breaths and steps (between end-inspiration and the preceding heel strike), they found only $20 \%$ entrainment across a number of treadmill walking and running speeds, similar to what was found in the present study.

Since the present study was conducted at an altitude of 1,524 meters, it is possible that the degree of entrainment was influenced by altitude. Only one study has examined the effect of different amounts of oxygen on the entrainment of breathing frequency to stride rate (Paterson et al., 1987), and found that the degree of entrainment decreased with increasing levels of hypoxia, from approximately $50 \%$ at sea-level to approximately $20 \%$ at an altitude of 5,000 meters. It is well documented that exercise at altitude causes a greater hyperventilatory response compared to exercise at the same intensity at sea-level (Brooks et al., 2000; Cibella et al., 1996; Paterson et al., 1987; Robergs \& 
Roberts, 1997). It is possible that any advantage conferred to runners by entraining breathing to stride rate is superseded at altitude by the increased need to ventilate to compensate for the decreased partial pressure of oxygen. Since SR would not be expected to increase from sea-level to altitude, a greater $F_{b}$ at altitude would cause steps and breaths to be more tightly coupled.

Contrary to the initial hypothesis, the degree of entrainment was largely consistent across all four intensities. During expiration, it slightly decreased with increasing intensity up to $100 \%$ VT, but the decrease was not significant. During inspiration, it slightly increased with increasing intensity, but was only significant between $70 \%$ VT and the two highest intensities (Figure 7). Since the perception of effort while running is closely linked to the runner's breathing, it seems that, as intensity changes, humans may subconsciously change "breathing gears" in concert with their stride rates to either optimize the energy cost of ventilation or to minimize the perception of effort. Bernasconi and Kohl (1993) also found that the degree of entrainment did not significantly change with increasing speed in subjects who were considered fit but not specifically trained. However, Bonsignore et al. (1998) found that triathletes decreased their degree of entrainment with increasing cycling and running speeds. The difference in the results of the present study with those of Bonsignore et al. (1998) may be due to differences in methodology. Bonsignore et al. (1998) examined entrainment during incremental exercise tests rather than during steady-state tests, and calculated the degree of entrainment solely on the occurrence of integer step-to-breath ratios. 
In support of the constant degree of entrainment between intensities, the breathing rhythm seemed to be linked to foot strike, with the time between an expiration and the closest step remaining unchanged despite large changes in intensity. The majority of inspirations $(70.3 \pm 14.8 \%)$ occurred an average of $0.10 \pm 0.02$ second before foot strike, while $29.2 \pm 14.6 \%$ occurred an average of $0.10 \pm 0.03$ second after foot strike. Half of expirations occurred an average of $0.09 \pm 0.02$ second before foot strike, while half occurred an average of $0.09 \pm 0.02$ second after foot strike. Moreover, as Figures 8-10 illustrate, both inspiration and expiration were associated with a foot strike of the same leg. This characteristic disappeared, however, when running at the highest intensity (110\% VT, close to 5,000-meter race pace) (Figure 11). Thus, it is possible that breathing is associated with the same foot strike when running at intensities lower than or at the ventilatory (lactate) threshold, when the intensity is almost purely aerobic, but becomes more erratic at intensities higher than the ventilatory threshold, when the intensity includes a significant oxygen-independent component and ventilation is consequently increased exponentially to expire the increased metabolic carbon dioxide production. Bramble and Carrier (1983) also found that expiration was associated with the same foot strike when subjects exhibited even-integer step-to-breath ratios (4:1 and 2:1).

\section{Running Economy}

The subjects were more economical at 90 and $100 \%$ VT compared to $70 \%$ VT $(p<0.01)$, but there was no significant difference in running economy between 90 and 
$100 \%$ VT $\left(231.6 \pm 21.1,217.1 \pm 24.8\right.$, and $213.8 \pm 23.7 \mathrm{ml}^{-1} \mathrm{~kg}^{-1} \mathrm{~km}^{-1}$, respectively $)$ Since runners tend to be more economical at the speeds at which they train the most (Jones \& Carter, 2000), it makes sense that running economy would be greater for these highly trained subjects at the higher intensities since the running speed at $70 \% \mathrm{VT}$ was slower than the slowest speed typically performed by these subjects. The speed corresponding to $90 \% \mathrm{VT}$ was close to the normal distance running speed of these subjects, and is therefore the intensity at which they were most experienced. The tendency to perform the majority of training at a low intensity is a common finding of studies on elite endurance athletes (Bale et al., 1985,1986; Billat et al., 2001; Fiskerstarand \& Seiler, 2004; Karp, 2007; Seiler \& Kjerland, 2006).

While it is an attractive argument that entraining the rhythm of breathing to the rhythm of locomotion improves the economy of locomotion, as has been suggested by other researchers (Bernasconi \& Kohl, 1993; Bonsignore et al., 1998; Bramble \& Carrier, 1983; Heinrich, 2001; Hill et al., 1988; Paterson et al., 1986), it was not possible to determine this in the present study since all of the subjects entrained their breathing to their stride rates. To determine if there was a relationship between running economy and the degree of entrainment, correlations were calculated between economy and percent entrainment and between economy and the $\mathrm{SR} / \mathrm{F}_{\mathrm{b}}$ quotient for the three intensities at which economy was measured. Contrary to the initial hypothesis, these correlations were not significant at any intensity $(\mathrm{r}=-0.28,0.01$, and 0.07 between economy and percent entrainment and $\mathrm{r}=-0.09,0.12$, and 0.24 between economy and the $\mathrm{SR} / \mathrm{F}_{\mathrm{b}}$ quotient at 70 , 90, and 100\% VT respectively; $\mathrm{p}>0.05$ ). 
While entraining the breathing rhythm to the stride rate may have economical ramifications in less fit or less experienced subjects, it may not improve running economy over and above what these athletes have already gained through training. The more optimal biomechanics, the hypertrophy of Type I skeletal muscle fibers, the greater skeletal muscle mitochondrial and capillary volumes, the greater ability for tendons to store and utilize elastic energy, the lower body mass, and the more optimal motor unit recruitment patterns gained from countless repetitions of the running movements all may have a greater effect on economy than entraining the breathing and stride rhythms. The economy values obtained in this study were only slightly higher (i.e., lower economy) than those obtained in other studies on distance runners of a higher performance level (Daniels \& Daniels, 1992; Weston et al., 2000), suggesting that these athletes were already very economical. Research on untrained humans while running has shown that whole body oxygen consumption is lower during periods of entrainment (Bernasconi \& Kohl, 1993; Bramble \& Carrier, 1983), however the mechanism for the improved economy has yet to be elucidated. No studies have compared economy between subjects who exhibit entrainment and those who do not.

\section{Directions for Future Research}

Based on the results of this study, there are a number of directions for future research. For example, since all of the subjects in the present study entrained their breathing rhythms to their stride rates, possibly due to the highly trained status of the study's subjects, future studies should compare individuals who entrain breathing to 
stride rate to those who do not to examine whether there is an economical advantage to entrainment. If it can be definitively established that there is such an advantage, research beyond that should address whether the improved economy is a result of entrainment reducing the mechanical work of breathing, as has been previously suggested, or whether economy improves by some other mechanism. Furthermore, if humans alter their breathing patterns for mechanical reasons that either optimize the energy cost of ventilation or minimize the perception of effort, the metabolic and neural frameworks in which the control of breathing has historically been studied would need to be altered to accommodate mechanical considerations. In addition, given the transient and fractional nature of entrainment found in this and previous research, the question that needs to be addressed is, "If entraining the breathing rhythm to the stride rate confers an economical advantage, why would someone entrain for only a fraction of the breaths? Why wouldn't all the breaths be entrained to the stride rate?"

The issue of quantifying entrainment also needs to be addressed in future studies, as much of the previous research has neglected the most important parameter of entrainment - the timing between the step and breathing cycles. To determine if the breathing rhythm is physiologically linked to the stride rhythm, it must be determined that each breath (or a specific multiple of breaths) occurs within a specific, non-changing time from a step action, such as heel strike or toe-off. In addition, a specific definition for the degree of entrainment needs to be established, as there is currently no minimal percentage of breaths or amount of time for determining the presence of entrainment, other than a statistical comparison to that which would be expected to occur by chance. 
Such a definition should be based on the physiological or mechanical advantages of entrainment to address the question, "To what degree or within what time frame of steps and breaths does entrainment need to occur to be beneficial?" Future research in this technical area may be best addressed with a multidisciplinary approach, in which both biomechanical and physiological issues are considered.

From a performance standpoint, future research should address whether running performance is improved or otherwise influenced as a result of entraining the breathing rhythm to the stride rate, as this would have great implications for coaches and runners, who could be taught to entrain these two rhythms.

Finally, future research should address the possible influences of EIH and FL on entrainment. The occurrence of EIH in highly-trained endurance athletes is thought to be a consequence primarily of a pulmonary diffusion limitation (Dempsey \& Wagner, 1999; Powers \& Williams, 1987). That the subjects were able to maintain their pre-exercise pulmonary performance (as determined by $\mathrm{VC}$ and $\mathrm{FEV}_{1}$ ) for 30 minutes following the $\dot{\mathrm{V}} \mathrm{O}_{2}$ max test suggests that they did not have a pulmonary diffusion limitation, which may be a reason why there was little presence of EIH found in this study. Given the unique cardiopulmonary characteristics often exhibited by highly-trained endurance athletes during intense exercise, which may have consequences for entrainment, future research should examine whether EIH and FL affect the lungs-legs relationship. 


\section{Conclusions}

This study was the first to examine the entrainment of breathing to locomotion in highly trained distance runners. These athletes entrained their breathing rhythms to their stride rates while running at different percentages of their VTs, most often with a 5:3 or 2:1 step-to-breath ratio. With increasing intensity, they more tightly coupled their breaths to their steps, taking close to three steps per breath at 70\% VT and close to two steps per breath at 100 and $110 \%$ VT. The percentage of breaths entrained to the stride rate was similar between intensities. Overall, entrainment occurred for an average of $25 \%$ of breaths, which was significantly greater than that which would occur by chance. Entrainment of breathing to locomotion therefore seems to be a physiological phenomenon in highly trained distance runners. Furthermore, running economy is not associated with the degree of entrainment. 


\section{References}

Aaron, E.A., Seow, K.C., Johnson, B.D., and Dempsey, J.A. (1992). Oxygen cost of exercise hyperpnea: Implications for performance. Journal of Applied Physiology. 72(5):1818-1825.

Abe, D., Yanagawa, K., Yamanobe, K., and Tamura, K. (1998). Assessment of middledistance running performance in sub-elite young runners using energy cost of running. European Journal of Applied Physiology and Occupational Physiology. 77(4):320-325.

Aliverti, A., Cala, S.J., Duranti, R., Ferrigno, G., Kenyon, C.M., Pedotti, A., Scano, G., Sliwinski, P., Macklem, P.T., and Yan, S. (1997). Human respiratory muscle actions and control during exercise. Journal of Applied Physiology. 83(4):1256-1269.

American College of Sports Medicine (1991). Guidelines for Exercise Testing and Prescription. Philadelphia: Lea \& Febiger, p.73.

Ástrand, P.-O. (1952). Experimental Studies of Physical Work Capacity in Relation to Sex and Age. Copenhagen, Denmark: Munksgaard.

Babb, T.G., Viggiano, R., Hurley, B., Staats, B., and Rodarte, J.R. (1991). Effect of mild-to-moderate airflow limitation on exercise capacity. Journal of Applied Physiology. 70(1):223-230.

Bale P., Bradbury, D., and Colley, E. (1986). Anthropometric and training variables related to $10 \mathrm{~km}$ running performance. British Journal Sports Medicine. 20:170-173.

Bale P., Rowell, S., and Colley, E. (1985). Anthropometric and training characteristics of female marathon runners as determinants of distance running performance. Journal of Sports Science. 3:115-126.

Banzett, R.B., Mead, J., Reid, M.B., and Topulos, G.P. (1992). Locomotion in men has no appreciable mechanical effect on breathing. Journal of Applied Physiology. 72(5):1922-1926.

Barstow, T.J. (1994). Characterization of $\mathrm{VO}_{2}$ kinetics during heavy exercise. Medicine and Science in Sports and Exercise. 26(11):1327-1334.

Bassett, D.R. and Howley, E.T. (2000). Limiting factors for maximum oxygen uptake and determinants of endurance performance. Medicine and Science in Sports and Exercise. 32(1):70-84. 
Baudinette, R.V., Gannon, B.J., Runciman, W.B., Wells, S., and Love, J.B. (1987). Do cardiorespiratory frequencies show entrainment with hopping in the tammar wallaby? Journal of Experimental Biology. 129:251-263.

Bayly, W.M., Redman, M.J., and Sides, R.H. (1999). Effect of breathing frequency and airflow on pulmonary function in high-intensity equine exercise. Equine Veterinary Journal. 30(Suppl.):19-23.

Bechbache, R.R. and Duffin, J. (1977). The entrainment of breathing frequency by exercise rhythm. Journal of Physiology. 272(3):553-561.

Bernasconi, P. and Kohl, J. (1993). Analysis of coordination between breathing and exercise rhythms in man. Journal of Physiology. 471:693-706.

Berry, M.J., Bacharach, D.W., and Moritani, T. (1985). Stride frequency and ventilation at constant carbon dioxide output. British Journal of Sports Medicine. 19(4):210-213.

Berry, M.J., Dunn, C.J., Pittman, C.L., Kerr, W.C., and Adair, N.E. (1996). Increased ventilation in runners during running as compared to walking at similar metabolic rates. European Journal of Applied Physiology and Occupational Physiology. 73(3-4):245-250.

Berry, M.J., Robergs, R.A., Weyrich, A.S., and Puntenney, P.J. (1988). Ventilatory responses of trained and untrained subjects during running and walking. International Journal of Sports Medicine. 9(5):325-329.

Billat, V.L., Demarle, A., Slawinski, J., Paiva, M., and Koralsztein, J-P. (2001). Physical and training characteristics of top-class marathon runners. Medicine and Science in Sports and Exercise. 33:2089-2097.

Boggs, D.F. (2002). Interactions between locomotion and ventilation in tetrapods. Comparative Biochemistry and Physiology. Part A. 133:269-288.

Bonsignore, M.R., Morici, G., Abate, P., Romano, S., and Bonsignore, G. (1998). Ventilation and entrainment of breathing during cycling and running in triathletes. Medicine and Science in Sports and Exercise. 30(2):239-245.

Brackenbury, J.H. and Avery, P. (1980). Energy consumption and ventilatory mechanisms in exercising fowl. Comparative Biochemistry and Physiology. 66A:439445.

Bramble, D.M. and Carrier, D.R. (1983). Running and breathing in mammals. Science. 219:251-256. 
Brooks, G.A., Fahey, T.D., White, T.P., and Baldwin, K.M. (2000). Exercise Physiology: Human Bioenergetics and Its Applications. Mountain View, CA: Mayfield, pp.250260,508-509.

Brown, D.D., Knowlton, R.G., Sanjab, P.B., and Szurgot, B.T. (1993). Re-examination of the incidence of exercise-induced hypoxaemia in highly trained subjects. British Journal of Sports Medicine. 27(3):167-170.

Buono, M.J. and Maly, R. (1996). Augmented hyperventilation via normoxic helium breathing does not prevent exercise-induced hypoxemia. Canadian Journal of Applied Physiology. 21(4):264-270.

Butler, P.J. and Woakes, A.J. (1980). Heart rates, respiratory frequency and wing beat frequency of free flying barnacle geese Branta leucopsis. Journal of Experimental Biology. 85:213-226.

Bye, P.T.P., Farkas, G.A., and Roussos, C. (1983). Respiratory factors limiting exercise. Annual Review of Physiology. 45:439-451.

Caiozzo, V.J., Davis, J.A., Ellis, J.F., Azus, J.L., Vandagriff, R., Prietto, C.A., and McMaster, W.C. (1982). A comparison of gas exchange indices used to detect the anaerobic threshold. Journal of Applied Physiology. 53(5):1184-1189.

Cavanagh, P.R. and Kram, R. (1989). Stride length in distance running: Velocity, body dimensions, and added mass effects. Medicine and Science in Sports and Exercise. 21(4):467-479.

Chapman, K.R., D’Urzo, A., and Rebuck, A.S. (1983). The accuracy and response characteristics of a simplified ear oximeter. Chest. 83(6):860-864.

Chapman, R.F., Emery, M., and Stager, J.M. (1998). Extent of expiratory flow limitation influences the increase in maximal exercise ventilation in hypoxia. Respiration Physiology. 113(1):65-74.

Cibella, F., Cuttitta, G., Kayser, B., Narici, M., Romano, S., and Saibene, F. (1996). Respiratory mechanics during exhaustive submaximal exercise at high altitude in healthy humans. Journal of Physiology. 494(3):881-890.

Conley, D. and Krahenbuhl, G. (1980). Running economy and distance running performance of highly trained athletes. Medicine and Science in Sports. 12:357-360.

Cumming, G.R. and Borysyk, L.M. (1972). Criteria for maximum oxygen uptake in men over 40 in a population survey. Medicine and Science in Sports and Exercise. 14:18-22. 
Cumming, G.R. and Friesen, W. (1967). Bicycle ergometer measurement of maximal oxygen uptake in children. Canadian Journal of Physiology and Pharmacology. 45(6):937-946.

Cunningham, D.A., Van Waterschoot, B.M., Paterson, D.H., Lefcoe, M., and Sangal, S.P. (1977). Reliability and reproducibility of maximal oxygen uptake measurement in children. Medicine and Science in Sports and Exercise. 9(2):104-108.

Daniels, J. (1989). Training distance runners - a primer. Sport Science Exchange. 1(11). Chicago, IL: Gatorade Sports Science Institute.

Daniels, J. (1998). Daniels’ Running Formula. Champaign, IL: Human Kinetics.

Daniels, J. and Daniels, N. (1992). Running economy of elite male and elite female runners. Medicine and Science in Sports and Exercise. 24(4):483-489.

Davis, J.A. (1995). Direct determination of aerobic power. In: Maud, P.J. and Foster, C. (Eds.). Physiological Assessment of Human Fitness. Champaign, IL: Human Kinetics, pp.9-17.

Dempsey, J.A. (1986). Is the lung built for exercise? Medicine and Science in Sports and Exercise. 18(2):143-155.

Dempsey, J.A., Hanson, P.G., and Henderson, K.S. (1984). Exercise-induced arterial hypoxaemia in healthy human subjects at sea level. Journal of Physiology. 355:161-175.

Dempsey, J.A., Hanson, D., Pegelow, D., Claremont, A., and Rankin, J. (1982).

Limitations to exercise capacity and endurance: Pulmonary system. Canadian Journal of Applied Sport Science. 7:4-13.

Dempsey, J.A. and Johnson, B.D. (1992). Demand vs. capacity in the healthy pulmonary system. Schweizerische Zeitschrift fur Sportmedizin. 40(2):55-64.

Dempsey, J.A. and Wagner, P.D. (1999). Exercise-induced arterial hypoxemia. Journal of Applied Physiology. 87(6):1997-2006.

Derchak, P.A., Stager, J.M., Tanner, D.A., and Chapman, R.F. (2000). Expiratory flow limitation confounds ventilatory response during exercise in athletes. Medicine and Science in Sports and Exercise. 32(11):1873-1879.

Dueck, R. (2000). Assessment and monitoring of flow limitation and other parameters from flow/volume loops. Journal of Clinical Monitoring. 16:425-432. 
Duncan, G.E., Howley, E.T., and Johnson, B.N. (1997). Applicability of $\mathrm{VO}_{2} \mathrm{max}$ criteria: Discontinuous versus continuous protocols. Medicine and Science in Sports and Exercise. 29(2):273-278.

Durand, F., Mucci, P., and Préfaut, C. (2000). Evidence for an inadequate hyperventilation inducing arterial hypoxemia at submaximal exercise in all highly trained endurance athletes. Medicine and Science in Sports and Exercise. 32(5):926-932.

Elliot, B. and Ackland, T. (1981). Biomechanical effects of fatigue on 10,000-meter running technique. Research Quarterly for Exercise and Sport. 52(2):160-166.

Farrell, P.A., Wilmore, J.H., Coyle, E.F., Billing, J.E., and Costill, D.L. (1979). Plasma lactate accumulation and distance running performance. Medicine and Science in Sports and Exercise. 11(4):338-344.

Fiskerstarand A. and Seiler, K.S. (2004). Training and performance characteristics among Norwegian International Rowers 1970-2001. Scandinavian Journal of Medicine and Science in Sports. 14:303-310.

Folinsbee, L.J., Wallace, E.S., Bedi, J.F., and Horvath, S.M. (1983). Exercise respiratory pattern in elite cyclists and sedentary subjects. Medicine and Science in Sports and Exercise. 15(6):503-509.

Forster, H.V. and Pan, L.G. (1988). Breathing during exercise: Demand, regulation, limitations. Advances in Experimental Medicine and Biology. 227:257-276.

Fox, S.M., Naughton, J.P., and Haskell, W.L. (1971). Physical activity and the prevention of coronary heart disease. Annals of Clinical Research. 3(6):404-432.

Franch, J., Madsen, K., Djurhuus, M.S., and Pedersen, P.K. (1998). Improved running economy following intensified training correlates with reduced ventilatory demands. Medicine and Science in Sports and Exercise. 30(8):1250-1256.

Freedson, P., Kline, G., Porcari, J., Hintermeister, R., McCarron, R., Ross, J., Ward, A., Gurry, M., and Rippe, J. (1986). Criteria for defining $\mathrm{VO}_{2} \max$ : A new approach to an old problem. (Abstract). Medicine and Science in Sports and Exercise. 18:S36.

Funk, G.D., Valenzuela, I.J., and Milson, W.K. (1997). Energetic consequences of coordinating wingbeat and respiratory rhythms in birds. Journal of Experimental Biology. 200:915-920.

Gaesser, G.A. and Poole, D.C. (1996). The slow component of oxygen uptake kinetics in humans. Exercise and Sport Sciences Reviews. 24:35-71. 
Gale, G.E., Torre-Bueno, J.R., Moon, R.E., Saltzman, H.A., and Wagner, P.D. (1985). Ventilation-perfusion inequality in normal humans during exercise at sea level and simulated altitude. Journal of Applied Physiology. 58(3):978-988.

Gavin, T.P. and Stager, J.M. (1999). The effect of exercise modality on exercise-induced hypoxemia. Respiration Physiology. 115(3):317-323.

Gledhill, N., Froese, A.B., Buick, F.J., and Bryan, A.C. (1978). VA/Q inhomogeneity and $\mathrm{AaDO}_{2}$ in man during exercise: Effect of SF6 breathing. Journal of Applied Physiology. 45(4):512-515.

Gledhill, N., Froese, A.B., and Dempsey, J.A. (1977). Ventilation to perfusion distribution during exercise in health. In: Dempsey, J.A. and Reed, C.E. (Eds.). Muscular Exercise and the Lung. Madison, WI: University of Wisconsin Press, pp.325-343.

Gledhill, N., Spriet, L., Froese, A., Wilkes, D., and Meyers, E. (1980). Acid-base status with induced erythrocemia and its influence on arterial oxygenation during heavy exercise. (Abstract). Medicine and Science in Sports and Exercise. 12:122.

Grimby, G. (1969). Respiration in exercise. Medicine and Science in Sports. 1(1):9-14.

Grimby, G., Saltin, B., and Wilhelmsen, L. (1971). Pulmonary flow-volume and pressure-volume relationship during submaximal and maximal exercise in young welltrained men. Bulletin de Physio-Pathologie Respiratoire. 7(1):157-172.

Grimby, G. and Stiksa, J. (1970). Flow-volume curves and breathing patterns during exercise in patients with obstructive lung disease. Scandinavian Journal of Clinical Laboratory Investigation. 25(3):303-313.

Hammond, M.D., Gale, G.E., Kapitan, K.S., Ries, A., and Wagner, P.D. (1986). Pulmonary gas exchange in humans during exercise at sea level. Journal of Applied Physiology. 60(5):1590-1598.

Hansen, J.E. and Casaburi, R. (1987). Validity of ear oximetry in clinical exercise testing. Chest. 91:333-337.

Harms, C.A. and Stager, J.M. (1995). Low chemoresponsiveness and inadequate hyperventilation contribute to exercise-induced hypoxemia. Journal of Applied Physiology. 79(2):575-580.

Hausdorff, J.M., Ladin, Z., and Wei, J.Y. (1995). Footswitch system for measurement of the temporal parameters of gait. Journal of Biomechanics. 28(3):347-351.

Heinrich, B. (2001). Why We Run. New York: Harper Collins, pp.98-100. 
Henke, K., Sharratt, M., Pegelow, D., and Dempsey, J.A. (1988). Regulation of endexpiratory lung volume during exercise. Journal of Applied Physiology. 64(1):135-146.

Hill, A.R., Adams, J.M., Parker, B.E. and Rochester, D.F. (1988). Short-term entrainment of ventilation to the walking cycle in humans. Journal of Applied Physiology. 65(2):570578.

Hill, A.V. and Lupton, H. (1923). Muscular exercise, lactic acid, and the supply and utilization of oxygen. Quarterly Journal of Medicine. 16:135-171.

Holmgren, A. and Linderholm, H. (1958). Oxygen and carbon dioxide tensions of arterial blood during heavy and exhaustive exercise. Acta Physiologica Scandinavica. 44(34):203-215.

Hopkins, S.R., Gavin, T.P., Siafakas, N.M., Haseler, L.J., Olfert, I.M., Wagner, H., and Wagner, P.D. (1998). Effect of prolonged, heavy exercise on pulmonary gas exchange in athletes. Journal of Applied Physiology. 85(4):1523-1532.

Hopkins, S.R., McKenzie, D.C., Schoene, R.B., Glenny, R.W., and Robertson, H.T. (1994). Pulmonary gas exchange during exercise in athletes. I. Ventilation-perfusion mismatch and diffusion limitation. Journal of Applied Physiology. 77(2):912-917.

Hopkins, S.R., Schoene, R.B., Henderson, W.R., Spragg, R.G., Martin, T.R., and West, J.B. (1997). Intense exercise impairs the integrity of the pulmonary blood-gas barrier in elite athletes. American Journal of Respiratory and Critical Care Medicine. 155:10901094.

Howley, E.T., Bassett, D.R., and Welch, H.G. (1995). Criteria for maximal oxygen uptake: Review and commentary. Medicine and Science in Sports and Exercise. 27(9):1292-1301.

Hurst, C.A., Kirby, R.L., and MacLeod, D.A. (2001). Locomotor-respiratory coupling during axillary crutch ambulation. American Journal of Physical Medicine and Rehabilitation. 80:831-838.

Iscoe, S. (1981). Respiratory and stepping frequencies in conscious exercising cats. Journal of Applied. Physiology. 51(4):835-839.

Issekutz, B., Birkhead, N.C., and Rodahl, K. (1962). Use of respiratory quotients in assessment of aerobic work capacity. Journal of Applied Physiology. 17:47-50.

Issekutz, B. and Rodahl, K. (1961). Respiratory quotient during exercise. Journal of Applied Physiology. 16:606-610. 
Iyengar, B.K.S. (1985). Light on Prãnãyãma: The Yogic Art of Breathing. New York, NY: Crossroad.

Jasinskas, C.L., Wilson, B.A., and Hoare, J. (1980). Entrainment of breathing rate to movement frequency during work at two intensities. Respiration Physiology. 42:199-209.

Jensen, J.I., Lyager, S., and Pedersen, O.F. (1980). The relationship between maximal ventilation, breathing pattern and mechanical limitation of ventilation. Journal of Physiology. 309:521-532.

Jensen, L.A., Onyskiw, J.E., and Prasad, N.G. (1998). Meta-analysis of arterial oxygen saturation monitoring by pulse oximetry in adults. Heart and Lung. 27(6):387-408.

Johnson, B.D., Beck, K.C., Zeballos, R.J., and Weisman, I.M. (1999b). Advances in pulmonary laboratory testing. Chest. 116(5):1377-1387.

Johnson, B.D., Reddan, W.G., Pegelow, D.F., Seow, K.G., and Dempsey, J.A. (1991a). Flow limitation and regulation of function residual capacity during exercise in a physically active aging population. American Review of Respiratory Disease. 143(5):960967.

Johnson, B.D., Reddan, W.G., Seow, K.G., and Dempsey, J.A. (1991b). Mechanical constraints on exercise hyperpnea in a fit aging population. American Review of Respiratory Disease. 143(5):968-977.

Johnson, B.D., Saupe, K.W., and Dempsey, J.A. (1992). Mechanical constraints on exercise hyperpnea in endurance athletes. Journal of Applied Physiology. 73(3):874-886.

Johnson, B.D., Scanlon, P.D., and Beck, K.C. (1995). Regulation of ventilatory capacity during exercise in asthmatics. Journal of Applied Physiology. 79(3):892-901.

Johnson, B.D., Weisman, I.M., Zeballos, R.J., and Beck, K.C. (1999a). Emerging concepts in the evaluation of ventilatory limitation during exercise: The exercise tidal flow-volume loop. Chest. 116(2):488-503.

Jones, A.M. (1998). A five year physiological case study of an Olympic runner. British Journal of Sports Medicine. 32(1):39-43.

Jones, A.M. and Carter, H. (2000). The effect of endurance training on parameters of aerobic fitness. Sports Medicine. 29(6):373-386.

Jones, J.H. and Lindstedt, S.L. (1993). Limits to maximal performance. Annual Review of Physiology. 55:547-569. 
Kamau, J.M. (1990). The entrainment of breathing rhythm to stride frequency in the dikdik antelope (Rhynchotragus kirki) with observations on the thermoregulatory consequences. Comparative Biochemistry and Physiology. 96A(2):291-295.

Karp, J.R. (2007). Training characteristics of qualifiers for the U.S. Olympic Marathon Trials. International Journal of Sports Physiology and Performance. 2(1):72-92.

Kelso, J.A.S. (1995). Dynamic Patterns: The Self-Organization of Brain and Behavior. Cambridge, MA: Massachusetts Institute of Technology.

Knudson, R.J., Slatin, R.C., Lebowitz, M.D., and Burrows, B. (1976). The maximal expiratory flow-volume curve. Normal standards, variability, and effects of age. American Review of Respiratory Disease. 113(5):587-600.

Lafortuna, C.L., Reinach, E., and Saibene, F. (1996). The effects of locomotorrespiratory coupling on the pattern of breathing in horses. Journal of Physiology. 492(2):587-596.

Landberg, T., Mailhot, J.D., and Brainerd, E.L. (2003). Lung ventilation during treadmill locomotion in a terrestrial turtle, Terrapene carolina. Journal of Experimental Biology. 206:3391-3404.

Leaver, D.G. and Pride, N.B. (1971). Flow-volume curves and expiratory pressures during exercise in patients with chronic airways obstruction. Scandinavian Journal of Respiratory Diseases. 77(Suppl.):23-27.

Liggins, A.B. and Bowker, P. (1991). A simple low cost footswitch. Journal of Biomedical Engineering. 13(1):87-88.

Maclennan, S.E., Silvestri, G.A., Ward, J., and Mahler, D.A. (1994). Does entrained breathing improve the economy of rowing? Medicine and Science in Sports and Exercise. 26(5):610-614.

Mahler, D.A., Shuhart, C.R., Brew, E., and Stukel, T.A. (1991). Ventilatory responses and entrainment of breathing during rowing. Medicine and Science in Sports and Exercise. 23(2):186-192.

Marciniuk, D.D., Watts, R.E., and Gallagher, C.G. (1994). Dead space loading and exercise limitation in patients with interstitial lung disease. Chest. 105(1):183-189.

Martinez, F.J., Orens, J.B., Whyte, R.I., Graf, L., Becker, F.S., and Lynch, J.P. 3rd. (1996). Lung mechanics and dyspnea after lung transplantation for chronic airflow obstruction. American Journal of Respiratory and Critical Care Medicine. 153(5):15361543. 
McClaran, S.R., Wetter, T.J., Pegelow, D.F., and Dempsey, J.A. (1999). Role of expiratory flow limitation in determining lung volumes and ventilation during exercise. Journal of Applied Physiology. 86(4):1357-1366.

McDermott, W.J., Van Emmerik, R.E.A., and Hamill, J. (2003). Running training and adaptive strategies of locomotor-respiratory coordination. European Journal of Applied Physiology. 89:435-444.

McKenzie, D.C., Lama, I.L., Potts, J.E., Sheel, A.W., and Coutts, K.D. (1999). The effect of repeat exercise on pulmonary diffusing capacity and EIH in trained athletes. Medicine and Science in Sports and Exercise. 31(1):99-104.

McMurray, R.G. and Ahlborn, S.W. (1982). Respiratory responses to running and walking at the same metabolic rate. Respiration Physiology. 47(2):257-265.

McMurray, R.G. and Smith, L.G. (1985). Ventilatory responses when altering stride frequency at a constant oxygen uptake. Respiration Physiology. 62(1):117-124.

Miyachi, M. and Tabata, I. (1992). Relationship between arterial oxygen desaturation and ventilation during maximal exercise. Journal of Applied Physiology. 73(6):2588-2591.

Morgan, D.W., Bransford, D.R., Costill, D.L., Daniels, J.T., Howley, E.T., and Krahenbuhl, G.S. (1995). Variation in the aerobic demand of running among trained and untrained subjects. Medicine and Science in Sports and Exercise. 27(3):404-409.

Morgan, D.W. and Daniels, J.T. (1994). Relationship between $\mathrm{VO}_{2} \mathrm{max}$ and aerobic demand of running in elite distance runners. International Journal of Sports Medicine. 15(7):426-429.

Morgan, D.W., Martin, P.E., and Krahenbuhl, G.S. (1989). Factors affecting running economy. Sports Medicine. 7(5):310-330.

Morgan, D.W., Strohmeyer, H.S., Daniels, J.T., Beaudoin, C.C., Craib, M.W., Borden, R.A., Greer, P.J., and Burleson, C.L. (1996). Short-term changes in 10-km race pace aerobic demand and gait mechanics following a bout of high-intensity distance running. European Journal of Applied Physiology and Occupational Physiology. 73(3-4):267-272.

Morris, J.F. (1976). Spirometry in the evaluation of pulmonary function. Western Journal of Medicine. 125:110-118.

Mota, S., Casan, P., Drobnic, F., Giner, J., Ruiz, O., Sanchis, J., and Milic-Emili, J. (1999). Expiratory flow limitation during exercise in competition cyclists. Journal of Applied Physiology. 86(2):611-616. 
Myers, J., Walsh, D., Buchanan, N., and Froelicher, V.F. (1989). Can maximal cardiopulmonary capacity be recognized by a plateau in oxygen uptake? Chest. 96(6):1312-1316.

Noakes, T.D. (1988). Implications of exercise testing for prediction of athletic performance: A contemporary perspective. Medicine and Science in Sports and Exercise. 20(4):319-330.

Norton, K.I., Squires, B., Norton, L.H., Craig, N.P., McGrath, P., and Olds, T.S. (1995). Exercise stimulus increases ventilation from maximal to supramaximal intensity. European Journal of Applied Physiology and Occupational Physiology. 70(2):115-125.

Olafsson, S. and Hyatt, R.E. (1969). Ventilatory mechanics and expiratory flow limitation during exercise in normal subjects. Journal of Clinical Investigation. 48(3):564-573.

Paterson, D.J., Wood, G.A., Marshall, R.N., Morton, A.R., and Harrison, A.B.C. (1987). Entrainment of respiratory frequency to exercise rhythm during hypoxia. Journal of Applied Physiology. 62(5):1767-1771.

Paterson, D.J., Wood, G.A., Morton, A.R., and Henstridge, J.D. (1986). The entrainment of ventilation frequency to exercise rhythm. European Journal of Applied Physiology. 55:530-537.

Pellegrino, R., Brusasco, V., Rodarte, J.R., and Babb, T.G. (1993). Expiratory flow limitation and regulation of end-expiratory lung volume during exercise. Journal of Applied Physiology. 74(5):2552-2558.

Persegol, L., Jordan, M., and Viala, D. (1991). Evidence for the entrainment of breathing by locomotor pattern in human. Journal of Physiology (Paris). 85(1):38-43.

Potter, W.A., Olafsson, S., and Hyatt, R.E. (1971). Ventilatory mechanics and expiratory flow limitation during exercise in patients with obstructive lung disease. Journal of Clinical Investigation. 50(4):910-919.

Powers, S.K., Dodd, S., Lawler, J., Landry, G., Kirtley, M., McKnight, T., and Grinton, S. (1988). Incidence of exercise induced hypoxemia in elite endurance athletes at sea level. European Journal of Applied Physiology and Occupational Physiology. 58(3):298302.

Powers, S.K., Lawler, J., Dempsey, J.A., Dodd, S., and Landry, G. (1989). Effects of incomplete pulmonary gas exchange on $\mathrm{VO}_{2} \mathrm{max}$. Journal of Applied Physiology. 66(6):2491-2495. 
Powers, S.K., Martin, D., Cicale, M., Collop, N., Huang, D., and Criswell, D. (1992). Exercise-induced hypoxemia in athletes: role of inadequate hyperventilation. European Journal of Applied Physiology and Occupational Physiology. 65(1):37-42.

Powers, S.K., Martin, D., and Dodd, S. (1993). Exercise-induced hypoxaemia in elite endurance athletes. Sports Medicine. 16(1):14-22.

Powers, S.K. and Williams, J. (1987). Exercise-induced hypoxaemia in highly trained athletes. Sports Medicine. 4(1):46-53.

Préfaut, C. Anselme, F., Caillaud, C., and Massé-Biron, J. (1994). Exercise-induced hypoxemia in older athletes. Journal of Applied Physiology. 76(1):120-126.

Raßler, B. and Kohl, J. (1996). Analysis of coordination between breathing and walking rhythm in humans. Respiration Physiology. 106(3):317-327.

Regnis, J.A., Donnelly, P.M., Robinson, M., Alison, J.A., and Bye, P.T. (1996). Ventilatory mechanics at rest and during exercise in patients with cystic fibrosis. American Journal of Respiratory and Critical Care Medicine. 154(5):1418-1425.

Rice, A.J., Scroop, G.C., Thornton, A.T., McNaughton, N.S., Rogers, K.J., Chapman, M.J., Greville, H.W., Scicchitano, R., and Gore, C.J. (2000). Arterial hypoxaemia in endurance athletes is greater during running than cycling. Respiration Physiology. 123(3):235-246.

Rice, A.J., Thornton, A.T., Gore, C.J., Scroop, G.C., Greville, H.W., Wagner, H., Wagner, P.D., and Hopkins, S. (1999). Pulmonary gas exchange during exercise in highly trained cyclists with arterial hypoxemia. Journal of Applied Physiology. 87(5):18021812.

Robergs, R.A. and Landwehr, R. (2002). The surprising history of the " $\mathrm{HR}_{\max }=220$-age" equation. Journal of Exercise Physiology Online. 5(2).

Robergs, R.A., Quintana, R., Parker, D.L., and Frankel, C.C. (1998). Multiple variables explain the variability in the decrement in $\mathrm{VO}_{2}$ max during acute hypobaric hypoxia. Medicine and Science in Sports and Exercise. 30(6):869-879.

Robergs, R.A. and Roberts, S.O. (1997). Exercise Physiology: Exercise, Performance, and Clinical Applications. New York: Mosby, p.293-295,483,650.

Ross, J.D. and Ashman, R.B. (1987). A thin foot switch. Journal of Biomechanics. 20(7):733-734. 
Rowell, L.B., Taylor, H.L., Wang, Y., and Carlson W.S. (1964). Saturation of arterial blood with oxygen during maximal exercise. Journal of Applied Physiology. 19(2):284286.

Rowland, T.W. and Cunningham, L.N. (1992). Oxygen uptake plateau during maximal treadmill exercise in children. Chest. 101(2):485-489.

Saunders, P.U., Telford, R.D., Pyne, D.B., Cunningham, R.B., Gore, C.J., Hahn, A.G., and Hawley, J.A. (2004). Improved running economy in elite runners after 20 days of simulated moderate-altitude exposure. Journal of Applied Physiology. 96:931-937.

Scrimgeour, A.G., Noakes, T.D., Adams, B., and Myburgh, K. (1986). The influence of weekly training distance on fractional utilization of maximum aerobic capacity in marathon and ultramarathon runners. European Journal of Applied Physiology and Occupational Physiology. 55(2):202-209.

Seiler, K.S. and Kjerland, G.O. (2006). Quantifying training intensity distribution in elite endurance athletes: is there evidence for an "optimal" distribution? Scandinavian Journal of Medicine Science in Sports. 16:49-56.

Shephard, R.J. (1975). Respiratory gas exchange ratio and prediction of aerobic power. Journal of Applied Physiology. 38(3):402-406.

Simons, R.S. (1999). Running, breathing, and visceral motion in the domestic rabbit (Oryctolagus cuniculus): Testing visceral displacement hypothesis. Journal of Experimental Biology. 202:563-577.

Sjodin, B. and Svedenhag, J. (1985). Applied physiology of marathon running. Sports Medicine. 2(2):83-99.

Steinacker, J.M., Both, M., and Whipp, B.J. (1993). Pulmonary mechanics and entrainment of respiration and stroke rate during rowing. International Journal of Sports Medicine. 14(Suppl. 1):S15-S19.

Stubbing, D.G., Pengelly, L.D., Morse, J.L.C., and Jones, N.L. (1980a). Pulmonary mechanics during exercise in normal males. Journal of Applied Physiology. 49(3):506510.

Stubbing, D.G., Pengelly, L.D., Morse, J.L.C., and Jones, N.L. (1980b). Pulmonary mechanics during exercise in subjects with chronic airflow obstruction. Journal of Applied Physiology. 49(3):511-515.

Takano, N. (1995). Phase relation and breathing pattern during locomotor/respiratory coupling in uphill and downhill running. Japanese Journal of Physiology. 45(1):47-58. 
Tanner, D.A. (2001). Exercise Mode and Ventilatory Strategies. Unpublished doctoral dissertation, Indiana University, Bloomington, IN.

Taylor, H.L., Buskirk, E., and Henschel, A. (1955). Maximal oxygen intake as an objective measure of cardio-respiratory performance. Journal of Applied Physiology. 8:73-80.

Todaro, A., Leonardi, L.M., Besi, M., Faccini, P., Sardella, F., Menchinelli, C., and Gallozzi, C. (1995). Pulmonary gas exchange in athletes with exercise-induced hypoxaemia. Journal of Sports Medicine and Physical Fitness. 35(2):114-123.

Torre-Bueno, J.R., Wagner, P.D., Saltzman, H.A., Gale, G.E., and Moon, R.E. (1985). Diffusion limitation in normal humans during exercise at sea level and simulated altitude. Journal of Applied Physiology. 58(3):989-995.

Turner, D.L. (1991). Cardiovascular and respiratory control mechanisms during exercise: An integrated view. Journal of Experimental Biology. 160:309-340.

Turner, S., McKenzie, D., Coutts, K., Wilcox, P., and Jespersen, D. (1992). The effects of intense exercise on DLCO and $\% \mathrm{~S}_{\mathrm{a}} \mathrm{O}_{2}$ in competitive athletes. (Abstract). Physiologist. $35: 231$.

van Alphen, J. and Duffin, J. (1994). Entrained breathing and oxygen consumption during treadmill walking. Canadian Journal of Applied Physiology. 19(4):432-440.

Wagner, P.D., Gillespie, J.R., Landgren, G.L., Fedde, M.R., Jones, B.W., DeBowes, R.M., Pieschl, R.L., and Erickson, H.H. (1989). Mechanism of exercise-induced hypoxemia in horses. Journal of Applied Physiology. 66(3):1227-1233.

Warren, G.L., Cureton, K.J., Middendorf, W.F., Ray, C.A., and Warren, J.A. (1991). Red blood cell pulmonary capillary transit time during exercise in athletes. Medicine and Science in Sports and Exercise. 23(12):1353-1361.

West, J.B. (2000a). Respiratory Physiology: The Essentials. Baltimore: Lippincott Williams \& Wilkins.

West, J.B. (2000b). Pulmonary capillary stress failure. Journal of Applied Physiology. 89:2483-2489.

West, J.B. (2003). Thoughts on the pulmonary blood-gas barrier. American Journal of Physiology: Lung, Cellular and Molecular Physiology. 285:L501-L513. 
Weston, A.R., Mbambo, Z., and Myburgh, K.H. (2000). Running economy of African and Caucasian distance runners. Medicine and Science in Sports and Exercise. 32(6):1130-1134.

Whipp, B.J. (1994). The slow component of $\mathrm{O}_{2}$ uptake kinetics during heavy exercise. Medicine and Science in Sports and Exercise. 26(11):1319-1326.

Whipp, B.J. and Wasserman, K. (1969). Alveolar-arterial gas tension differences during graded exercise. Journal of Applied Physiology. 27(3):361-365.

Williams, J.H., Powers, S.K., and Stuart, M.K. (1986). Hemoglobin desaturation in highly trained athletes during heavy exercise. Medicine and Science in Sports and Exercise. 18(2):168-173.

$\mathrm{Xu}, \mathrm{F}$. and Rhodes, E.C. (1999). Oxygen uptake kinetics during exercise. Sports Medicine. 27(5):313-327.

Younes, M. and Kivinen, G. (1984). Respiratory mechanics and breathing pattern during and following maximal exercise. Journal of Applied Physiology. 57(6):1773-1782.

Young, I.S., Alexander, R., Woakes, A.J., Butler, P.J., and Anderson, L. (1992). The synchronization of ventilation and locomotion in horses (Equus caballus). Journal of Experimental Biology. 166:19-31.

Zavorsky, G.S., Walley, K.R., and Russell, J.A. (2003). Red cell pulmonary transit times through the healthy human lung. Experimental Physiology. 88(2):191-200.

Żołądź, J.A. and Korzeniewski, B. (2001). Physiological background of the change point in $\mathrm{VO}_{2}$ and the slow component of oxygen uptake kinetics. Journal of Physiology and Pharmacology. 52(2):167-184. 
Appendix A 


\section{Human Research Review Committee}

MSC 084560 BMSB Room B71

1 University of New Mexico Albuquerque, NM 87131-0001

(505) 272-1129 Facsimile (505) 272-0803

http://hsc.unm.edu/som/research/hrre/

$8 / 18 / 2006$

Robert Robergs, PhD

Physical Perform Dev Phy Perf Dev

MSC: 042610

Albuquerque, New Mexico 87131

SUBJECT: HRRC Approval of New Research Protocol

HRRC\#: 06-186

Study Title: Entrainment of breathing to locomotion in elite distance runners

Type of Review: Full Committee Review

Approval Date: 18-Aug-2006

Expiration Date: 17-Jul-2007

Dear Dr. Robergs:

The Human Research Review Committee (HRRC) has reviewed and approved* the above-mentioned research protocol including the following:

HRRC Application received 6/23/2006

UNMHSC Consent Form v6/23/2006

Investigator Protocol v5/5/2006

Physical Activity Readiness Questionnaire (PAR-Q)

Recruitment E-mail Correspondence

UNMHSC HIPAA Form v5/31/2006

Consent decision:

Requires a signed consent form

HIPAA Authorization on record; signed HIPAA required

Sincerely,

William Reed, M.D.

Executive Chairman

Human Research Review Committee

\footnotetext{
* Under the provisions of this institution's Federal Wide Assurance (FWA00003255), the HRRC has determined that this proposal provides adequate safeguards for protecting the rights and welfare of the subjects involved in the study and is in compliance with HHS Regulations (45 CFR 46), FDA Regulations (21 CFR 50, 56).
} 
Human Research Review Committee

MSC 084560 BMSB Room B71

1 University of New Mexic 0 Albuquerque, NM 87131-0001

(505) 272-1129 Facsimile (505) 272-0803

http://hsc.unm.edu/som/research/hrrc/

$9 / 5 / 2006$

Robert Robergs, PhD

Physical Perform Dev Phy Perf Dev

MSC: 042610

Albuquerque, New Mexico 87131

SUBJECT: HRRC Approval of Amendment/Change

HRRC\#: 06-186

Study Title: Entrainment of breathing to locomotion in elite distance runners

Review Date: 05-Sep-2006

Type of Review: Expedited Review

Approval Date: 05-Sep-2006 Expiration Date: 17-Jul-2007

Dear Dr. Robergs:

The Human Research Review Committee (HRRC) has reviewed and approved* the following requested amendment(s) and/or changes to the above mentioned protocol:

Revised consent form dated 09/01/06 submitted under the amendment/change form dated 09/01/06.

Consent forms attached.

Sincerely,

William Reed, M.D.

Executive Chairman

Human Research Review Committee

\footnotetext{
* Under the provisions of this institution's Federal Wide Assurance (FWA00003255), the HRRC has deternined that this proposal provides adequate safeguards for protecting the rights and welfare of the subjects involved in the study and is in compliance with HHS Regulations (45 CFR 46), FDA Regulations (2I CFR 50,56).
} 


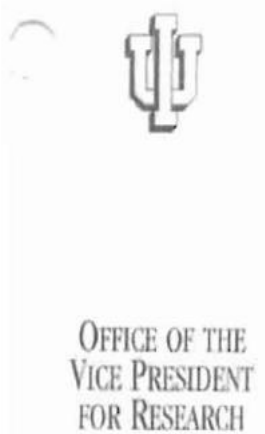

Bloomisctos Canples

COMBITTHE FOR THE

Protection of

Homav Sibjects

Location:

Indiana Unimersity

Camichael Conter 1.03

530 East Kirkwood Avenue

Bloomington, Indiana

Mailing Address:

P.0. Box 1847

Bloomington, Indianla 47402

$812-855-3067$

Fax: $812-856-1535$

E-mail:

b_hsc@indiana.extu

WWW Address

http //www. research, indiana edu/schcomp/hmpghtml

\section{NOTICE OF APPROVAL EXPEDITED REVIEW}

TO: Jason Karp

DATE: August 31, 2006

FROM: Human Subjects Risk Compliance

RE: Protocol entitled: Entrainment of Breathing to Locomotion in Elite Distance Runners Protocol \#: 06-11307

The Human Subjects Committee (HSC) has reviewed and approved the research protocol referenced above. As the principal investigator of this study you assume the following reporting responsibilities:

CONTINUING REVIEW: A status report must be filed with the committee. You are required to apply for renewal of approval at least once a year for as long as the study is active. The HSC will attempt to notify you by e-mail before approval expires, but it is ultimately your responsibility to make sure your approval does not expire. This study is approved from August 30, 2006 to August 29, 2007.

AMENDMENTS: Investigators are required to report on the Study Amendment Form ANY changes to the research study (such as design, procedures, study information sheet/consent form, or subject population, including size). Changes may not be initiated until HSC approval has been given. The PDF interactive Study Amendment Form may be found at: http://www.research.indiana.edu/rschcomp/pdf/amendpdf2.pdf

AUDIT OR INSPECTION REPORTS: Investigators are required to provide to the HSC a copy of any audit or inspection reports or findings issued to them by regulatory agencies, cooperative research groups, contract research organizations, the sponsor, or the funding agency.

COMPLETION: You are required to notify the HSC office when your study is completed (data analysis finished). Please contact the HSC office for the appropriate form to use.

CONSENT FORMS: All subjects should be given a copy of the stamped approved consent form. You must retain signed consent documents for at least three years past completion of the research activity.

We suggest you keep this letter with your copy of the approved protocol. Please refer to the exact project title and protocol number in any future correspondence with our office. All correspondence must be typed.

Enclosures: Documentation of Review and Approval

Federal Wide Assurance \#FWA00003544-IRB00000222

For additional FWA information, see the Web site at http://www.iupui.edu/ resgrad/spon/fwa.htm 
INDIANA UNIVERSITY
BLOOMINGTON CAMPUS COMMITTEE FOR THE PROTECTION OF HUMAN SUBJECTS

DOCUMENTATION OF REVIEW AND APPROVAL

AUG 282006

Study $=06-1 / 307$

Research Project Utilizing Human Subjects

HUMA SUEJECT:

TITLE OF PROJECT Entrainment of Breathing to Locomotion in Elive Distanco Runners

PROJECT DURATION - START DATE $01 / 1 / 2006$

PRIN. INVESTIGATOR Jason Karp, M.S. SCHOOLJDEPARTMENT HPER/Kinesiology

ADDRESS 1705 Girard Blvd. S.E. Aot. 6

E-MAll runmangindiana.edu PHONE 505.242.0363

Albucuerque, NM 87106

RANK Faculty O Res. ScientistO Post-DocO Staff $O$ Student: undergradO masters $O$ PhDIEdD $\odot$

If PI's rank is OTHER than faculty, name of faculty overseeing the research (SPONSOR) David Koceja, Ph.D.

SPONSOR'S E-MAIL kOceja@indiana .odu CAMPUS ADOR HPER Bulding 032, Eloomington, IN PHONE(812) 855-7302

FUNDING AGENCY and \#

As the principal investigator, my signature testifies that I pledge to conform to the following:

As one engaged in investigation utilizing human subjects, I acknowledge the rights and welfare of the human subject involved

I acknowledge my responsibility as an investigator to secure the informed consent of the subject by explaining the procedures, in so far as possible, and by describing the risks as weighed against the potential benefits of the investigation

I assure the Committee that all procedures performed under the project will be conducted in accordance with those Federal regulations and University policies which govern research involving human subjects. Any deviation from the project (e.g., change in principal investigator, research methodology, subject recruitment procedures, etc.) will be submitted to the Committee in the form of an amendment for its approval prior to implementation.

PRINCIPAL INVESTIGATOR

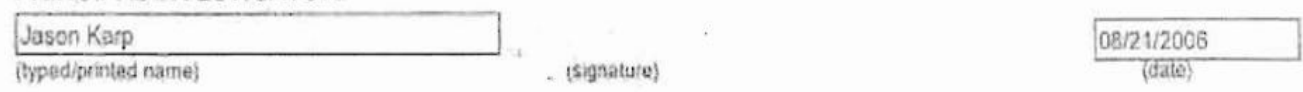

As the faculty sponsor, my signature testifies that i have reviewed this application and that I will oversee the research in its entirety, through the termination report.

FACULTY SPONSOR:

Dawid Kocoja

(typediprinted name)

Neveture)

$08: 21 / 2006$

\{datel

\section{CAMPUS LEVEL REVIEW}

This protocol for the use of human subjects has been reviewed and approved by the Indiana University/Bloomington Campus Committee for the Protection of Human Subjects

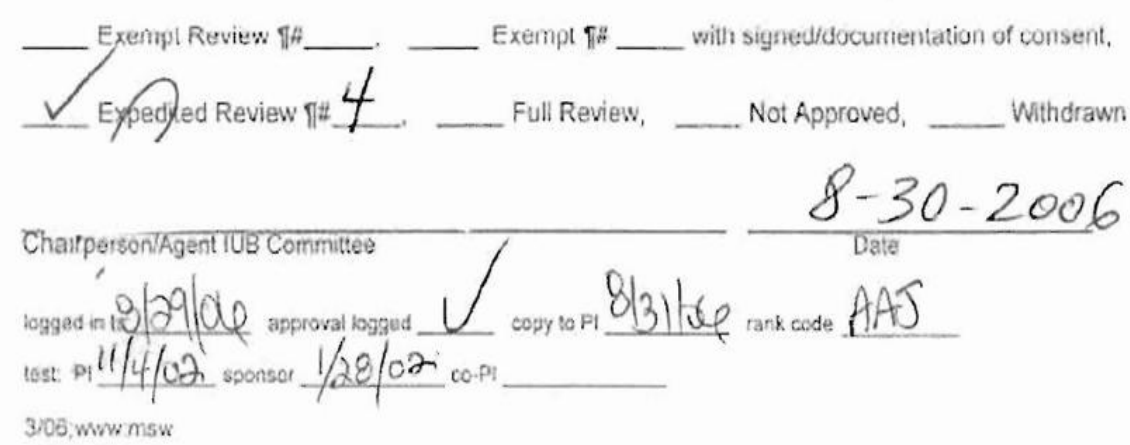

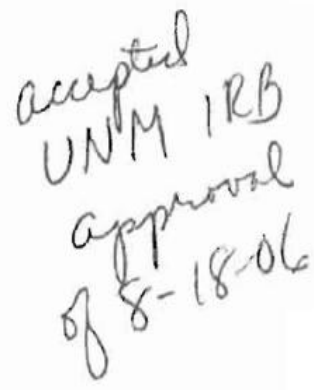




\section{UNIVERSITY OF NEW MEXICO HEALTH SCIENCES CENTER}

\section{CONSENT TO PARTICIPATE IN RESEARCH}

\section{Entrainment of Breathing to Locomotion in Highly-Trained Distance Runners}

\section{PURPOSE AND BACKGROUND}

Robert Robergs, Ph.D., the Principal Investigator, and Jason Karp, research assistant, are conducting a research study. The purpose of the study is to examine how highly-trained distance runners breathe at different intensities.

You are being asked to participate in this study because of your status as an highly-trained distance runner. Approximately 26 subjects from the University of New Mexico CrossCountry team and Albuquerque, New Mexico community will participate in this study.

\section{PROCEDURES}

If you decide to participate, you will be asked to report to the Exercise Physiology Laboratories (EPL) on 2 separate occasions for testing that will take approximately 1.5 to 2 hours each.

For the first testing session, you will be asked to complete a health history questionnaire and you will perform a maximal oxygen consumption $\left(\mathrm{VO}_{2} \mathrm{max}\right)$ test, which consists of a maximal exercise bout on a treadmill with the intensity increasing throughout the test until exhaustion is reached. Electrodes will be placed on your chest to record your heart rate during the test, and you will wear a clip on your finger to measure blood oxygen levels. You will be asked to wear a nose clip and breathe through a plastic breathing valve. The valve is similar to a snorkel and is attached to hoses to allow monitoring of the air you exhale. Prior to the start of the test, you will warm-up for 10 minutes using progressively increasing speeds, culminating with a speed close to your 5,000-meter race pace for the last 2 minutes. You will then recover for 5 minutes. The test will begin with the treadmill speed at 2.0 miles per hour ( $\mathrm{mph}$ ) below your final warm-up speed (approximately 5,000-meter race pace) and 0\% grade. Every 2 minutes, the speed will

Initials

HRRC\# 06-186

Version: 11/01/06

Approv ed: 11/30/06

Expires: 7/17/2007

The University of New Mexico Human Research Review Committee 
increase $1.0 \mathrm{mph}$ until 5,000-meter race pace is reached. After 2 minutes at 5,000-meter race pace and $0 \%$ grade, the grade of the treadmill will increase by $2 \%$ every minute until you can no longer continue running. The test will be terminated when either (1) you have reached volitional exhaustion, or (2) there is no further increase in $\mathrm{VO}_{2}$ with an increase in treadmill grade. Immediately before and after the test (and again every 10 minutes for 30 minutes following the test), you will be asked to perform 3 maximal breathing maneuvers as part of pulmonary function testing, during which you will exhale and inhale as deep and as fast as you can. You will be verbally coached through each maneuver. The first testing session will take approximately 1.5 to 2 hours.

For the second testing session, you will perform two tests separated by 30 minutes. For the first test, you will run on a treadmill at $0 \%$ grade for six minutes at each of three submaximal intensities $(75,90$, and $100 \%$ of the speed at your ventilatory threshold, which will be determined from the $\mathrm{VO}_{2}$ max test), with each run separated by five minutes of recovery. As explained above, you will be asked to wear a nose clip and breathe through a plastic breathing valve. For the second test, you will run on the treadmill at $0 \%$ grade for three minutes at each of four intensities: $75,90,100$, and $110 \%$ of the speed at your ventilatory threshold. Again, you will be asked to wear a nose clip and breathe through a plastic breathing valve. For this test, special insoles will be placed in your running shoes to determine heel strike and toe-off while you run.

\section{RISKS AND DISCOMFORTS}

Possible side effects of maximal exertion include brief feelings of nausea, lightheadedness, muscle cramps, or dizziness after completion of exercise. In addition, you may have discomfort associated with running to maximal exertion while breathing through a mouthpiece. In people who are highly endurance-trained, exercise testing with gradually increasing workloads to the point of fatigue has a very minimal risk of death $(<0.005 \%)$ and complications of the heart $(<0.001 \%)$. All personnel conducting the test are trained in cardiac life support, and are competent in exercise testing procedures. Furthermore, all research team members have previous exercise testing experience and are aware of the signs and symptoms that are associated with possible adverse reactions during exercise.

Confidentiality: There may be a possible risk or inconvenience related to a loss of privacy and confidentiality in this study.

Initials

HRRC\# 06-186

Version: $11 / 01 / 06$

Approv ed: 11/30/06

Expires: 7/17/2007

The University of New Mexico Human Research Review Committee 


\section{BENEFITS}

Results from the tests of maximal oxygen consumption $\left(\mathrm{VO}_{2} \mathrm{max}\right)$ and running economy will give you information regarding your aerobic fitness level that may be used for training purposes. Benefits to society include an understanding of how highly-trained human endurance athletes breathe while running, which may give us insight into an important aspect of pulmonary physiology.

\section{ALTERNATIVES TO PARTICIPATION}

The only alternative is to not participate in this study.

\section{CONFIDENTIALITY}

Participation in research will involve a loss of privacy, but all information obtained during the course of your participation will be accessible only to the investigator and coinvestigator. You will be identified by code to preserve your confidentiality. Also, your file will be kept in locked cabinets accessible only to the investigator and co-investigator. All identifying links to the study will be destroyed within one year of the study's completion. Representatives from the University of New Mexico Health Sciences Center Human Research Review Committee that oversees human subject research will be permitted access to your records. Also, your participation in the study and information in your study records may be disclosed as otherwise provided by law. However, your name will not be used in published manuscripts concerning this investigation.

\section{COST OF STUDY}

You will not be charged for any of the study's procedures.

\section{EMERGENCY TREATMENT AND COMPENSATION FOR INJURY}

If you are injured as a result of this study, the University of New Mexico Health Sciences Center (UNMHSC) will provide you with emergency treatment, at usual charge. No commitment is made by the UNMHSC to provide free medical care or money for injuries to participants in this study. If you have any questions about these issues, or believe that you have been treated carelessly in the study, please contact the Human Research Review Committee at the University of New Mexico Health Sciences Center, Albuquerque, New Mexico 87131, (505) 272-1129 for more information.

Initials

HRRC\# 06-186

Version: 11/01/06

Approv ed: 11/30/06

Expires: $7 / 17 / 2007$

The University of New Mexico Human Research Review Committee 


\section{PAYMENT FOR PARTICIPATION}

There will be no financial compensation for your participation in this study.

\section{NEW FINDINGS}

You will be informed of any significant new findings that become available during the course of the study, such as changes in the risks or benefits resulting from participation in the research or new alternatives to participation that might change your mind about participating.

\section{WITHDRAWAL}

Your participation in this study is strictly voluntary. You have the right to choose not to participate or to withdraw your participation at any point in this study without prejudice to your future health care or other services to which you are otherwise entitled. The investigator may withdraw you from this research if circumstances arise which warrant doing so. For example, if it is discovered that you have a history of pulmonary dysfunction or disease, including exercise-induced bronchoconstriction, you will be withdrawn from the study.

\section{QUESTIONS}

If you have any questions, concerns or complaints at any time about the research study, please feel free to contact Robert Robergs, Ph.D. at (505) 277-2658, Monday Through Friday 8:00am $-5: 00 \mathrm{pm}$. For research-related injuries or emergencies that arise after hours or on weekends, you should call Dr. Milt Icenogle (Medical Director of the EPL) at 251-1899 (pager), or the University Hospital operator at 272-2111 and ask for the faculty physician on call for the emergency medicine department. If you have questions, problems or concerns about your participation in the research and would like to speak with someone other than the research team, you may call the UNMHSC Human Research Review Committee at 272-1129. You may also call this number if you have questions about your rights as a research subject. For more information, you may also access the HRRC website at http://hsc.unm.edu/som/research/hrrc/.

Initials

HRRC\# 06-186

Version: $11 / 01 / 06$

Approv ed: 11/30/06

Expires: 7/17/2007

The University of New Mexico Human Research Review Committee 


\section{CONSENT}

You will be given a copy of this consent form to keep. By signing this consent form, you are not waiving any of your legal rights, claims, or remedies.

You have read (or someone has read to you) the information in this consent form. You have had an opportunity to ask questions and all questions have been answered to your satisfaction. By signing this consent form, you willingly agree to participate in this study.

Name of Subject (type or print)

$\overline{\text { Signature of Subject }} \frac{/}{\text { Date }}$

I have explained the research to the subject and answered all of his/her questions. I believe that he/she understands the information described in this consent form and freely consents to participate.

Name of Investigator/Research Team Member (type or print)

Signature of Investigator/Research Team Member

Date

Initials

HRRC\# 06-186

Version: 11/01/06

Approv ed: 11/30/06

Expires: 7/17/2007

The University of New Mexico Human Research Review Committee 
Appendix B 
Physical Activity Readiness Questionnaire (PAR-Q)

YES NO

1. Have you ever been diagnosed with a heart condition?

2. In the past month, have you had chest pain when you were not doing physical activity?

3. Do you feel pain in your chest when you do physical activity?

4. Do you lose balance because of dizziness or do you ever lose consciousness?

5. Have you ever been diagnosed with abnormal lung function and/or exercise-induced bronchoconstriction?

6. Are you currently taking any medications? If so, what?

7. Do you know of any reason why you should not do physical activity?

NOTE: 1 . This questionnaire applies only to those 15 to 69 years of age.

2. If you have temporary illness, such as a fever or cold, or are not feeling well at this time, you may wish to postpone the proposed activity.

3. If your health changes so that you then answer yes to any of the above questions, inform the study investigator.

I have read, understood, and completed this questionnaire.

Signature

Date

Witness

Date 
Appendix C 


\section{$\dot{\mathrm{V}} \mathrm{O}_{2} \max$ Criteria}

It is helpful and informative to briefly discuss the criteria used to validate the attainment of a true maximal value of $\dot{\mathrm{VO}}_{2}$, since their widespread use in exercise physiology is of some significance. The most highly contested of these criteria is the $\dot{\mathrm{V}} \mathrm{O}_{2}$ plateau, first described by Hill and Lupton (1923). Since many subjects do not exhibit a plateau (Åstrand, 1952; Cumming \& Borysyk, 1972; Cumming \& Friesen, 1967; Cunningham et al., 1977; Freedson et al., 1986; Myers et al., 1989; Noakes, 1988; Rowland \& Cunningham, 1992), it has been argued that meeting this criterion is not necessary for a true $\dot{\mathrm{V}}_{2} \max$ (Rowland \& Cunningham, 1992). The use of a single number as a cut-off value has also been questioned (Howley et al., 1995). The most often used cut-off value is $0.15 \mathrm{Lmin}^{-1}$ of Taylor et al. (1955), a value that is based on a discontinuous test performed over several days, during which the treadmill speed remained constant at $7 \mathrm{~m} h r^{-1}$ and the grade increased by $2.5 \%$.

The original RER criterion $(\geq 1.15)$ was developed from a discontinuous cycle ergometer test protocol (Duncan et al., 1997; Howley et al., 1995; Issekutz et al., 1962; Issekutz \& Rodahl, 1961), and is based on an assumed true metabolic respiratory quotient (RQ) of 0.75 and the finding that all subjects reached $\dot{\mathrm{V}}_{2}$ max at the same "excess" RQ value of $0.4(0.75+0.4=1.15)$ (Issekutz et al., 1962; Issekutz \& Rodahl, 1961). However, the concept of a uniform maximal RER is not supported since maximal RER can differ between exercise modes (Shephard, 1975), and not all subjects achieve an RER $\geq 1.15$, even when a $\dot{\mathrm{VO}}_{2}$ plateau has occurred (Howley et al., 1995). In their review of 29 studies over a seven-month period in 1993-1994, Howley et al. (1995) found that the 
majority of studies reporting the use of RER as a $\dot{\mathrm{VO}}_{2}$ max criterion used an RER of $\geq 1.10$. A review of the literature on treadmill studies with trained athletes reveals the same often-cited RER of 1.10, which will therefore be the RER value used in the present study.

Of the above criteria, the use of HR may be the least valid, since the standard deviation associated with the estimate of $\mathrm{HR}_{\max }$ is \pm 11 beats $\min ^{-1}$ (Howley et al., 1995), making an assessment of attainment of a given percentage of $\mathrm{HR}_{\max }$ difficult at best. Indeed, it is not even clear from where the most often used formula to predict $\mathrm{HR}_{\max }$ $\left(\mathrm{HR}_{\max }=220-\mathrm{age}\right)$ originates, as there is no published research for the formula (Robergs \& Landwehr, 2002). In their review of the history of the formula, Robergs and Landwehr (2002) attribute its origin to Fox et al. (1971), who estimated a "line of best fit" on a series of raw and mean data compiled from a review of research on physical activity and heart disease. Moreover, it was discovered that there are at least 43 formulas in the literature to predict $\mathrm{HR}_{\max }$, none of which provides acceptable accuracy of $\mathrm{HR}_{\max }$ prediction (Robergs \& Landwehr, 2002). For this reason, the American College of Sports Medicine (1991) contends that predicted $\mathrm{HR}_{\max }$ should not be used as an absolute endpoint in termination of an exercise test. Despite all of the issues and tenuous foundations associated with the above criteria, they are still widely used in exercise physiology to validate $\dot{\mathrm{V}} \mathrm{O}_{2} \max$. 
VITA

JASON R. KARP

1705 Girard Blvd. S.E., Apt. 6

Albuquerque, New Mexico 87106

Phone: (505) 242-0363

E-mail: jason@runcoachjason.com

Website: http://www.runcoachjason.com

\section{EDUCATION:}

9/07

INDIANA UNIVERSITY

Bloomington, IN

Ph.D. in Exercise Physiology (minor in Physiology)

Dissertation: Lungs and Legs: Entrainment of Breathing to Locomotion in

Highly-Trained Distance Runners

$8 / 97$

UNIVERSITY OF CALGARY

Calgary, Alberta, Canada

Master of Kinesiology

Thesis: Motor Unit Recruitment Strategy in Muscle During Eccentric

Contractions

5/95 PENNSYLVANIA STATE UNIVERSITY

University Park, PA

Bachelor of Science in Exercise and Sport Science (minor in English)

\section{EXPERIENCE:}

\section{COACHING:}

2003 - present FOUNDER \& COACH

RunCoachJason.com

- Professional coaching and consulting services

8/07 - present DIRECTOR \& COACH

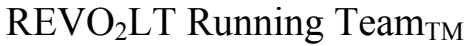

3/00 - 8/00 ASSISTANT COACH

Impala Racing Team, San Francisco, CA

10/99 - 7/00 MARATHON COACH

San Francisco Fit ${ }^{\circledR}$, San Francisco, CA

- Lead marathon training groups for San Francisco Marathon

- Conducted weekly seminars

- Designed running courses

- Recruited/oversaw volunteer assistants

12/99 - 6/00 HEAD TRACK AND FIELD COACH

George Washington High School, San Francisco, CA 


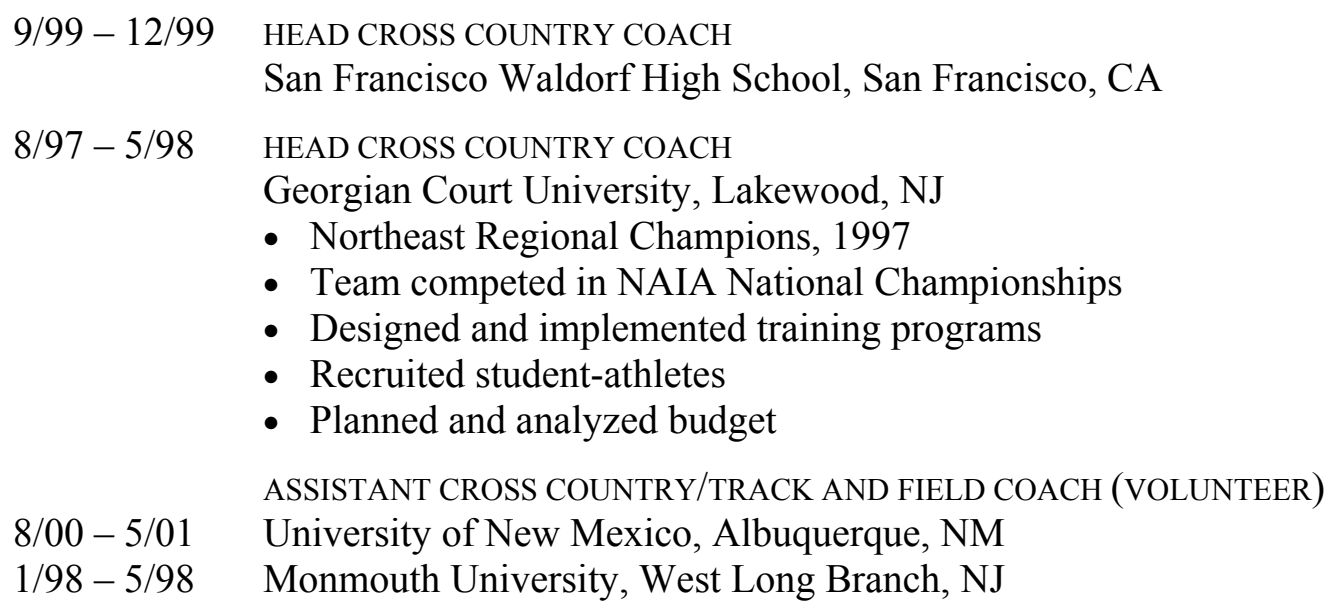

\section{TEACHING:}

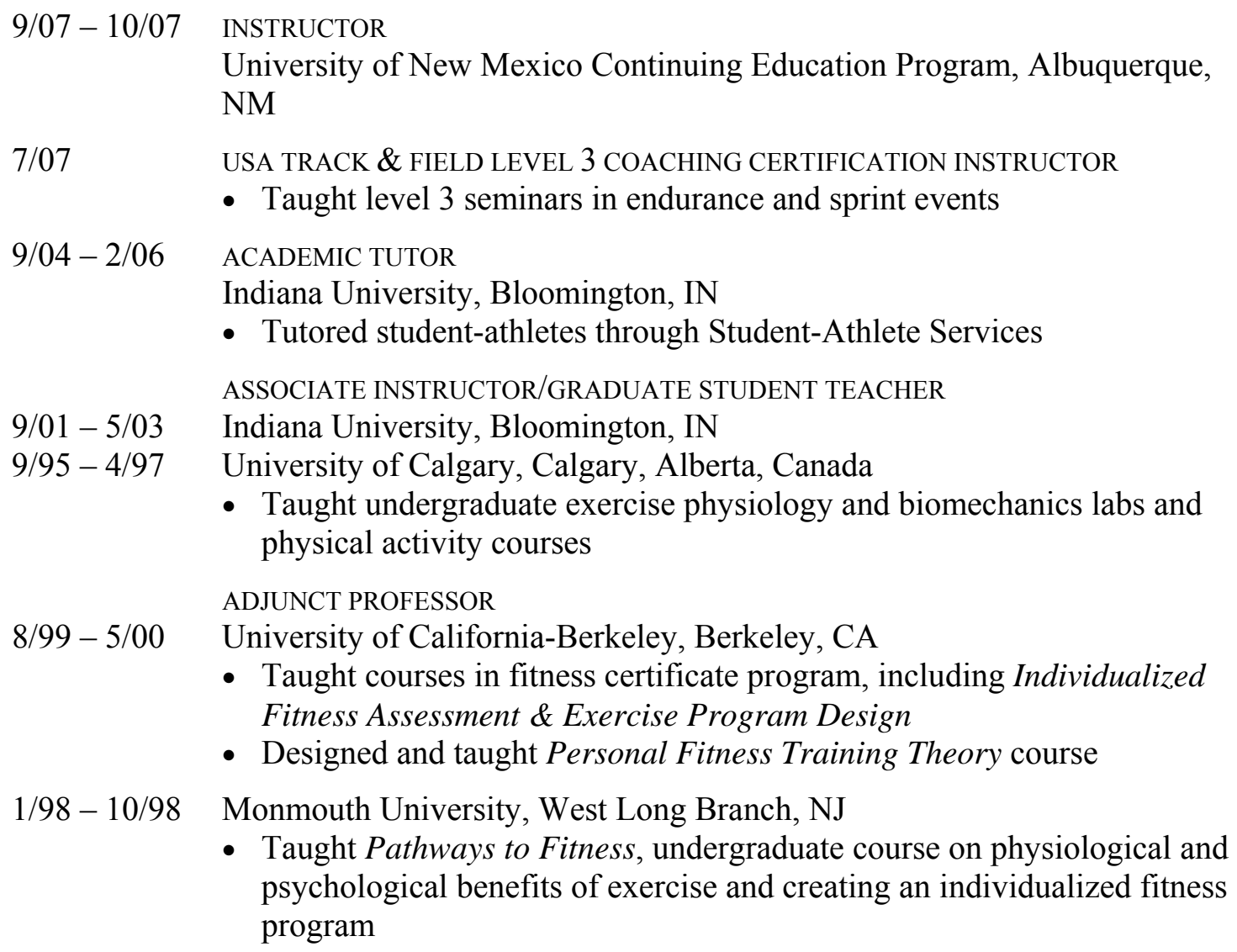

- Taught undergraduate exercise physiology and biomechanics labs and physical activity courses

\section{ADJUNCT PROFESSOR}

8/99 - 5/00 University of California-Berkeley, Berkeley, CA

- Taught courses in fitness certificate program, including Individualized Fitness Assessment \& Exercise Program Design

- Designed and taught Personal Fitness Training Theory course

1/98 - 10/98 Monmouth University, West Long Branch, NJ

- Taught Pathways to Fitness, undergraduate course on physiological and psychological benefits of exercise and creating an individualized fitness program

\section{WRITING:}

11/99 - present FREELANCE WRITER, International fitness, running, and coaching trade and consumer magazines

2/05 - present CONTRIBUTING/TECHNICAL EDITOR, Fitness Management 
1/02 - present CONTRIBUTOR, Runner's World's “Ask the Experts" column

\section{FITNESS INDUSTRY:}

FITNESS SPECIALIST

7/98 - 10/98 Community Medical Center, Toms River, NJ

- Conducted fitness evaluations; wrote exercise prescriptions for cardiac, stroke, and post physical therapy patients

- Conducted exercise and fitness seminars

PERSONAL FITNESS TRAINER

12/98 - 8/00 Club One, San Francisco, CA

7/98 - 10/98 NY Sports Club, Marlboro, NJ

- Conducted fitness evaluations; trained clients for cardiovascular fitness, strength, and weight loss

\section{OTHER RELATED EXPERIENCE:}

12/06 ORGANIZER/DIRECTOR

$\mathrm{VO}_{2}$ max Distance Running Clinic, Albuquerque, NM

12/98 - 8/00 CONSULTANT

Kinesense, Inc., Berkeley, CA

- Consulted on fitness product design and implementation for use in fitness centers

INTERN

9/96 - 5/97 Canadian National Sport Center, Calgary, Alberta, Canada

- Biomechanical motion analysis for National Luge Team

- Researched and wrote articles about National Sport Center and its athletes for inclusion in local publications

1/92 - 1/95 Sport Biomechanics Laboratory, Penn State University

- Assisted graduate students with data collection and biomechanical motion analysis

6/94 - 8/94 Boston Athletic Association - Boston Marathon

- Wrote articles for newsletter

- Created database of Boston Marathon memorabilia

\section{ACHIEVEMENTS \& AWARDS:}

2005

2005

2003

2003

2003

$2001-2003$

$1999-2000$

$1999-2000$

1997
Travel Grant-in-Aid Award, Indiana University School of HPER/Dept. of Kinesiology

Research Grant-in-Aid Award, Indiana University Graduate School

Research Grant, Counsilman Center for the Science of Swimming

Research Grant, Dairy and Nutrition Council, Inc.

Associate Instructor Research Award, Indiana University

Graduate Teaching Assistantship, Indiana University

Coaching Achievement Award, California Interscholastic Federation

Coaching Excellence Award, San Francisco Waldorf High School

Cross Country Coach of the Year, NAIA Northeast Region 
1995 - 1997 Graduate Teaching Assistantship, University of Calgary

1992 - 1995 Dean's List/Honor Society, Penn State University

1991 - 1995 Academic Scholarship, Penn State University

1992 - 1993 Scholar-Athlete Award, NCAA Big Ten Conference

\section{CERTIFICATIONS:}

USA Track \& Field Level 1 Coach

CPR

\section{PRESENTATIONS:}

7/07 Lactic Acid: Fatigue's Faulty Scapegoat, USA Track \& Field Coaches Education Program Advanced Endurance Summit (Level 3 Certification), Chicago, IL

7/07 Chasing Mercury: Training to Combat Fatigue, USA Track \& Field Coaches Education Program Advanced Endurance Summit (Level 3 Certification), Chicago, IL

7/07 Lactic Acid: Fatigue's Faulty Scapegoat, USA Track \& Field Coaches Education Program Advanced Sprint Summit (Level 3 Certification), Chicago, IL

7/07 Chasing Mercury: Training to Combat Fatigue, USA Track \& Field Coaches Education Program Advanced Sprint Summit (Level 3 Certification), Chicago, IL

5/07 Lactate Threshold: Best $\mathrm{O}_{2}$ Bang for Your Buck, Albuquerque Road Runners, Albuquerque, NM

4/07 Lactate Threshold: Best $\mathrm{O}_{2}$ Bang for Your Buck, IDEA Fitness Fusion, Chicago, IL

4/07 Planning Clients’ Training With Periodization, IDEA Fitness Fusion, Chicago, IL

3/07 The Secrets of Endurance Training and Performance, Sports Physiology course, University of New Mexico, Albuquerque, NM

12/06 Physiological Secrets of Distance Running, $\mathrm{VO}_{2} \max$ Distance Running Clinic, Albuquerque, NM

12/06 Lactate Threshold: Best $\mathrm{O}_{2}$ Bang for Your Buck, $\mathrm{VO}_{2} \mathrm{max}$ Distance Running Clinic, Albuquerque, NM

12/06 Periodization Training, $\mathrm{VO}_{2}$ max Distance Running Clinic, Albuquerque, NM

12/06 Endurance Training Research, $\mathrm{VO}_{2}$ max Distance Running Clinic, Albuquerque, NM

10/06 Marathon Training, Team In Training ${ }^{\circledR}$, Albuquerque, NM

3/06 Training Characteristics of U. S. Olympic Marathon Trials Qualifiers, American Society of Exercise Physiologists Annual Conference, Albuquerque, NM

6/05 Training Characteristics of U. S. Olympic Marathon Trials Qualifiers, American College of Sports Medicine Annual Conference, Nashville, TN

6/04 The Efficacy of Chocolate Milk as a Recovery Aid, American College of Sports Medicine Annual Conference, Indianapolis, IN 
12/02 Endurance Training Research, U.S. Track Coaches Association Annual Convention, Kansas City, MO

5/01 Running to Your Health, Road Runners Club of America Annual Convention, Albuquerque, NM

1/01 Periodization, Club One, Oakland, CA

11/00 Endurance Training, U.S. Track Coaches Association Annual Convention, Albuquerque, NM

\section{PUBLICATIONS:}

\section{PEER-REVIEWED SCIENTIFIC PUBLICATIONS}

Karp, J.R. Training Characteristics of Qualifiers for the U.S. Olympic Marathon Trials. International Journal of Sports Physiology and Performance. Mar. 2007, 2(1), pp. 72-92.

Karp, J.R., Johnston, J.D., Tecklenburg, S., Mickleborough, T.D., Fly, A.D., and Stager, J.M. Chocolate Milk as a Post-Exercise Recovery Aid. International Journal of Sport Nutrition and Exercise Metabolism. Feb. 2006, 16(1), pp. 78-91.

Karp, J.R. Muscle Fiber Types and Training. Strength and Conditioning Journal. Oct. 2001, 23(5), pp. 21-26.

Karp, J.R. Interval Training for the Fitness Professional. Strength and Conditioning Journal. Aug. 2000, 22(4), pp. 64-69.

\section{BOOKS}

Karp, J.R. Directions for SPSS ${ }^{\circledR}$ : A Manual for Students in Statistics. Bloomington, IN:

RunCoachJason.com, 2004.

Karp, J.R. Chapter Contributor, "Some Training Methods for Middle and Long Distance Running.” In: Doherty, K. and Kernan, J.N. Track \& Field Omnibook (5th Edition). Mountain View, CA: Tafnews Press, 2007, pp. 177-179.

\section{SCIENTIFIC ABSTRACTS}

Karp J.R. Training Characteristics of the 2004 U.S. Olympic Marathon Trials Qualifiers. Journal of Exercise Physiologyonline. March 2006, 9(2).

Karp, J.R. and Stager, J.M. Training Characteristics of United States Olympic Marathon Trials Qualifiers. Medicine and Science in Sports and Exercise. May 2005, 37(5), p. S88.

Karp, J.R., Johnston, J.D., Tecklenburg, S., Mickleborough, T., Fly, A., and Stager, J.M. The Efficacy of Chocolate Milk as a Recovery Aid. Medicine and Science in Sports and Exercise. May 2004, 36(5), p. S126.

\section{CONSUMER \& TRADE MAGAZINE ARTICLES}

Karp, J.R. The Three Players of Distance Running: An In-Depth Look at Lactate Threshold. Track Coach. In press (Fall 2007).

Karp, J.R. The Three Players of Distance Running: An In-Depth Look at Running Economy. Track Coach. In press (Winter 2008). 
Karp, J.R. A Matter of Survival: Training to Combat Fatigue. Running Times. In press (Dec. 2007).

Karp, J.R. The 7 Habits of Highly Effective Triathletes. Triathlete. In press (Dec. 2007).

Karp, J.R. The 7 Habits of Highly Effective Fitness and Figure Competitors. Oxygen. In press.

Karp, J.R. How They Train: A Study of U.S. Olympic Marathon Trials Qualifiers. Running Times. In press (Nov. 2007).

Karp, J.R. Better Body Series: Caveman Chest. Ultra-Fit. In press (Nov. 2007).

Karp, J.R. Know Your Fitness Level. Ultra-Fit. In press (Oct. 2007).

Karp, J.R. Unsure of Whether to Join a Gym? Ultra-Fit. In press (Sept. 2007).

Karp, J.R. Better Body Series: Cool Calves. Ultra-Fit. In press (Sept. 2007).

Karp, J.R. Fitness News: Take Your Interval Workouts to the Track, Exercise and Anemia, Care for Concentric?, and Bench Press or Push-Up. Oxygen. Oct. 2007, 10(10), pp. 30-31,34.

Karp, J.R. Fitness News: What Time of Day Should You Exercise?, Don't Stretch for Strength, How Often Do You Need to Train?, and Is Interval Training or Continuous Exercise Better for Burning Fat? Oxygen. Sept. 2007, 10(9), pp. 30-32,34.

Karp, J.R. Top 3 Fat Fighting Workouts. Ultra-Fit. Aug. 2007, 17(6), pp. 58-61.

Karp, J.R. Better Body Series: Popeye Biceps. Ultra-Fit. Aug. 2007, 17(6), pp. 66-68,70-71.

Karp, J.R. Fitness News: How Many Calories Am I Burning?, Drink Chocolate Milk for Optimal Recovery, Weights for Weight Loss, Do Your Liver a Favor: Get Moving, and Order in the Gym. Oxygen. Aug. 2007, 10(8), pp. 30-32.

Karp, J.R. The Three Players of Distance Running: An In-Depth Look at $\mathrm{VO}_{2}$ max. Track Coach. Summer 2007, 180, pp. 5737-5742.

Karp, J.R. Fitness News: Train Smart, Gear Up for Your Asthma, When Should I Take a Supplement?, Pre-Exercise Nutrition, and How Many Joints Should I Train? Oxygen. July 2007, 10(7), pp. 32-34,36.

Karp, J.R. Better Body Series: Blitz Cellulite \& Get Your Beach Legs. Ultra-Fit. June 2007, 17(5), pp. 64-66,68-69.

Karp, J.R. Fitness News: Train for Endurance to Burn More Fat, Exercise and Your Bones, and How Do I Get Awesome Abs? Oxygen. June 2007, 10(6), pp. 34,35,38.

Karp, J.R. Summer Body Special: Nix Your UnderButt; Refine Your Abs. Marie Claire. June 2007, 14(6), pp. 204,207.

Karp, J.R. Miles to Go Before I Sleep: How Much Mileage is Enough? Running Times. May 2007, 346, pp. 38-40,42-45.

Karp, J.R. Hey! Back Off! Tapering for the Marathon. Marathon \& Beyond. May/June 2007, 11(3), pp. 20-26.

Karp, J.R. Fitness News: De-training and Fitness, Carbohydrates and Immune Function, and How Does Strength Improve? Oxygen. May 2007, 10(5), pp. 32-34. 
Karp, J.R. Better Body Series: Beautiful Back. Ultra-Fit. May 2007, 17(4), pp. 64-66,68-69.

Karp, J.R. Better Body Series: Tighter Butt. Ultra-Fit. Apr. 2007, 17(3), pp. 64-66,68-69.

Karp, J.R. Fitness News: The Value of Recovery, Strength Versus Hypertrophy, Lifting Speed: Does It Matter?, When to Squeeze the Muscle?, Pick Up the Pace \& Zap More Calories, and Better Body Image With Weight Training. Oxygen. Apr. 2007, 10(4), pp. 2830,32 .

Karp, J.R. Better Body Series: Shapely Shoulders. Ultra-Fit. Feb. 2007, 17(2), pp. 64-66,6869.

Karp, J.R. Get a Grip. Oxygen. Feb. 2007, 10(2), pp. 80-83.

Karp, J.R. Fitness News: Weight Machines Provide Greater Resistance Than Free Weights, Menstrual Cycle and Strength, Hill Running, and Exercise More Often to Lower Blood Pressure. Oxygen. Feb. 2007, 10(2), pp. 29,32.

Karp, J.R. On Science and Running. Marathon \& Beyond. Jan./Feb. 2007, 11(1), pp. 41-42.

Karp, J.R. The Top Three Marathon Workouts. Marathon \& Beyond. Jan./Feb. 2007, 11(1), pp. 85-86,88.

Karp, J.R. Better Body Series: Fab Abs. Ultra-Fit. Jan. 2007, 17(1), pp. 64-69.

Karp, J.R. Personal Training and Cardio? Fitness Management. Jan. 2007, 23(1), pp. 42-43.

Karp, J.R. The Resting Metabolic Rate Debate. Fitness Management. Jan. 2007, 23(1), pp. 44-46.

Karp, J.R. Training Characteristics of U.S. Olympic Marathon Trials Qualifiers. Track Coach. Winter 2007, 178, pp. 5693-5698.

Karp, J.R. Fitness News: Exercise and Bone Density, Muscle Fibers, Is There a Fat-Burning Zone?, and Fat Burns in a Carbohydrate Flame. Oxygen. Jan. 2007, 10(1), pp. 28,30,32.

Karp, J.R. Fitness News: Do Muscles Have Tone?, Cardio and Your Health, and Exercise and Metabolism. Oxygen. Dec. 2006, 9(12), pp. 28-30.

Karp, J.R. Fitness News: Training Your Back, How Deep Should You Squat?, Periodize Your Training, Choose Your Parents Wisely, It's as Simple as a Normal Crunch, and Eccentric Contractions. Oxygen. Nov. 2006, 9(11), pp. 28-30,32.

Karp, J.R. To Lift or Not to Lift: Put the Dumbbells Down-Why Distance Runners Don't Need Strength Training. Running Times. Oct. 2006, 340, pp. 22-23,25-26,28-29.

Karp, J.R. Fitness News: Can Exercise Make You Smarter?, Bulging Female Muscles?, Can Stretching Prevent Injuries?, and Greater Muscle Growth with Pre-Workout Protein. Oxygen. Oct. 2006, 9(10), pp. 26-27.

Karp, J.R. The Limits of Running Performance. New Studies in Athletics. Sept. 2006, 21(3), pp. 51-56.

Karp, J.R. "I Can't Catch My Breath": Lungs and Running Performance. Running Times. Sept. 2006, 339, p. 18. 
Karp, J.R. Fitness News: Exercise for a Better Sex Drive, Have Exercise-Induced Asthma? Try Vitamin C, How Many Sets Do You Need to Gain Strength?, and Fitness and Immunity. Oxygen. Sept. 2006, 9(9), pp. 26,28,30.

Karp, J.R. Is Bigger Better? The Muscular Truth About Tone and Stretching. Trail Runner Inside Dirt e-zine. Aug. 2006.

Karp, J.R. Carbohydrates and The Distance Runner: A Scientific Perspective. Track Coach. Summer 2006, 176, pp. 5622-5627.

Karp, J.R. Fitness News: Exercise to Reduce Anxiety, Lungs and Exercise, and Rehydrate After Your Workout. Oxygen. Aug. 2006, 9(8), p. 27.

Karp, J.R. The Magic of Muscles. Her Sports. July/Aug. 2006, 15, pp. 30-32.

Karp, J.R. The Errors of Our Running Ways. Running Times. July/Aug. 2006, 338, pp. 28,3033.

Karp, J.R. Workout Express. Shape. July 2006, 25(11), p. 136.

Karp, J.R. Fitness News: Burn More Calories with Interval Training, Downhill Running, and Your Menstrual Cycle and Bone Health. Oxygen. July 2006, 9(7), pp. 26-27.

Karp, J.R. Fitness News: Cardio on an Empty Stomach?, Lactic Acid Doesn't Cause Muscle Burn, Want to Gain Strength? Get a Trainer, and Free Weights Better Than Machines For Increasing Strength? Oxygen. June 2006, 9(6), pp. 25,26,28.

Karp, J.R. "I Can't Catch My Breath”: Lungs and Distance Running Performance. Track Coach. Spring 2006, 175, pp. 5577-5579.

Karp, J.R. Turn on the Power: Energy System Specific Training. Running Times. May 2006, 336, pp. 16,57.

Karp, J.R. Fitness News: Order in the Gym, Cooling Off, Post-Workout Chow, and Cool Your Inflammation. Oxygen. May 2006, 9(5), pp. 26,28,30.

Karp, J.R. Workout Express. Shape. Apr. 2006, 25(8), p. 140.

Karp, J.R. The Burning Question. Runner's World. Apr. 2006, 41(4), pp. 80-83.

Karp, J.R. Your Ultimate Fat-Burning Cardio Program. Oxygen. Apr. 2006, 9(4), pp. 84-86.

Karp, J.R. Weight Machines vs. Free Weights. Fitness Management. Feb. 2006, 22(2), pp. $50-52$.

Karp, J.R. Weight Training for Beginners. Oxygen. Winter 2006, Fat Loss Issue, pp. 32-35.

Karp, J.R. Workout Express. Shape. Nov. 2005, 25(3), p. 140.

Karp, J.R. Ask the Experts column: Hill training. Runner's World. Nov. 2005, 40(11), p. 36.

Karp, J.R. Lungs and Legs. Track Coach. Fall 2005, 173, pp. 5529-5530,5537.

Karp, J.R. There's No "I" in Team: How to Find a Training Group. Fitness Plus. Oct. 2005, 21(10), p. 28.

Karp, J.R. Strength Training and the Distance Runner: A Scientific Perspective. Running Times. Oct. 2005, 330, pp. 22-24,26. 
Karp, J.R. Chin-Ups, Push-Ups, and Hills. Midwest Running. July/Aug. 2005, 2(5), p. 18.

Karp, J.R. Endorphins-Alignment of the Moons. Midwest Running. July/Aug. 2005, 2(5), p. 19.

Karp, J.R. Show Me the Bagels: Glycogen as a Metabolic Fuel for Runners. Marathon \& Beyond. July/Aug. 2005, 9(4), pp. 108-112.

Karp, J.R. Optimal Recovery. Fitness Plus. Apr. 2005, 21(4), p. 35.

Karp, J.R. My Love Affair With Lactate. Track Coach. Spring 2005, 171, pp. 54635465,5468 .

Karp, J.R. Running Between the Lines: Track Running. Fitness Plus. Oct. 2004, 19(10), p. 22.

Karp, J.R. Speed, Strength, and Power Training for Endurance Athletes. Fitness Plus. July 2004, 16(7), p. 14.

Karp, J.R. Endurance Training Research. Track and Field Coaches Review. Sept. 2002, 75(3), pp. 18-21.

Karp, J.R. and Kelley, L.C. Running at Altitude. Track Coach. Summer 2002, 160, pp. 50975100.

Karp, J.R. Top 10 Most Frequently Asked Questions in a Fitness Center (and Their Answers). IDEA Health and Fitness Source. Apr. 2002, 20(4), pp. 59-65.

Karp, J.R. Heart Rate Training for Improved Running Performance. Track Coach. Winter 2002, 158, pp. 5035-5039.

Karp, J.R. Medical and Training Advice column: Training for marathon while playing other sports. Runner's World. Jan. 2002, 37(1), pp. 26-27.

Karp, J.R. Metabolizing Fat and Carbohydrate. Fitness Management. Dec. 2001, 17(13), pp. 46-49.

Karp, J.R. and Kelley, L.C. Altitude and Figure Skating Performance. Professional Skater Magazine. Nov./Dec. 2001, 32(6), pp. 12-13,26.

Karp, J.R. I've Written the Training Program, Now What? Track \& Field Coaches Review. June 2001, 74(2), pp. 17-21.

Karp, J.R. Designing Programs That Work Best for Your Clients. Fitness Management online, June 2001.

Karp, J.R. Muscle Fiber Types and Training. Track Coach. Spring 2001, 155, pp. 4943-4946.

Karp, J.R. Periodization Training. Track Coach. Winter 2001, 154, pp. 4905-4908.

Karp, J.R. Heart Rate Training. Fitness Management. Dec. 2000, 16(13), pp. 37-38.

Karp, J.R. Interval Training. Fitness Management. Aug. 2000, 16(9), pp. 46-48.

Karp, J.R. Periodization Training for Improved Performance. Fitness Management. June 2000, 16(7), pp. 38-41.

Karp, J.R. Training the Energy Systems. Track \& Field Coaches Review. June 2000, 73(2), pp. 18-20. 
Karp, J.R. A Primer on Periodization Training. IDEA Health and Fitness Source. May 2000, 18(5), pp. 23-29.

Karp, J.R. Flexibility for Fitness. Fitness Management. Apr. 2000, 16(5), pp. 52-54.

Karp, J.R. Strong on Group Strength Training. IDEA Fitness Edge. Nov./Dec. 1999, 2(5), pp. $1-7$.

Karp, J. Optimal Athletic Output: U of C Lab Helps Olympic Hopefuls Go for the Gold. Calgary Herald. May 10, 1997, p. B6.

Karp, J. Making Your Writing Richer With Detail. The Writing Room Newsletter. Fall, 1996, pp. 2-3.

\section{POEMS}

Karp, J. This is Just to Say. Treasured Poems of America. Sistersville, WV: Sparrowgrass Poetry Forum Inc., 1994, p. 197.

Karp, J. Window Reflections. American Collegiate Poets. Los Angeles, CA: International Publications, 1994, p. 46.

\section{REPRINTS}

Karp, J.R. Strength Training and Distance Running. The Coach. Summer 2007, 37, pp. 2733.

Karp, J.R. The Top Three Marathon Workouts. Washington Running Report. May/June 2007, 23(3), p. 32.

Karp, J.R. Turn on the Power: Energy System Specific Training. Atlanta Sports \& Fitness. In press (Apr. 2007).

Karp, J.R. The Top Three Cardio Workouts. Duke City Fit. Spring 2007, pp. 22-23.

Karp, J.R. The Top Three Marathon Workouts. Colorado Runner. Mar./Apr. 2007, 22, pp. 20-21.

Karp, J.R. The Top Three Marathon Workouts. Atlanta Sports \& Fitness. In press (Mar. 2007).

Karp, J.R. Turn on the Power: Energy System Specific Training. Florida Running \& Triathlon. Jan./Feb. 2007, 20(1), pp. 26-27.

Karp, J.R. "I Can't Catch My Breath": Lungs and Running Performance. Duke City Fit. Winter 2006/2007, pp. 6-7.

Karp, J.R. The Errors of Our Running Ways. Florida Running \& Triathlon. Nov./Dec. 2006, 19(6), pp. 34-36.

Karp, J.R. The Errors of Our Running Ways. The Coach. Autumn 2006, 35, pp. 47-50.

Karp, J.R. The Errors of Our Running Ways. Duke City Fit. Fall 2006, pp. 24,25,30.

Karp, J.R. The Errors of Our Running Ways. Colorado Runner. Sept./Oct. 2006, 19, pp. 1214.

Karp, J.R. Optimal Recovery. Duke City Fit. Summer 2006, pp. 12-13. 
Karp, J.R. Running Between the Lines. Atlanta Sports \& Fitness. May 2006, pp. 44-45.

Karp, J.R. The Road to Recovery. Atlanta Sports \& Fitness. Feb. 2006, pp. 25-26.

Karp, J.R. Speed, Strength, and Power Training for Endurance Athletes. Florida Running \& Triathlon. Jan./Feb. 2006, 19(1), p. 23.

Karp, J.R. Optimal Recovery. Trail Runner Inside Dirt e-zine. Nov. 2005.

Karp, J.R. FAQs on Fat. IDEA Personal Trainer. Sept. 2003, 14(8), p. 48.

Karp, J.R. Weight Training Q \& A. IDEA Personal Trainer. July/Aug. 2003, 14(7), p. 48.

Karp, J.R. Endurance Training Research. Modern Athlete and Coach. Jan. 2003, 41(1), pp. 712.

Karp, J.R. Periodization Training. Modern Athlete and Coach. Oct. 2002, 40(4), pp. 21-26. 